U.S. DEPARTMENT OF ENERGY

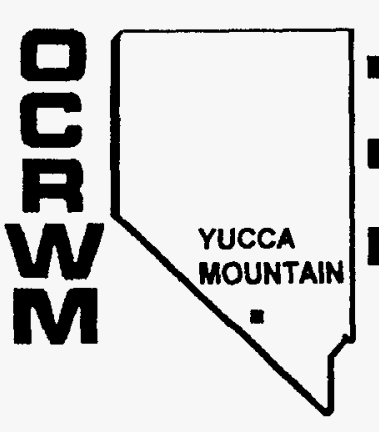

YUCCA MOUNTAIN

\title{
SITE CHARACTERIZATION
}

PROJECT

YMP/TR--003-NP-ReV. 1

RECEIVEO

OCT 30 ใลS

TOPICAL REPORT OSTI

\author{
PRECLOSURE \\ SEISMIC DESIGN METHODOLOGY \\ FOR A GEOLOGIC REPOSITORY \\ AT YUCCA MOUNTAIN
}

REV. 1

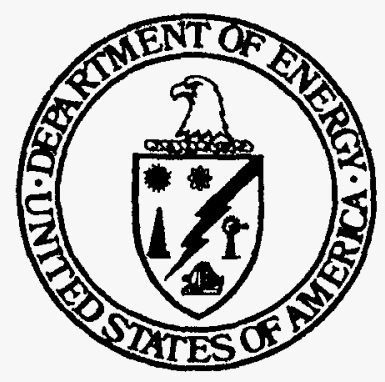

MASTER

DISTRISUTION OF His DOWURENT IS UNMMIED

OCTOBER 1996 


\title{
TOPICAL REPORT YMP/TR-003-NP
}

\author{
PRECLOSURE SEISMIC DESIGN \\ METHODOLOGY FOR A GEOLOGIC \\ REPOSITORY AT YUCCA MOUNTAIN
}

Revision 1

October 1996 


\section{DISCLAIMER}

Portions of this document may be illegible in electronic image products. Images are produced from the best available original document. 
Approved by:
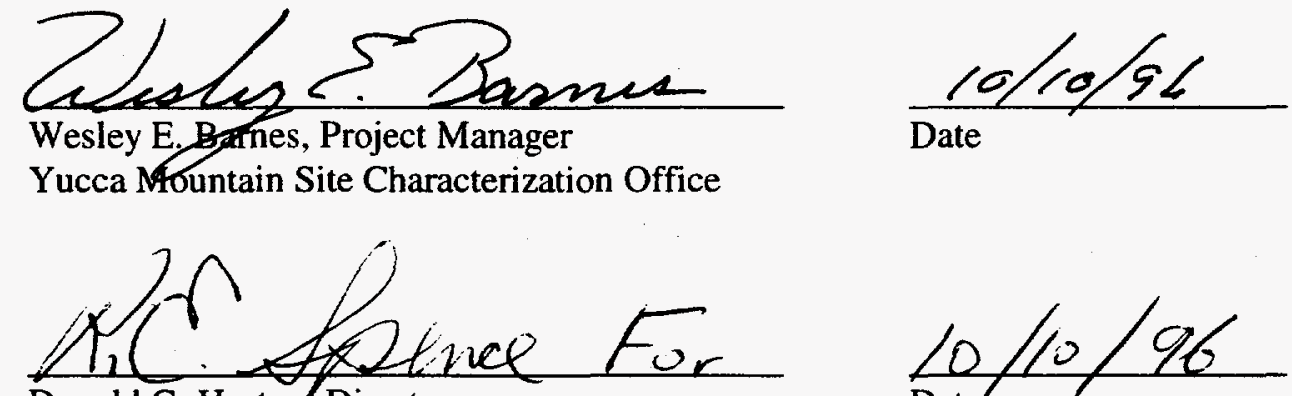

Donald G. Hortop, Director

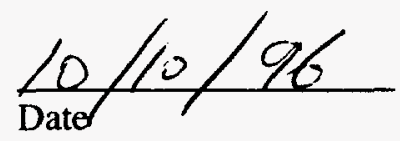

Office of Quality Assurance 


\section{EXECUTIVE SUMMARY}

This topical report is the second in a series of three reports that the U.S. Department of Energy (DOE) has planned to document the preclosure seismic design of structures, systems, and components (SSCs) that are important to the radiological safety of the potential repository at Yucca Mountain, Nevada. The first topical report, Methodology to Assess Fault Displacement and Vibratory Ground Motion Hazards at Yucca Mountain, YMP/TR-002-NP, was submitted to the U.S. Nuclear Regulatory Commission (NRC) staff for review and comment in 1994 and has been accepted by the staff. The DOE plans to implement this methodology in fiscal year 1997 to develop probabilistic descriptions of the vibratory ground motion hazard and the fault displacement hazard at the Yucca Mountain site. The second topical report (this report) describes the DOE methodology and acceptance criteria for the preclosure seismic design of SSCs important to safety. Development of seismic design inputs is planned to begin in fiscal year 1997 and to be documented in a Seismic Design Report during fiscal year 1998. For formal NRC staff review, the DOE plans to develop a third seismic topical report that would document the results of the probabilisitic seismic hazard assessment and the development of design inputs.

This report addresses preclosure seismic design methodology only, but SSCs important to safety must, ultimately, be built to a single design that meets all requirements, including those for postclosure performance. To ensure that all SSCs meet all of their design requirements, and to avoid suboptimalization with respect to any single design requirement, the DOE is employing a systematic approach to the development, integration, and management of all site characterization, development, and operational activities. This approach is specifically intended to result in a one-pass design for the repository, which requires that all functions of the repository throughout its life cycle be understood and all aspects of the repository be designed in advance.

Preclosure seismic design must meet NRC requirements in Title 10, Part 60 of the Code of Federal Regulations (10 CFR 60), Disposal of High-Level Radioactive Wastes in Geologic Repositories. These include requirements to identify SSCs important to safety and their corresponding performance objectives, design criteria, and design bases. Performance requirements must be identified for both normal and anticipated operational conditions and accident conditions, including those caused by natural phenomena. The DOE must demonstrate that the repository can be operated without unreasonable risk to the health and safety of the public and provide reasonable assurance that all performance objectives and criteria will be satisfied. Although $10 \mathrm{CFR} 60$ provides general design criteria for the repository and for the waste package, it does not specify or provide guidance regarding acceptable seismic design methodologies or seismic design acceptance criteria. Therefore, the DOE is submitting this topical report for NRC staff review and comment to reach agreement on an acceptable preclosure seismic design approach before the DOE implements the license application design.

This topical report has been written to comply with pending NRC requirements in the proposed rulemaking (60 FR 15180) for 10 CFR 60 that newly creates two categories of design basis events. These events are defined by qualitative descriptions of their likelihood of occurrence before closure of the repository. The DOE refers to the two categories of design basis events as Frequency-Category-1 and FrequencyCategory-2 and in this topical report proposes target annual probabilities for the corresponding design basis vibratory ground motions and design basis fault displacements.

The DOE intends to use mean annual probabilities of $1 \times 10^{-3}$ and $1 \times 10^{-4}$, respectively, as reference values in determining the Frequency-Category-1 and -2 design basis vibratory ground motions. The reference probability of $1 \times 10^{-3}$ is an extremely conservative translation of "those natural and human-induced events that are reasonably likely to occur regularly, moderately frequently, or one or more times before permanent closure of the geologic repository operations area," which is the definition of Category-1 events in the proposed rulemaking. The reference probability of $1 \times 10^{-4}$ for Frequency-Category-2 design basis ground 
motion is appropriate and conservative based on the observations that (1) it is comparable to the mean probabilities of the design basis ground motions for operating nuclear power reactors in the United States, (2) these accepted reactor design bases and their associated design acceptance criteria have resulted in acceptably safe seismic designs, (3) design acceptance criteria will be used in repository design that are the same as or comparable to those used in reactor designs, and (4) an operating mined geologic disposal system is inherently less hazardous and less vulnerable to earthquake-initiated accidents than is an operating nuclear power reactor. The reference probabilities presented in this report are intended for seismic design only and do not necessarily constitute appropriate frequency or likelihood criteria for identifying other types of design basis events.

The DOE general policy is to use existing NRC guidance documents where they can appropriately be applied to the design and operation of repository facilities. Accordingly, the DOE reviewed NUREG-0800, Standard Review Plan for the Review of Safety Analysis Reports for Nuclear Power Plants, for potential use in repository seismic design. With certain exceptions, the DOE considers that Standard Review Plans 3.7.1, Seismic Design Parameters; 3.7.2, Seismic System Analysis; 3.7.3, Seismic Subsystem Analysis; and 3.10, Seismic and Dynamic Qualification of Mechanical and Electrical Equipment, provide appropriate acceptance criteria for the preclosure vibratory-ground-motion design of repository surface facilities that are important to safety.

Underground openings in the repository consist principally of shafts, ramps, and drifts. The general design criteria in 10 CFR 60 require that underground openings be designed so that operations can be carried out safely and the retrievability option maintained. Although the requirement in 10 CFR 60 is to design the repository such that any or all of the emplaced waste can be retrieved on a reasonable schedule starting at any time up to 50 years after waste emplacement operations are initiated, the DOE currently is assuming a 100-year retrievability period and a main drift and emplacement drift design lifetime of 150 years.

The DOE has concluded that the ability to monitor, inspect, and maintain emplacement drifts during the preclosure period is the only design attribute that is necessary to accommodate the potential for repetitive seismic loading, in addition to designing emplacement drifts for the applicable design basis earthquake. The likelihood of experiencing drift-damaging seismic loads more than once or twice during the preclosure period is negligible, and displacements across rock joints, regardless of the number of seismic events, are considered in the design of underground openings.

Design of underground openings in jointed rock generally involves a combination of empirical methods, which are experience-based rules summarized in design charts, and analytical methods, which are based on solid mechanics and rock mechanics principles. The empirical methods can be used for initial evaluation and selection of ground support but have limited application beyond static and ambient temperature load conditions. To more accurately account for thermal and dynamic effects, analytical methods are used. Neither empirical nor analytical methods are fully validated under the loads and time frame of interest for repository design. Therefore, both methods are utilized here for selection of ground support systems.

In establishing fault displacement design criteria for the potential repository, the DOE intends to follow and implement NRC guidance provided in NUREG-1494, Staff Technical Position on Consideration of Fault Displacement Hazards in Geologic Repository Design (NRC 1994). That document recommends that Type I faults within the geologic repository operations area be avoided when reasonably achievable. Type I faults are defined in NUREG-1451, Staff Technical Position on Investigations to Identify Fault Displacement Hazards and Seismic Hazards at a Geologic Repository (NRC 1992), as faults or fault zones that are subject to displacement and of sufficient length and located such that they may affect repository design or performance. NUREG-1494 recommends fault avoidance but explicitly recognizes that fault avoidance may not be possible for all SSCs, especially those that are spatially extended. To the 
extent reasonably achievable, the DOE will avoid Type I faults in the design of SSCs important to safety. When this cannot reasonably be achieved, the potential for fault displacement will be accommodated through design or repair and rehabilitation actions to provide reasonable assurance that all seismic safety requirements will be met.

As for design basis vibratory ground motion, the DOE considers that probabilistic criteria for design basis fault displacements are most appropriate. Specifically, the DOE considers that fault displacements having mean annual probabilities of $1 \times 10^{-4}$ and $1 \times 10^{-5}$ are appropriate for the Frequency-Category- 1 and Frequency-Category-2 design basis fault displacements, respectively. These values are a factor of ten lower than the probabilities of the corresponding Frequency-Category-1 and -2 design basis vibratory ground motions, reflecting the more limited experience with engineering design of facilities for fault displacement. There is a strong technical basis for fault displacement design where such design is necessary. When designing for fault displacement, the DOE will use conservative design acceptance criteria based on allowable strain levels in construction materials.

Consistent with NUREG-1494, fault avoidance is the DOE preferred approach to accommodating potential fault displacements. To implement this approach, criteria for when fault avoidance has been achieved are needed. Given the randomness inherent in faulting processes and uncertainty in the characterization of local faults, a probabilistic definition of fault avoidance is the most appropriate. Specifically, the DOE considers that a Type I fault can be deemed to be avoided or, for an SSC that crosses a fault, a fault can be deemed to be not a Type I fault, when the mean annual probability of displacement for which there is negligible engineering concern is less than $1 \times 10^{-4}$ for SSCs that must be designed for FrequencyCategory- 1 design basis events, and $1 \times 10^{-5}$ for SSCs that must be designed for Frequency-Category-2 design basis events. These probability levels are the same values as the reference probabilities for fault displacement design. Fault setback distances under this approach will be highly SSC- and fault-specific.

The waste package consists of a waste form in a sealed disposal container, possibly surrounded by shielding, packing, and absorbent materials. The DOE has tentatively identified waste packages as Quality Assurance Classification 2-Important to Waste Isolation (DOE 1994d). A final determination will be made in accordance with the applicable quality assurance procedure for classifying permanent items. Postclosure design criteria for waste packages, including postclosure seismic design criteria, will be established accordingly through the systems engineering process. For postclosure items, this process is based on iterating total system and subsystem performance assessments and developing design solutions until all postclosure performance requirements are met. Although a definitive determination has not yet been made, it is likely that waste packages will also be determined to be Quality Assurance Classification 1-Important to Radiological Safety - i.e., to provide functions necessary to meet preclosure radiation protection requirements. If confirmed to be important to radiological safety, waste packages will be designed to withstand Frequency-Category-1 or Frequency-Category-2 design basis ground motions, as appropriate. If multiple seismic design criteria apply, the most stringent will control the waste package design. 
Topical Report YMP/TR-003-NP, Rev. 1

Preclosure Seismic Design Methodology for a Geologic Repository at Yucca Mountain

INTENTIONALLY LEFT BLANK 


\section{CONTENTS}

Page

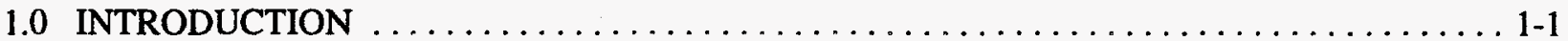

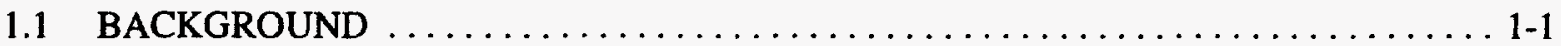

1.2 CONTENT OF THE SEISMIC TOPICAL REPORTS $\ldots \ldots \ldots \ldots \ldots \ldots \ldots \ldots \ldots 1-2$

1.3 INTEGRATION OF PRECLOSURE AND POSTCLOSURE REQUIREMENTS

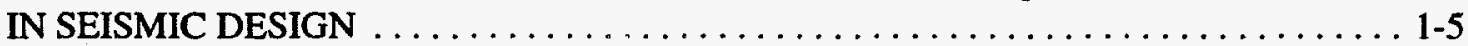

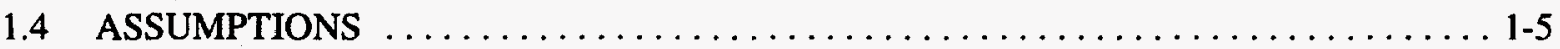

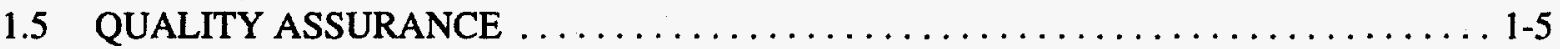

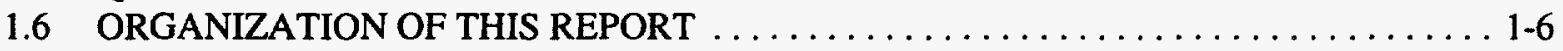

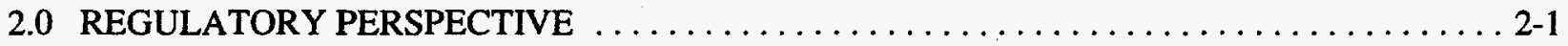

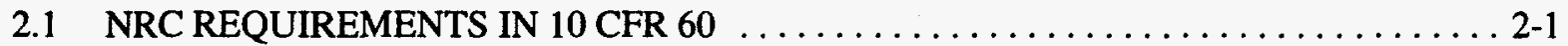

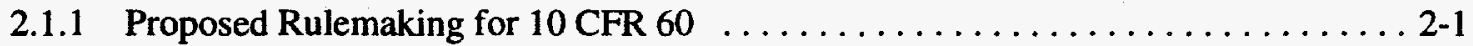

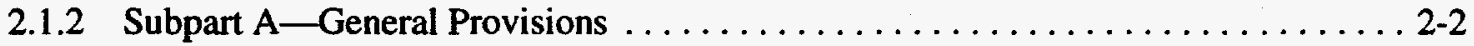

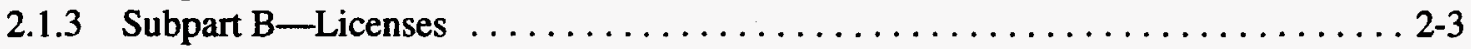

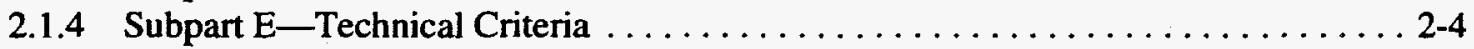

2.1.4.1 Performance Objectives ..................... 2-4

2.1.4.2 Design Criteria for the Geologic Repository Operations Area . . . . . . . 2 2-5

2.1.4.3 Design Criteria for the Waste Package ................. 2-5

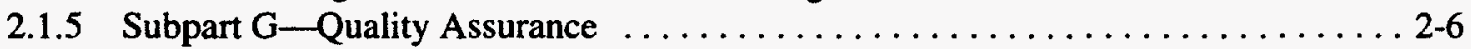

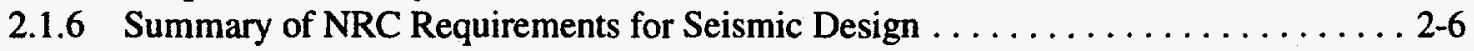

2.2 NRC GUIDANCE DOCUMENTS FOR GEOLOGIC REPOSITORIES $\ldots \ldots \ldots \ldots \ldots 2-6$

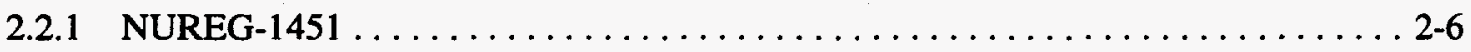

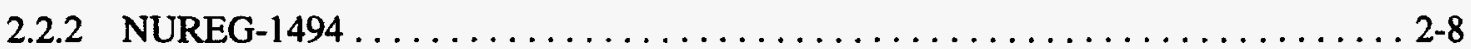

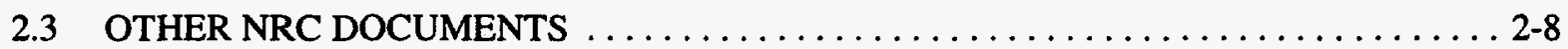

2.3.1 Proposed Rule Change to 10 CFRs 50, 52, and $100 \ldots \ldots \ldots \ldots \ldots \ldots \ldots$

2.3.2 Policy Statement on Use of Probabilistic Risk Assessment Methods in Nuclear

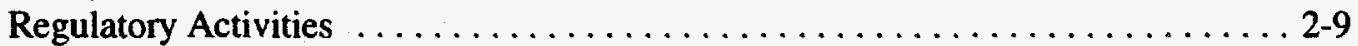

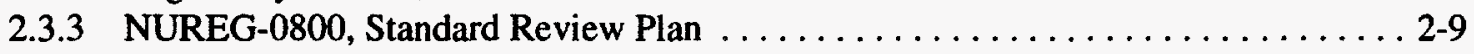

3.0 DESIGN OF STRUCTURES, SYSTEMS, AND COMPONENTS FOR

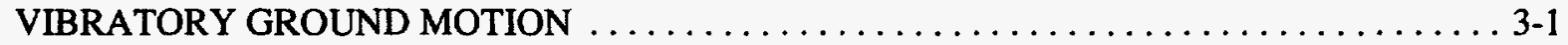

3.1 HAZARD LEVELS FOR DESIGN BASIS GROUND MOTIONS $\ldots \ldots \ldots \ldots \ldots \ldots \ldots$.

3.1.1 Frequency-Category-1 Reference Probability $\ldots \ldots \ldots \ldots \ldots \ldots \ldots \ldots \ldots \ldots \ldots \ldots$

3.1.2 Frequency-Category-2 Reference Probability .............. 3-2

3.1.2.1 Comparison with Nuclear Power Reactor Seismic Design Bases . . . . . . 3-2

3.1.2.2 Conservatism of the Reference Probability ................. 3-3

3.1.3 Use of Reference Probabilities for Other Types of Events . . . . . . . . . . 3-5

3.2 DESIGN OF SURFACE FACILITIES FOR VIBRATORY GROUND MOTION $\ldots \ldots \ldots$ 3-5

3.3 DESIGN OF UNDERGROUND OPENINGS FOR VIBRATORY GROUND MOTION .. 3-6

3.3.1 Performance Objectives and General Design Criteria $\ldots \ldots \ldots \ldots \ldots \ldots \ldots$ 3-6

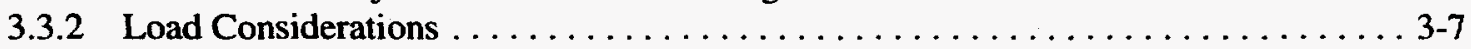

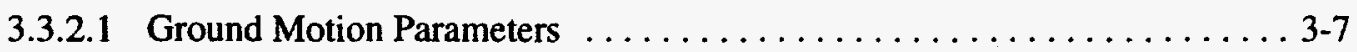

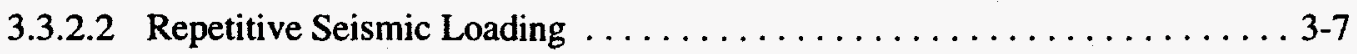

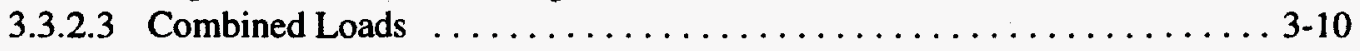

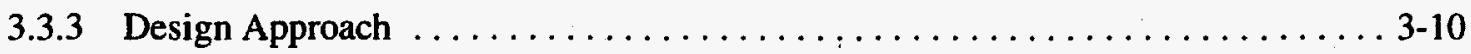

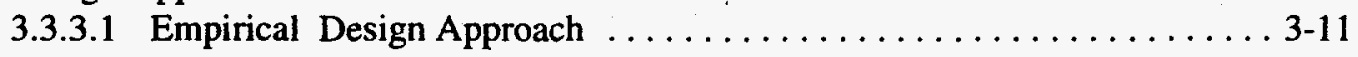

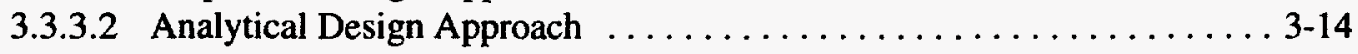


3.3.4 Acceptance Criteria

3.4 DESIGN OF OTHER UNDERGROUND SSCs FOR VIBRATORY GROUND

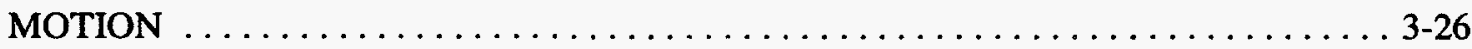

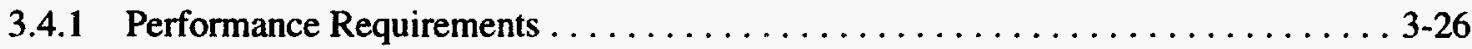

3.4 .2 Load Considerations . . . . . . . . . . . .

4.0 DESIGN OF REPOSITORY SSCS FOR FAULT DISPLACEMENT $\ldots \ldots \ldots \ldots \ldots \ldots \ldots \ldots$ 4-1

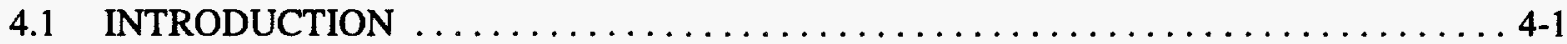

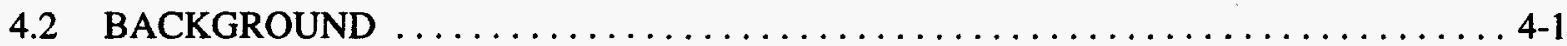

4.2.1 Experience in Design of Surface SSCs to Accommodate Fault Displacement ... . . 4-1

4.2.2 Experience in Design of Tunnels to Accommodate Fault Displacement . . . . . . . 4-2

4.3 IMPLEMENTATION OF THE NRC STAFF TECHNICAL POSITION ON SEISMIC

DESIGN FOR TYPE I FAULTING AT YUCCA MOUNTAIN $\ldots \ldots \ldots \ldots \ldots \ldots \ldots \ldots 4-3$

4.4 CRITERIA FOR IMPLEMENTATION OF FAULT DISPLACEMENT DESIGN $\ldots \ldots$. 4-4

4.4.1 Criteria for Fault Avoidance . . . . . . . . . . . . . . . . . . . . . . . 4-4

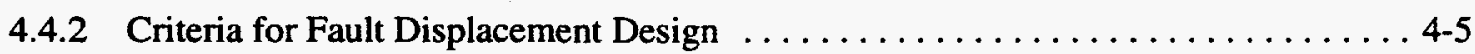

4.4.2.1 Determination of Design Basis Fault Displacements . . . . . . . . 4-5

4.4.2.2 Acceptance Criteria for Fault Displacement Design . . . . . . . . . . 4-6

5.0 SEISMIC DESIGN OF THE WASTE PACKAGE $\ldots \ldots \ldots \ldots \ldots \ldots \ldots \ldots \ldots \ldots \ldots \ldots$.

5.1 WASTE PACKAGE PERFORMANCE REQUIREMENTS $\ldots \ldots \ldots \ldots \ldots \ldots \ldots \ldots .5$ 5-1

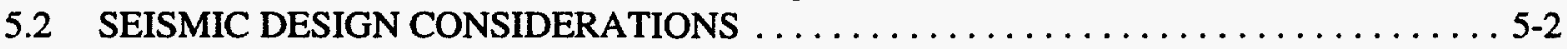

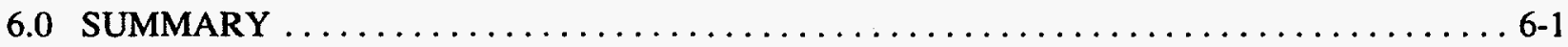

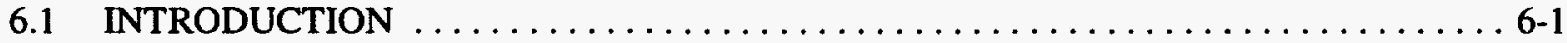

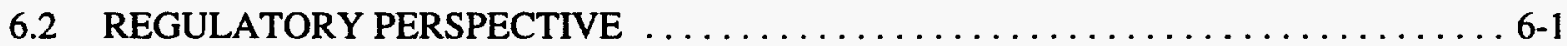

6.3 HAZARD LEVELS FOR DESIGN BASIS GROUND MOTIONS $\ldots \ldots \ldots \ldots \ldots \ldots \ldots 6-2$

6.4 DESIGN OF FACILITIES FOR VIBRATORY GROUND MOTION $\ldots \ldots \ldots \ldots \ldots \ldots 6-3$

6.5 DESIGN OF FACILITIES FOR FAULT DISPLACEMENT $\ldots \ldots \ldots \ldots \ldots \ldots \ldots \ldots 6-4$

6.6 SEISMIC DESIGN OF WASTE PACKAGES $\ldots \ldots \ldots \ldots \ldots \ldots \ldots \ldots \ldots \ldots \ldots$

APPENDIX A - INTEGRATION OF PRECLOSURE AND POSTCLOSURE $\ldots \ldots \ldots \ldots \ldots \ldots$ A-1 REQUIREMENTS IN SEISMIC DESIGN

APPENDIX B - PROCESS FOR IDENTIFYING STRUCTURES, SYSTEMS, AND . . . . . . . B-1 COMPONENTS IMPORTANT TO RADIOLOGICAL SAFETY

APPENDIX C - PROBABILITIES OF EXCEEDING THE SEISMIC DESIGN BASES $\ldots \ldots \ldots . C-1$ OF NUCLEAR POWER PLANTS IN THE WESTERN UNITED STATES

APPENDIX D - EXAMPLES OF TUNNEL DESIGN AND PERFORMANCE THROUGH

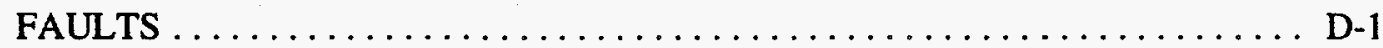

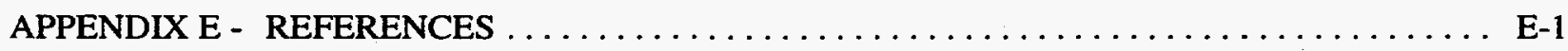

APPENDIX F - ACRONYMS $\ldots \ldots \ldots \ldots \ldots \ldots \ldots \ldots \ldots \ldots \ldots \ldots \ldots \ldots \ldots \ldots \ldots \ldots \ldots \ldots$ 


\section{FIGURES}

1-1. Steps in Seismic Hazard Assessment and Development of a Seismic Design Basis

3-1. Calculated Peak Velocities and Acceleration and Associated Damage Observations on Underground Openings

3-2. Ground Support Estimation Using Q Method

3-3. Idealized Diagram Showing the Transition from Intact Rock to a Heavily Jointed Rock Mass with Increasing Sample Size

3-4. FLAC Model for Seismic Loading Analysis of an Unjointed Rock Mass

3-5. Input Waves at the Bottom of Model and Output Waves at the Top of Model

3-6. Horizontal and Vertical Closures for the Center Drift under Seismic Loading 3-22

3-7. UDEC Model for Seismic Loading Analysis of Jointed Rock Mass 3-24

3-8. Rock and Joint Displacements by Seismic Loading after 50-Year Thermal Loading 3-25 
Topical Report YMP/TR-003-NP, Rev. 1

Preclosure Seismic Design Methodology for a Geologic Repository at Yucca Mountain

INTENTIONALLY LEFT BLANK 


\section{TABLES}

Page

3-1. Summary of Numerical Results for Seismic Load for Concrete Liner 3-23 
Topical Report YMP/TR-003-NP, Rev. 1

Preclosure Seismic Design Methodology for a Geologic Repository at Yucca Mountain

INTENTIONALLY LEFT BLANK 


\subsection{INTRODUCTION}

This topical report describes the methodology and criteria that the U.S. Department of Energy (DOE) proposes to use for preclosure seismic design of structures, systems, and components (SSCs) of the proposed geologic repository operations area that are important to safety. Title 10 of the Code of Federal Regulations, Part 60 (10 CFR 60), Disposal of High-Level Radioactive Wastes in Geologic Repositories, states that for a license to be issued for operation of a high-level waste repository, the U.S. Nuclear Regulatory Commission (NRC) must find that the facility will not constitute an unreasonable risk to the health and safety of the public (Section 60.41 [c]). Section 60.131(b)(1) requires that SSCs important to safety be designed so that natural phenomena and environmental conditions anticipated at the geologic repository operations area will not interfere with necessary safety functions. Among the natural phenomena specifically identified in the regulation as requiring safety consideration are the hazards of ground shaking and fault displacement due to earthquakes.

Part 60.21 describes the required content of the license application. In particular, Sections $60.21(\mathrm{c})(2)$ and (3) require that the DOE describe (1) the principal design criteria and their relation to performance objectives set forth in Section 60.111, (2) the codes and standards that the DOE proposes to use to demonstrate compliance with the design criteria, and (3) the analysis and performance requirements for SSCs important to safety. This topical report responds to the license application requirements of Sections 60.21 (c)(2) and (3) with respect to preclosure seismic design, and it describes the seismic design methodology and acceptance criteria that the DOE intends to use to provide reasonable assurance of achieving the preclosure radiation health and safety performance objectives contained in Section 60.111.

10 CFR 60 does not provide guidance regarding the appropriate preclosure seismic design methodology that should be implemented or the technical criteria that should be satisfied to meet the regulatory requirements. Therefore, the DOE is submitting this topical report for NRC staff review and comment to facilitate reaching an agreement with the staff on an acceptable technical approach to the preclosure design of the geologic repository operations area for vibratory ground motion and fault displacement.

\subsection{BACKGROUND}

The DOE presented an approach for assessing seismic hazards ${ }^{1}$ and accomplishing seismic design of the proposed Yucca Mountain geologic repository operations area in its Site Characterization Plan (DOE 1988, Section 8). In its review of that proposed approach, NRC staff identified a number of items that required additional development and clarification (NRC 1989a). In addition, since publication of the Site Characterization Plan, NRC staff has issued guidance on investigations to identify and evaluate faults that are significant for assessing seismic hazards (NRC 1992) and on consideration of fault displacements for seismic design of a geologic repository (NRC 1994a). This topical report updates the DOE seismic design methodology, in part, to address staff concerns and incorporate the new NRC guidance.

An additional motivation for this topical report is that there have been significant technical and regulatory developments in determining the seismic design bases of nuclear power plants that can

I The phrase "seismic hazard" in its broadest definition is any physical phenomenon (e.g., ground shaking or ground failure) associated with an earthquake that may produce adverse effects on human activities. This report uses the phrase to mean either vibratory ground motion or fault displacement. 
gainfully be applied to the seismic design of repository SSCs. During the past 10 years, the nuclear utility industry and the NRC have developed comprehensive probabilistic seismic hazard assessment methodologies. The industry methodology, which is the basis for the computational code EQHAZARD, was submitted to the NRC in a topical report by the Electric Power Research Institute (EPRI 1989). The EPRI report was extensively reviewed by NRC staff and its advisor, the U.S. Geological Survey, and accepted for evaluating seismic design bases for nuclear power plants. ${ }^{2}$ Recently the NRC has initiated revision of its seismic and geologic siting regulation governing power reactor licensing, 10 CFR 100, Reactor Site Criteria. In the draft revision published for review (59 FR 52255) the NRC incorporated probabilistic techniques for seismic hazard assessment in an effort to achieve stable and consistent design bases for future nuclear power plants. Many of these technical and regulatory advancements can appropriately be applied to the preclosure seismic design of geologic repository operations area facilities that are important to safety and have been incorporated into this topical report.

\subsection{CONTENT OF THE SEISMIC TOPICAL REPORTS}

This topical report is the second in a series of three reports that the DOE has planned that together will describe the preclosure seismic design process. The relationship of the three topical reports is illustrated in Figure 1-1. Topical Report I, Methodology to Assess Fault Displacement and Vibratory Ground Motion Hazards at Yucca Mountain (DOE 1994a), described the DOE methodology for assessing vibratory ground motion and fault displacement hazards. Topical Report II (this report) describes the DOE preclosure seismic design methodology and design acceptance criteria and establishes seismic hazard levels that are appropriate for design. The DOE anticipates that a third report, currently scheduled for fiscal year 1998, will describe the results of the DOE assessment of the vibratory ground motion and fault displacement hazards at Yucca Mountain and the DOE determination of the appropriate design bases for these hazards.

The content of the three seismic reports is described in more detail in the following paragraphs.

Topical Report I-Topical Report I describes the DOE methodology for probabilistic assessment of vibratory ground motion and fault displacement hazards. The methodology involves a series of workshops structured so that multiple experts can interact to evaluate hypotheses and models using the Yucca Mountain site and area geological, geophysical, and seismological data sets. The data sets will be made available to all participant experts uniformly and at common scales. Importantly, the methodology requires that the experts specifically evaluate all hypotheses and models that have credible support in the data. The product of the methodology is multiple interpretations by the experts of seismic sources, source properties, and evaluations of ground motion, all of which include specific expressions of uncertainty. The methodology does not involve expert opinion, which implies judgments unconstrained by data or normal scientific rigor, but instead employs normal earth science procedures and practice, and carries the usual past practice one step further by requiring uncertainty in the interpretations to be specifically expressed. Moreover, it forces a consistent level of scientific rigor, a comprehensive and consistent consideration of data, and documentation of interpretations beyond normal past practice.

Additional information on the methodology is contained in Probabilistic Analyses of Ground Motion and Fault Displacement at Yucca Mountain, Yucca Mountain Study Plan 8.3.1.17.3.6 (DOE 1995a).

2 NRC staff prepared a Safety Evaluation Report accepting the industry's probabilistic seismic hazard methodology for application (EPRI 1989). 


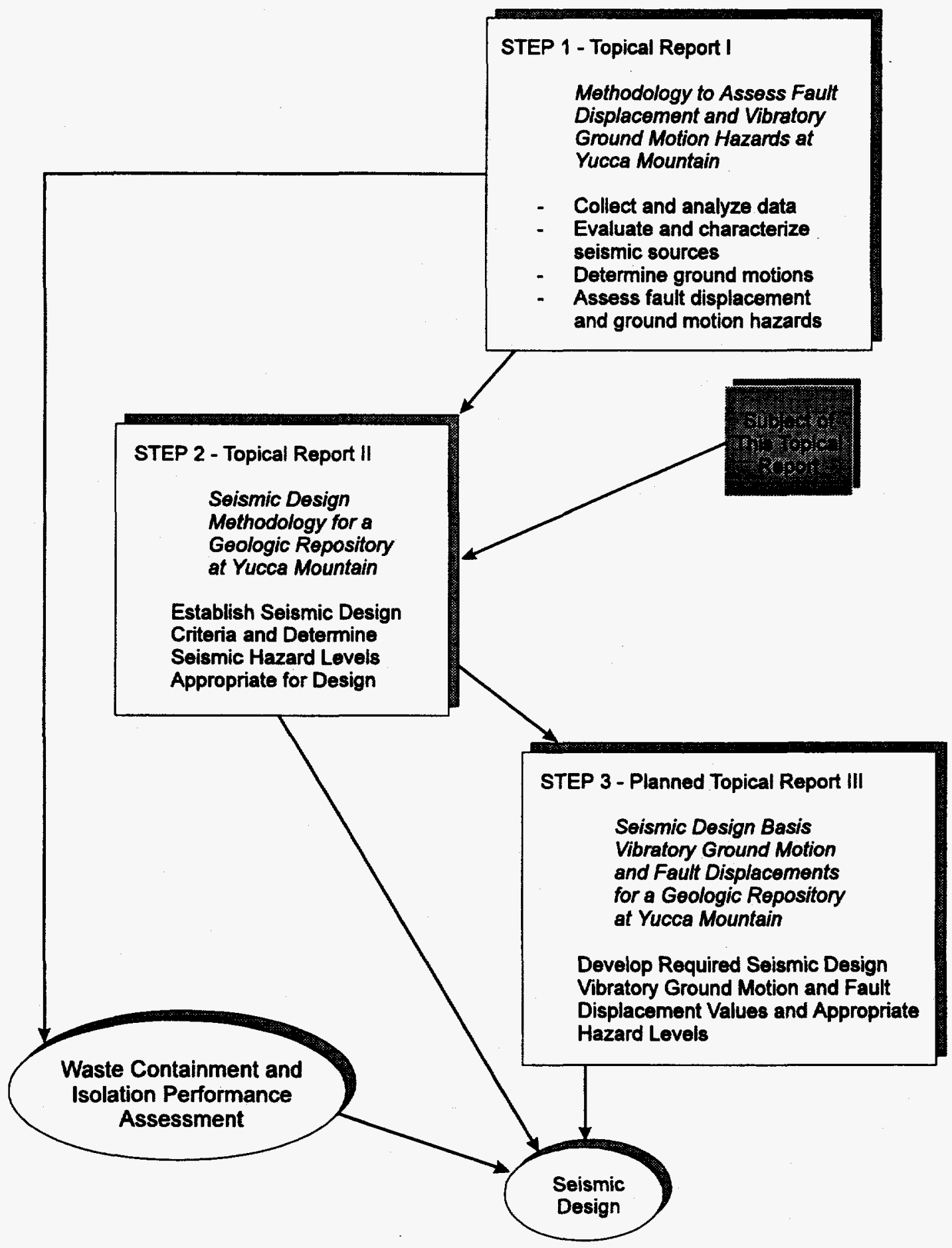

1-1.CDR.TPM.DOCS.YMP.REPORTS.SEISMIC/10-2-96

Figure 1-1. Steps in Seismic Hazard Assessment and Development of a Seismic Design Basis 
Topical Report I does not provide the values of vibratory ground motion and fault displacement hazards for design of the facility SSCs; it describes only the methodology for hazard assessment. The application of this methodology at the Yucca Mountain site will yield hazard results that will, together with planned deterministic evaluations, comprise the information base considered in determining design basis vibratory ground motion and fault displacement values. The methodology also can be used to develop seismic hazard inputs to the assessment of waste containment and isolation performance.

Topical Report II-Topical Report II (this report) describes the design methodology and criteria that the DOE intends to implement to provide reasonable assurance that vibratory ground motions and fault displacements will not compromise the preclosure safety functions of SSCs important to safety. These seismic design methodology and criteria implement the requirements of 10 CFR 60 . In addition, this report has been written to comply with pending requirements in the NRCproposed rulemaking (60 FR 15180) for 10 CFR 60 . Accordingly, this report summarizes the DOE approach to identifying (Frequency-) Category-1 and -2 design basis events and establishes hazard (probability) levels that are appropriate for determining the two levels of design basis vibratory ground motions and the two levels of design basis fault displacements. Acceptance criteria for both surface and underground facilities are provided for vibratory ground motion and fault displacement design. In addition, the report provides criteria for fault avoidance, which is the DOE preferred approach to mitigating fault displacement hazards. Seismic design considerations for waste packages, which will function on the surface and underground and which have a number of unique performance requirements, are discussed separately. NRC guidance documents for the seismic design of nuclear power reactors that can appropriately be applied to preclosure seismic design of the geologic repository operations area are identified in Topical Report II.

Topical Report III-A third seismic topical report is planned for completion in fiscal year 1998. The DOE intends to conduct and document the probabilistic seismic hazard assessment during fiscal year 1997 using the methodology of Topical Report I. Using the results of the hazard assessment, preclosure seismic design inputs will be developed and documented in a Seismic Design Report, which currently is scheduled for the second quarter of fiscal year 1998. The third topical report would document the results of both of these efforts for formal NRC staff review.

It is expected that seismic design inputs will be determined from controlling earthquakes identified from a disaggregation of the probabilistic seismic hazard results and from a consideration of deterministic hazard assessments. Disaggregation of the hazard results will be carried out for hazard exceedance probability levels established in Topical Report II and for ground motion frequencies of interest. Different earthquakes may control the hazard in different frequency ranges. For the controlling earthquakes, the DOE expects to evaluate deterministically ground motions at the site.

Approaches for combining probabilistic seismic hazard assessments with deterministic evaluations to develop seismic design bases are described in the draft American Society of Civil Engineers guideline, Seismic and Dynamic Analysis and Design Considerations for High Level Nuclear Waste Repositories, (ASCE 1993) and in Draft Regulatory Guide DG-1032, Identification and Characterization of Seismic Sources and Determination of Safe Shutdown Earthquake Ground Motion (NRC 1995a). The DOE intends to use approaches similar to those described in these documents to determine fault displacement and vibratory ground motion values appropriate for the preclosure seismic design of SSCs important to safety. 
In addition to conducting the probabilistic hazard assessment, the DOE intends to perform deterministic evaluations of Type I faults and candidate Type I faults that lie within $5 \mathrm{~km}$ of the Yucca Mountain site, including estimations of maximum earthquake magnitudes for the faults. The DOE intends to evaluate where the hazards from these deterministic evaluations fall within the probabilistic results. It is expected that such an evaluation will allow development of a logical and appropriate approach to combine the results of the deterministic and probabilistic evaluations.

\subsection{INTEGRATION OF PRECLOSURE AND POSTCLOSURE REQUIREMENTS IN SEISMIC DESIGN}

SSCs important to safety must, ultimately, be built to a single design that meets all requirements, including those for postclosure performance. To ensure that all SSCs meet all of their design requirements, and to avoid sub-optimalization with respect to any single design requirement, the DOE is employing a systematic approach to the development, integration, and management of all site characterization, development, and operational activities. This approach, summarized here in Appendix A, is specifically intended to result in a one-pass design for the repository, which requires that all functions of the repository throughout its life cycle be understood and all aspects of the repository be designed in advance. To illustrate the design integration process, Appendix A examines the linkage between preclosure seismic design criteria for emplacement drifts and postclosure performance considerations related to seismic loading. This examination concludes that the preclosure seismic design criteria are expected to control the emplacement drift seismic design.

\subsection{ASSUMPTIONS}

This document assumes that the NRC's proposed rulemaking (60 FR 15180) for 10 CFR 60, which calls for the identification of two categories of design basis events, will be promulgated. The document further assumes that waste packages will be placed in-drift in a horizontal mode and that the repository will be designed for a retrievability period of up to 100 years after initiation of emplacement (CRWMS M\&O 1995a, Key Assumptions Nos. 011 and 016, respectively). Consistent with the latter assumption, it is assumed that underground openings and ground support systems will have a maintainable service life of 150 years following first emplacement of waste (CRWMS M\&O 1996b, Table 4-12). Finally, it is assumed that access and emplacement drifts will be monitored and designed to allow inspection and, if necessary, maintenance and repairs during the preclosure operations period (CRWMS M\&O 1996b, Section 8.5.8).

\subsection{QUALITY ASSURANCE}

This document was prepared under Yucca Mountain Site Characterization Project Procedure YAP-5.1Q, Submittal of Documents for Development, Change, Review, and Deliverable Acceptance, and was reviewed under OCRWM Quality Assurance Procedure QAP 6.2, Document Review. This topical report describes a design methodology that is intended to guide future design activities. However, data used in the preparation of the report are unqualified, and the output of the report must be considered to be unqualified. As this is a methodology report (only), there are no applicable design inputs, interfaces, analyses, test equipment, or specified controls. Design verification in accordance with CRWMS M\&O Quality Administrative Procedure QAP-3-2, Design Verification, is not required, as this document is a design approach description which will not be used for procurement.

Results from two commercially available computer programs, FLAC and UDEC, are presented in Section 3.3.3 of this report to illustrate the DOE proposed methodology for the preclosure seismic 
design of underground openings for vibratory ground motion. The FLAC results are taken from the Mined Geologic Disposal System Advanced Conceptual Design Report (CRWMS M\&O 1996b). The UDEC results have not been published elsewhere. UDEC is based on a Lagrangian calculation scheme which is suitable for modeling large deformations in a blocky system. The UDEC code used here is Version 2.0 (CSCI \#B00000000-01717-1200-30004) and has been verified and validated according to applicable CRWMS M\&O procedures. It was run on a $90 \mathrm{MHZ}$ Pentium microcomputer with $16 \mathrm{MB}$ of random access memory. However, its installation on this machine has not been documented, and additional documentation would be required before the UDEC results in this report would be considered to be qualified.

Per QAP 6.2, the Document Review Records generated during the review of this report are lifetime QA records; the document review Comment Sheets, the review draft of the report, and the approved report are nonpermanent QA records. These QA records will be collected, submitted to the Records Processing Center, and maintained in accordance with Yucca Mountain Site Characterization Project Procedure YAP-17.1Q, Records Management Requirements and Responsibilities.

\subsection{ORGANIZATION OF THIS REPORT}

Section 2 reviews the regulatory requirements that govern geologic repository operations area preclosure seismic design and identifies the NRC guidance documents that the DOE believes can appropriately be used. Design of SSCs for vibratory ground motion is discussed in Section 3. This design includes the determination of hazard levels for the two categories of design basis ground motions and design acceptance criteria for surface facilities, underground openings and ground support systems, and other underground SSCs. Section 4 describes hazard levels for the two categories of design basis fault displacements, fault displacement design methodologies and acceptance criteria, and criteria for fault avoidance. The seismic design of waste packages is discussed in Section 5. Section 6 is a summary of the report. Appendix A discusses integration of preclosure and postclosure requirements in seismic design. Appendix B briefly describes the DOE process for identifying SSCs important to safety, in accordance with the NRC-proposed rulemaking for $10 \mathrm{CFR} 60$. Appendix $\mathrm{C}$ documents estimated probabilities of exceeding the seismic design bases of nuclear power reactors in the western United States, which are part of the basis for the reference probabilities used here. Appendix D documents case studies of the design and performance of tunnels through fault zones. Finally, Appendixes $E$ and $F$ list references and acronyms, respectively. 


\subsection{REGULATORY PERSPECTIVE}

This section provides the regulatory context for the methodology discussed in this topical report. It includes a discussion of applicable NRC requirements for geologic repositories, applicable NRC guidance documents for geologic repositories, and other NRC regulations and guidance documents that pertain to seismic design. It also discusses an important potential rule change to 10 CFR 60 .

\section{$2.1 \quad$ NRC REQUIREMENTS IN 10 CFR 60}

\subsubsection{Proposed Rulemaking for 10 CFR 60}

This topical report has been written to comply with pending requirements in the NRC-proposed

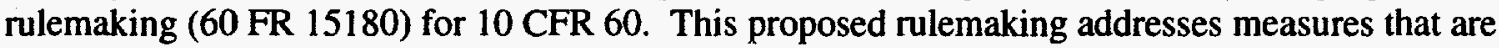
required to provide defense in depth against the consequences of "design basis events." The proposed rule change would modify the definition of "important to safety," establish two categories of design basis events, and specify dose limits for those design basis events. The proposed rule change addresses, in part, concerns that were expressed in the DOE 1990 petition for rulemaking (55 FR 28771).

The proposed new definitions of "design basis events," "important to safety," and "preclosure controlled area" are as follows:

"Design basis events means (1) those natural and human-induced events that are reasonably likely to occur regularly, moderately frequently, or one or more times before permanent closure of the geologic repository operations area; and (2) other natural and man-induced events that are considered unlikely, but sufficiently credible to warrant consideration, taking into account the potential for significant radiological impacts on public health and safety.

"The events described in paragraph (1) of this definition are referred to as 'Category 1' design basis events. The events described in paragraph (2) of this definition are referred to as 'Category 2 ' design basis events.

"Important to safety, with reference to structures, systems, and components, means those features of the repository whose function is (1) to provide reasonable assurance that high-level waste can be received, handled, packaged, stored, emplaced, and retrieved without exceeding the requirements of 60.111(a) for Category 1 design basis events; or (2) to prevent or mitigate Category 2 design basis events that could result in doses equal to or greater than the values specified in Section 60.136 to any individual located on or beyond the nearest boundary of the preclosure controlled area.

"Preclosure controlled area means that surface area immediately surrounding the geologic repository operations area for which the licensee exercises authority over its use, in accordance with the provisions of this part, until permanent closure has been completed."

The proposed rulemaking also invokes radiation protection limits for Category 1 and Category 2 design basis events.

"[Section 60.21(c)(3)] [The Safety Analysis Report shall include a] description and analysis of the design and performance requirements for structures, systems, and components of the geologic repository that are important to safety. The analysis must include a demonstration that - (i) the requirements of Section 60.111(a) will be met, assuming occurrence of 
Category 1 design basis events; and (ii) the requirements of Section 60.136 will be met, assuming occurrence of Category 2 design basis events. The dose limits associated with the preclosure controlled area are specified.

"[Section 60.136] Preclosure controlled area. (a) A preclosure controlled area must be established for the geologic repository operations area. (b) The geologic repository operations area shall be designed so that, for Category 2 design basis events, no individual located on or beyond the nearest boundary of the preclosure controlled area will receive the more limiting of a total effective dose equivalent of $0.05 \mathrm{~Sv}$ ( $5 \mathrm{rem}$ ), or the sum of the deepdose equivalent and the committed dose equivalent to any individual organ or tissue (other than the lens of the eye) of $0.5 \mathrm{~Sv}(50 \mathrm{rem})$. The eye dose equivalent may not exceed $0.15 \mathrm{~Sv}(15 \mathrm{rem})$, and the shallow dose equivalent to skin may not exceed $0.5 \mathrm{~Sv}(50 \mathrm{rem})$. The minimum distance from the surface facilities in the geologic repository operations area to the boundary of the preclosure controlled area must be at least 100 meters."

To avoid confusion with the term "Seismic Category I," which is used in the licensing of nuclear power reactors to refer to SSCs that must be designed for safe shutdown earthquake ground motion, this topical report refers to the two categories of design basis earthquakes as "FrequencyCategory-1" and "Frequency-Category-2" design basis earthquakes. This nomenclature also emphasizes the important fact that, in the proposed rulemaking, design basis events are defined in terms of their likelihood of occurrence.

The proposed rulemaking specifies performance requirements for the design of SSCs important to safety. For Frequency-Category-1 design basis events, Section 60.111(a) invokes the limits in 10 CFR 20, Standards for Protection Against Radiation, for exposure of workers and members of the public to radiation. Those limits are currently $0.1 \mathrm{rem}$ total effective dose equivalent for the public, and $5 \mathrm{rem}$ total effective dose equivalent for workers. For Frequency-Category-2 design basis events, a $5 \mathrm{rem}$ total effective dose equivalent limit would be applied for the public at the preclosure controlled area boundary.

The process that the DOE intends to use to identify SSCs important to safety is described in Appendix A.

\subsubsection{Subpart A-General Provisions}

Key definitions from 10 CFR 60.2 relating to seismic design are provided below.

"'Anticipated processes and events' mean those natural processes and events that are reasonably likely to occur during the period the intended performance objective must be achieved. To the extent reasonable in light of the geologic record, it shall be assumed that those processes operating in the geologic setting during the Quaternary Period continue to operate but with the perturbations caused by the presence of emplaced radioactive waste superimposed thereon.

"'Geologic repository operations area' means a high-level radioactive waste facility that is part of a geologic repository, including both surface and subsurface areas, where waste handling activities are conducted.

"'Important to safety,' with reference to structures, systems, and components, means those engineered structures, systems, and components essential to the prevention or mitigation of an accident that could result in a radiation dose to the whole body, or any organ, of $0.5 \mathrm{rem}$ 
or greater at or beyond the nearest boundary of the unrestricted area at any time until the completion of permanent closure. (The proposed 10 CFR 60 rulemaking would change the definition of 'important to safety' to refer to Category 1 and Category 2 design basis events.)

"'Retrieval' means the act of intentionally removing radioactive waste from the underground location at which the waste had been previously emplaced for disposal.

\subsubsection{Subpart B-Licenses}

Subpart B to 10 CFR 60 addresses the regulatory requirements for construction authorization, license application, and license amendments.

"[Section 60.21(c)(2)] The Safety Analysis Report shall include ... a description and discussion of the design, both surface and subsurface, of the geologic repository operations area including (i) the principal design criteria and their relationship to any general performance objectives promulgated by the Commission, (ii) the design bases and the relation of the design bases to the principal design criteria, (iii) information relative to materials of construction (including geologic media, general arrangement, and approximate dimensions), and (iv) codes and standards that DOE proposes to apply to the design and construction of the geologic repository operations area.

"[Section 60.21(c)(3)] A description and analysis of the design and performance requirements for structures, systems, and components of the geologic repository which are important to safety. This analysis shall consider (i) the margins of safety under normal conditions and under conditions that may result from anticipated operational occurrences, including those of natural origin; and (ii) the adequacy of structures, systems, and components provided for the prevention of accidents and mitigation of the consequences of accidents, including those caused by natural phenomena.

"[Section 60.31] Upon review and consideration of an application and environmental impact statement submitted under this part, the Commission may authorize construction if it determines

a. Safety. That there is reasonable assurance that the types and amounts of radioactive materials described in the application can be received, possessed, and disposed of in a geologic repository operations area of the design proposed without unreasonable risk to the health and safety of the public. In arriving at this determination, the Commission shall consider whether

(1) DOE has described the proposed geologic repository including but not limited to ...

(iii) the principal architectural and engineering criteria for the design of the geologic repository operations area...."

To summarize, the DOE will be required to document its design criteria, design bases, and applicable codes and standards relating to seismic design. The DOE must analyze and document the design and performance requirements for SSCs important to (radiological) safety. Normal operations, anticipated operational occurrences, and accidents must be considered, including those caused by natural phenomena such as seismic events. The DOE will be required to demonstrate with reasonable assurance that the repository can be operated without unreasonable risk to the public health and safety. 


\subsubsection{Subpart E-Technical Criteria}

Subpart E to 10 CFR 60 contains the technical criteria that a license application must address.

"[Section 60.101(a)(2)] While these performance objectives and criteria are generally stated in unqualified terms, it is not expected that complete assurance that they will be met can be presented. A reasonable assurance, on the basis of the record before the Commission, that the objectives and criteria will be met is the general standard that is required.

"[Section 60.101(b)] Subpart B of this part also lists findings that must be made in support of an authorization to construct a geologic repository operations area. In particular, Section 60.31(a) requires a finding that there is reasonable assurance that the types and amounts of radioactive materials described in the application can be received, possessed, and disposed of in a geologic repository operations area of the design proposed without unreasonable risk to the health and safety of the public. As stated in that paragraph, in arriving at this determination, the Commission will consider whether the site and design comply with the criteria contained in this subpart. Once again, while the criteria may be written in unqualified terms, the demonstration of compliance may take uncertainties and gaps in knowledge into account, provided that the Commission can make the specified finding of reasonable assurance as specified in paragraph (a) of this section."

This important section of the regulation invokes the "reasonable assurance" doctrine for the findings that the NRC must make on a license application. The regulation clearly states that absolute proof or complete assurance is not required or expected, and that the demonstration of compliance is expected to involve uncertainties and gaps in knowledge. The key criterion for acceptability is no "unreasonable risk to the health and safety of the public."

\subsubsection{Performance Objectives}

This section of $10 \mathrm{CFR} 60$ provides performance objectives for the repository both before and after permanent closure.

"[Section 60.111(a)] Protection against radiation exposures and releases of radioactive material. The geologic repository operations area shall be designed so that until permanent closure has been completed, radiation exposures and radiation levels, and releases of radioactive materials to unrestricted areas, will at all times be maintained within the limits specified in Part 20 of this chapter and such generally applicable environmental standards for radioactivity as may have been established by the Environmental Protection Agency (emphasis added)."

The proposed rulemaking for 10 CFR 60 would delete the phrase "at all times" from the performance objective of $\$ 60.111$ (a) to clarify that this requirement does not apply to radiation exposures, levels, and releases from Frequency-Category-2 design basis events (see Section 2.1.1).

"[Section 60.111(b)] Retrievability of waste. (1) The geologic repository operations area shall be designed to preserve the option of waste retrieval throughout the period during which wastes are being emplaced and, thereafter, until the completion of a performance confirmation program and Commission review of the information obtained from such a program. To satisfy this objective, the geologic repository operations area shall be designed so that any or all of the emplaced waste could be retrieved on a reasonable schedule starting at any time up to 50 years after waste emplacement operations are initiated, unless a 
different time period is approved or specified by the Commission. This different time period may be established on a case-by-case basis consistent with the emplacement schedule and the planned performance confirmation program."

Although 10 CFR 60 requires the design of the repository to allow for retrievability of the waste for at least $\mathbf{5 0}$ years after the initiation of waste emplacement operations, the DOE currently is assuming a 100-year retrievability period for design purposes (CRWMS M\&O 1995a).

\subsubsection{Design Criteria for the Geologic Repository Operations Area}

This section of 10 CFR 60 provides design criteria for the geologic repository operations area. In addition to the criteria cited in this section, the NRC notes in Section 60.130 that "Omissions in Sections 60.131 through 60.134 do not relieve DOE from any obligation to provide such safety features in a specific facility needed to achieve the performance objectives."

"[Section 60.131(b)] Structures, systems, and components important to safety. (1) Protection against natural phenomena and environmental conditions. The structures, systems, and components important to safety shall be designed so that natural phenomena and environmental conditions anticipated at the geologic repository operations area will not interfere with necessary safety functions.

"[Section 60.133(e)] Underground openings. (1) Openings in the underground facility shall be designed so that operations can be carried out safely and the retrievability option maintained. (2) Openings in the underground facility shall be designed to reduce the potential for deleterious rock movement or fracturing of overlying or surrounding rock.

"[Section $60.133(\mathrm{~g})]$ Underground facility ventilation. The ventilation system shall be designed ... to assure continued function during normal operations and under accident conditions."

Sections $60.131(\mathrm{~b})$ and $60.133(\mathrm{~g})$ would be revised by the proposed Part 60 rulemaking to read as follows:

"[Section 60.131(b)] Protection against design basis events. The structures, systems, and components important to safety shall be designed so they will perform their necessary safety functions, assuming occurrence of design basis events.

"[Section 60.133(g)] Underground Facility Ventilation. The ventilation system shall be designed to ... assure the ability to perform essential safety functions assuming occurrence of design basis events."

Implicit in the above requirements is the need to consider seismic events in the design of underground openings and facilities.

\subsubsection{Design Criteria for the Waste Package}

This section of 10 CFR 60 provides design criteria for the waste package and its components.

"[Section 60.135(a)] High-level-waste package design in general. (1) Packages for HLW shall be designed so that the in situ chemical, physical, and nuclear properties of the waste package and its interactions with the emplacement environment do not compromise the 
function of the waste packages or the performance of the underground facility or the geologic setting."

Interactions with the emplacement environment of the waste package include mechanical interactions that might result from seismic events.

\subsubsection{Subpart G-Quality Assurance}

10 CFR 60 requires that quality assurance be applied to the repository program.

"[Section 60.151] Applicability. The quality assurance program applies to all structures, systems, and components important to safety, the design and characterization of barriers important to waste isolation, and to activities related thereto.

"[Section 60.152] Implementation. DOE shall implement a quality assurance program based on the criteria of Appendix B of 10 CFR 50 as applicable, and appropriately supplemented by additional criteria as required by $\$ 60.151 . "$

The design of SSCs important to safety to withstand seismic hazards is therefore an activity that is covered by the quality assurance program.

\subsubsection{Summary of NRC Requirements for Seismic Design}

10 CFR 60 provides general requirements related to the seismic design methodology for the repository. Important to safety SSCs must be designed to accommodate seismic events, and designs and analyses must be described in the license application for a repository. The NRC recognizes that there will be uncertainties and gaps in knowledge; reasonable assurance, not absolute proof, is the standard that must be met by the license application. Repository SSCs are required to meet a number of requirements, including limiting operational radiation exposure, providing for retrievability, and protecting against natural phenomena. Waste packages shall be designed to accommodate interactions with the emplacement environment.

A proposed rulemaking would modify the current definition of "important to safety" and provide for two, frequency-based categories of design basis events. The DOE seismic design methodology described in this report conforms to the design basis event criteria in the proposed rule.

\section{NRC GUIDANCE DOCUMENTS FOR GEOLOGIC REPOSITORIES}

This section discusses guidance documents (staff technical positions) that have been issued by the NRC specifically for use with 10 CFR 60 . While staff technical positions are not regulations, and compliance with them is not required, they do provide methods that are acceptable to NRC staff for implementing specific parts of NRC regulations.

\subsubsection{NUREG-1451}

NUREG-1451, Staff Technical Position on Investigations to Identify Fault Displacement Hazards and Seismic Hazards at a Geologic Repository (NRC 1992) primarily pertains to seismic hazard assessment, not seismic design; however, some information related to seismic design is described and discussed below. 
Appendix A of NUREG-1451 discusses the relationship between NRC requirements for a geologic repository, as provided in 10 CFR 60 , and the NRC siting and design policy related to geological and seismological hazards for nuclear power stations, as contained in Appendix A of 10 CFR 100 . NUREG-1451, Appendix A, makes the following statements:

"The staff has not adopted Appendix A [to 10 CFR Part 100] for guidance on geologic and seismologic criteria for application to geologic repositories.

"Because of site- and design-specific considerations, the language in 10 CFR 60 is intentionally non-prescriptive. It leaves to the U.S. Department of Energy responsibility, in the first instance, to determine, among other things, how to site and design the repository. The staff does consider that the Commission's intent, under 10 CFR 60, for DOE to select a site with favorable geologic conditions, is consistent with the approach used in siting other nuclear facilities. Moreover, the staff considers that current NRC design policy, as derived from Appendix A to 10 CFR Part 100 (see NRC 1977) ${ }^{3}$, is not applicable to the geologic repository program, considering the character of a geologic repository.

"Thus, although NRC's regulatory requirements, in 10 CFR 60, regarding the siting and design for a geologic repository, are different from those that pertain to the regulatory requirements for other types of nuclear facilities, NRC health and safety standards for all types of nuclear facilities are consistent with the Commission's defense-in-depth safety philosophy and, accordingly, are considered to provide appropriate levels of protection against radiological hazards."

The DOE seismic design methodology for a potential geologic repository is consistent with the above NRC guidance. The repository seismic design methodology is not, and is not intended to be, entirely consistent with the design criteria for nuclear power plants contained in $10 \mathrm{CFR} 100$, Appendix A. However, the design methodology is consistent with the NRC philosophy and goal of providing appropriate levels of protection against radiological hazards.

NUREG-1451, Section 3, provides the following definitions for different types of faults:

"Type III faults Faults or fault zones either (1) not subject to displacement or (2) subject to displacement, but of such length, or located in such a manner that they will not affect repository design and/or performance. Consequently, they do not need to be investigated in detail.

"Type II faults Faults or fault zones that are candidates for detailed investigation.

"Type I faults Faults or fault zones that are subject to displacement and of sufficient length and located such that they may affect repository design and/or performance. As such they should be investigated in detail. Only faults that are determined to be 'Type I' are of regulatory concern, because it is those faults, both inside and outside the controlled area, that may require consideration in repository design, could have an effect on repository performance, or could provide significant input into models used to assess repository performance."

3 The reference to "NRC 1977" is part of Appendix A of NUREG-1451. It is not a citation in this document, but refers to 10 CFR 100 , listed in this document's reference section. 
The definition of Type I faults is significant in the context of NUREG-1494, discussed next, which provides guidance for the consideration of fault displacement hazards in geologic repository design.

\subsubsection{NUREG-1494}

NUREG-1494, Staff Technical Position on Consideration of Fault Displacement Hazards in Geologic Repository Design (NRC 1994), was published by the NRC in September 1994. The following two positions are provided in Section 3 of that document:

"1) It is the NRC staff position that the presence of 'Type I' faults, as defined by NUREG-1451, inside the controlled area of a geologic repository, does not, by itself, disqualify a candidate site for a geologic repository.

"2) In general, areas within the controlled area of a geologic repository that contain 'Type I' faults should be avoided, where this can be reasonably achieved, when locating structures, systems, and components important to safety or important to waste isolation. However, if DOE chooses to locate structures, systems, and components important to safety or important to waste isolation in areas that contain 'Type I' faults, then

a) DOE should recognize that reliance on engineering may be of limited value; and

b) DOE must be able to demonstrate, with reasonable assurance, that any proposed geologic repository designed to accommodate the effects of faulting meets the 10 CFR Part 60 design criteria, and pre- and postclosure performance objectives."

Further clarification to the second position is provided in Section 1 of NUREG-1494, as follows:

"For the purposes of this Staff Technical Position, 'Type I' faults are adequately taken into account, accommodated, or compensated for when it can be demonstrated that their effects do not preclude meeting the pertinent 10 CFR 60 design criteria and the pre- and postclosure performance objectives. However, DOE should seek early resolution of fault-related design and performance issues, at the staff level, before submitting a license application to construct and operate a geologic repository."

The proposed methodology and criteria in this topical report are consistent with the NRC technical positions in NUREG-1494. The primary fault displacement design criterion will be fault avoidance to the extent reasonably achievable, by facility layout and placement of SSCs important to safety. When the fault avoidance criterion is not reasonably achievable, engineering design criteria or repair and rehabilitation actions will provide reasonable assurance that preclosure safety performance objectives are met.

\subsection{OTHER NRC DOCUMENTS}

\subsubsection{Proposed Rule Change to 10 CFRs 50, 52, and 100}

On October 17, 1994, the NRC proposed to amend its regulations to update the criteria used in decisions regarding power reactor siting, including geologic, seismic, and earthquake engineering considerations for future nuclear power plants (59 FR 52255). These criteria do not apply to mined geologic disposal systems, which are to be licensed under 10 CFR 60 . However, the DOE has considered those aspects of the proposed rule that are related to seismic siting criteria and 
earthquake engineering criteria in the development of the preclosure seismic design methodology for the Yucca Mountain geologic repository operations area.

Section V.B.3 of the Supplementary Information provided in 59 FR 52255 states, "The proposed revision to the regulation now explicitly recognizes that there are inherent uncertainties in establishing the seismic and geologic design parameters and allows for the option of using a probabilistic seismic hazard methodology capable of propagating uncertainties as a means to address these uncertainties" (in lieu of a strictly deterministic approach).

The DOE approach to seismic hazard assessment and seismic design is generally consistent with the proposed revision to 10 CFRs 50,52, and 100. The DOE will conduct a probabilistic seismic hazard assessment of the site that incorporates the uncertainty in interpretations of site characterization data and will use target exceedance probabilities (discussed in Sections 3 and 4) as a basis for establishing Frequency-Category- 1 and Frequency-Category- 2 design basis ground motions and fault displacements. The DOE approach builds upon concepts developed in the regulatory environment for nuclear power reactors and takes advantage of improvements in methodology to address the unique aspects of a geologic repository.

\subsubsection{Policy Statement on Use of Probabilistic Risk Assessment Methods in Nuclear Regulatory} Activities

On August 16, 1995, the NRC issued its final policy statement regarding the use of probabilistic risk assessment in nuclear regulatory matters (60 FR 42622). The first of the four parts of the policy is stated below.

"1) The use of PRA [probabilistic risk assessment] technology should be increased in all regulatory matters to the extent supported by the state-of-the-art in PRA methods and data and in a manner that complements the NRC's deterministic approach and supports the NRC's defense-in-depth philosophy."

Probabilistic seismic hazard assessment is the state-of-the-art approach to seismic hazard assessment, as indicated by the proposed rule change to 10 CFR 100. The DOE methodology uses probabilistic seismic hazard assessment as the primary basis for determining the vibratory ground motion and fault displacement inputs for the seismic design of SSCs. Once those design inputs are determined, the methodology prescribes a traditional deterministic approach to design, incorporating established regulatory guidance, codes, and practices, when available. Thus, probabilistic hazard assessment techniques are used to complement the traditional deterministic design approach in a manner consistent with the NRC policy statement.

\subsubsection{NUREG-0800, Standard Review Plan}

NUREG-0800, Standard Review Plan for the Review of Safety Analysis Reports for Nuclear Power Reactors (NRC 1987), provides guidance to the Office of Nuclear Reactor Regulation staff who are responsible for the review of applications to construct and operate nuclear power plants. Portions of standard review plans are often incorporated by reference in NRC regulatory guides and, thereby, also become guidance to applicants. NUREG-0800 applies only to nuclear power reactors and is not applicable to mined geologic disposal systems. For the latter, the staff of the Office of Nuclear Material Safety and Safeguards, Division of Waste Management, has developed a draft review plan, NUREG-1323, License Application Review Plan for a Geologic Repository for Spent Nuclear Fuel and High-Level Radioactive Waste, Rev. 1 (NRC 1995b). However, in its present form, the License Application Review Plan does not provide specific seismic design 
acceptance criteria, as does NUREG-0800. For this reason, the DOE has evaluated the sections of NUREG-0800 that directly relate to seismic design methodology for potential applicability to a repository at Yucca Mountain. Specific Standard Review Plan sections and their applicability are detailed in Section 3.2. 


\subsection{DESIGN OF STRUCTURES, SYSTEMS, AND COMPONENTS FOR VIBRATORY GROUND MOTION}

\subsection{HAZARD LEVELS FOR DESIGN BASIS GROUND MOTIONS}

In accordance with the proposed 10 CFR 60 rulemaking discussed in Section 2.1.1, the DOE will identify SSCs important to (radiological) safety. The DOE procedure for identifying these SSCs is summarized in Appendix B. The classification process involves the identification of FrequencyCategory-1 and Frequency-Category-2 design basis events and event-initiated accident scenarios and the calculation of corresponding exposures to workers and the public. The calculated exposures are compared to regulatory limits, and any SSC that must continue to function after a design basis event to ensure the exposure limits are not exceeded is classified as important to safety. No SSCs have yet been classified. Note that SSCs may be important to safety for both Frequency-Category-1 and Frequency-Category-2 design basis events. Where this occurs, the most stringent (i.e., Frequency-Category-2) design basis will apply.

In the proposed 10 CFR 60 rulemaking, the definitions of Category-1 and -2 design basis events are qualitative descriptions of the likelihood of occurrence before permanent closure of the geologic repository operations area. For use in SSC classification, which requires knowledge of the design basis events and calculation of radiation exposures, these definitions require quantitative interpretations. As discussed next, the DOE intends to use mean annual exceedance probabilities of $1.0 \mathrm{E}-03$ and $1.0 \mathrm{E}-04$, respectively, as reference values in determining the Frequency-Category-1 and -2 design basis vibratory ground motions. These reference values will be used in the disaggregation of probabilistic seismic hazard estimates to identify those earthquakes that control the seismic hazard at the reference probabilities. The identification of controlling earthquakes and the DOE determination of the design basis ground motions are planned to be detailed in the third seismic topical report.

\subsubsection{Frequency-Category-1 Reference Probability}

The definition of Category-1 design basis events in the proposed 10 CFR 60 rulemaking is "those natural and human-induced events that are reasonably likely to occur regularly, moderately frequently, or one or more times before permanent closure of the geologic repository operations area." The DOE considers that a reasonable annual probability of occurrence to assign to this qualitative description of likelihood, given the time frame of preclosure operations, is 1.0E-02. Assuming a Poisson probability distribution, events with this occurrence rate would have a 37 percent chance of not occurring, a 37 percent chance of occurring once, and an 18 percent chance of occurring twice in 100 years (see Equation 3.1, below).

Although an annual occurrence rate of $1.0 \mathrm{E}-02$ is a reasonable interpretation of the definition of Category-1 events in the NRC-proposed rulemaking, the DOE does not consider that it would be appropriate to use this value, which would correspond to the 100-year earthquake, as a reference probability for the Frequency-Category-1 design basis ground motion. The Uniform Building Code (ICBO 1994) and the National Earthquake Hazards Reduction Program (BSSC 1995) both recommend using peak ground motion values that have a 90 percent chance of not being exceeded in $\mathbf{5 0}$ years for the life-safety seismic design of new buildings. This exceedance probability corresponds to a return period of about 500 years, or an annual probability of about 2.0E-03. DOE Standard 1020-94 (DOE 1994b) is not being applied to the mined geologic disposal system program; however, it documents a general DOE policy that a 500-year return period is the minimum to be used for the seismic design of new buildings. Reflecting the fact that SSCs important to safety must function to prevent significant radiological impacts on public health and 
safety, the DOE intends to use a reference mean annual probability of exceedance of $1.0 \mathrm{E}-03$ in determining the Frequency-Category-1 design basis ground motion. The DOE considers that this probability, which corresponds to a 1,000-year return period, represents an extremely conservative quantitative translation of the qualitative frequency description for (Frequency) Category-1 design basis events in the NRC-proposed rulemaking for 10 CFR 60.

\subsubsection{Frequency-Category-2 Reference Probability}

For Frequency-Category-2 design basis ground motion, the DOE intends to use a reference mean annual exceedance probability of $1.0 \mathrm{E}-04$. The $\mathrm{DOE}$ considers that this mean value is appropriate and conservative based on the observations that (1) it is comparable to the mean exceedance probabilities of the seismic design bases of operating nuclear power reactors in the United States, (2) these accepted reactor design bases and their associated design-acceptance criteria have resulted in acceptably safe seismic designs, (3) design-acceptance criteria will be used in repository design that are the same as or comparable to those used in reactor designs, and (4) an operating mined geologic disposal system is inherently less hazardous and less vulnerable to earthquake-initiated accidents than is an operating nuclear power reactor.

\subsubsection{Comparison with Nuclear Power Reactor Seismic Design Bases}

In Draft Design Guide DG-1032 (NRC 1995a) NRC staff states that a reference median annual exceedance probability of $1.0 \mathrm{E}-05$ will be acceptable for use in determining the safe shutdown earthquake for new nuclear power reactors. The cited rationale for this reference probability is that it is the annual probability level such that 50 percent of a set of currently operating plants (selected by the NRC) has an annual median probability of exceeding the safe shutdown earthquake that is below this level. In other words, $1.0 \mathrm{E}-05$ is the median of the distribution of median exceedance probabilities. The selected plants represent relatively recent designs that used design response spectra in accordance with Regulatory Guide 1.60, Design Response Spectra for Seismic Design of Nuclear Power Plants (AEC 1973), or similar spectra. All of the plants selected are located in the central or eastern United States (CEUS). DG-1032 provides an option for the applicant to use a different reference probability, to be reviewed and accepted on a case-by-case basis, considering the slope of the site-specific hazard curve, the overall uncertainty in hazard estimates, including differences between mean and median hazard estimates, and knowledge of the seismic sources that contribute to the hazard.

In developing DG-1032, NRC staff considered whether to define the reference probability as a mean or median value. The mean value has the advantage of better reflecting the uncertainty in the seismic hazard evaluation (i.e., it is sensitive to the range of interpretations of seismic source zone configurations, earthquake magnitude recurrence relationships, and ground motion attenuation relationships). In contrast to the mean value, the median value is more stable in the face of uncertainty because it is less sensitive to divergent interpretations of seismic parameters. In the supplementary information published with the proposed rulemaking for 10 CFR 100 (59 FR 52255), NRC staff cited the need for stability in regulatory standards as a reason for its decision to define the reference probability in DG- 1032 as a median value. Additional reasons include the findings that, when median hazard curves were disaggregated, the magnitudes and distances of the controlling earthquakes tended to be more sharply defined and to agree better with the safe shutdown earthquakes of the selected plants than when mean hazard curves were disaggregated (Bernreuter et al. 1996).

To identify the earthquakes that control the Frequency-Category-2 design basis ground motion, the DOE plans to use a mean annual exceedance probability of 1.0E-04. NRC-sponsored research has 
shown that a mean value of $1.0 \mathrm{E}-04$ corresponds to a median value of $1.0 \mathrm{E}-05$ at sites in the CEUS (NRC 1994b). That is, while 1.0E-05 is the median of the distribution of median exceedance probabilities of the safe shutdown earthquakes of the more recently designed nuclear power reactors in the CEUS, 1.0E-04 is the median of the distribution of means. So, 50 percent of the nuclear power reactors in the selected set have an annual mean probability of exceeding the safe shutdown earthquake that is below this level. Using a mean value of $1.0 \mathrm{E}-04$ to determine the safe shutdown earthquake for a new nuclear power reactor in the CEUS would, thus, be riskconsistent with using a median value of $1.0 \mathrm{E}-05$.

In contrast to sites in the CEUS, the equivalency of 1.0E-04 mean and 1.0E-05 median annual probabilities of exceedance does not generally hold in the western United States and is not expected to hold at Yucca Mountain. Because the distributions of probabilistic seismic hazard estimates typically are skewed about the median towards higher probability levels, mean exceedance probabilities usually are greater than median probabilities, and the greater the uncertainty (i.e., spread of the distribution of hazard curves), the greater the difference between the mean and median values. This fact, together with the fact that the uncertainty in seismic hazard evaluations is almost always greater at CEUS sites than at western sites, indicates that mean values normally are closer to median values at western sites than at CEUS sites. Thus, if one were siting a nuclear power reactor at a typical western U.S. site, choosing a mean annual exceedance probability of $1.0 \mathrm{E}-04$ would be risk-consistent with the accepted seismic design bases of the more recently designed power reactors in the CEUS, but choosing a median value of $1.0 \mathrm{E}-05$ would not be risk-consistent.

As a check on the reasonableness of using a mean annual exceedance probability of $1.0 \mathrm{E}-04$ as the reference probability for determining the Frequency-Category-2 design basis ground motion, the DOE compiled published information on the annual probability of exceeding the accepted seismic design bases of nuclear power plants in the western United States. Specifically, information was compiled for the Diablo Canyon Power Plant (Units 1 and 2) in Port San Luis, California; Palo Verde Nuclear Generating Station (PVNGS) in Wintersburg, Arizona; San Onofre Nuclear Generating Station (Units 2 and 3) in Southern California; Washington Nuclear Plant 2 near Hanford, Washington; and Washington Nuclear Plant 3 at Satsop, Washington. All of these power reactors are currently operating, with the exception of Washington Nuclear Plant 3 , which was only partially constructed and which has now been canceled. It is included in this analysis because its seismic design basis was completed and accepted provisionally by NRC staff (NRC 1991a). In accordance with the guidance in DG-1032 (NRC 1995a), this analysis used for reference the probability of exceeding the average of the 5 and $10 \mathrm{~Hz}$ safe shutdown earthquake response spectrum ordinates.

Results of the compilation are presented in Appendix C. As shown there the estimated mean annual probability of exceeding the safe shutdown earthquake of each western plant is greater than 1.0E-04/yr, with the single exception of the PVNGS, which is located in a low-seismic-hazard region. The average mean annual probability of exceeding the safe shutdown earthquake of each plant is $2.0 \mathrm{E}-04$, which is twice the value of the reference probability to be used in determining the Frequency-Category- 2 design basis ground motion.

\subsubsection{Conservatism of the Reference Probability}

As noted earlier, the use of NRC-accepted seismic design bases for nuclear power reactors as a benchmark for Frequency-Category-2 design basis ground motion is based on the premise that reactor design bases correspond to acceptable seismic risk levels. Of course, the seismic design bases of all nuclear power reactors operating in the United States have been reviewed extensively 
by NRC staff, using standardized review criteria, and all have been found to satisfy applicable regulatory requirements by NRC licensing boards. In addition, a substantial body of recently developed information indicates that these plants have adequate margins of safety against potential accidents and that they have acceptably safe seismic designs. In June 1991 the NRC requested that its nuclear power reactor licensees perform a plant-specific Individual Plant Examination of External Events (IPEEE) to identify vulnerabilities, if any, to earthquakes, fires, winds, floods, and nearby transportation and other-facility accidents (NRC 1991b). The IPEEE program corroborated the adequacy of the seismic design bases of the Nation's operating nuclear power reactors. For example, specific IPEEE findings for operating reactors in the western United States were as follows:

- In the IPEEE study of the Diablo Canyon Power Plant, Pacific Gas and Electric Company (PG\&E 1994) found that the mean core damage frequency due to external events is about $6.7 \mathrm{E}-5 / \mathrm{yr}$. The component of this risk due to earthquake-initiated accident scenarios was estimated to be $4.0 \mathrm{E}-5 / \mathrm{yr}$.

- The PVNGS is located in Wintersburg, Arizona, and is operated by the Arizona Public Service Company (APS). The PVNGS site is in a region of low seismic hazard relative to most other regions of the western United States; the PVNGS horizontal design basis response spectrum is anchored at $0.25 \mathrm{~g}$ peak ground acceleration (APS 1978). Given the relatively low seismic hazard, APS was required to conduct a seismic margins analysis for the IPEEE program, rather than a seismic risk assessment. The margins analysis was conducted with respect to a peak horizontal ground acceleration of $0.3 \mathrm{~g}$, and the analysis found that at least one safe shutdown path in excess of $0.3 \mathrm{~g}$ exists for the PVNGS plants (APS 1995).

- The IPEEE study conducted by Southern California Edison (SCE 1995) for the San Onofre Nuclear Generating Station found that the mean core damage frequency due to externalevent initiators is approximately 3.3E-5/yr. The component of this risk due to earthquakeinitiated accident scenarios was estimated to be about $1.7 \mathrm{E}-5 / \mathrm{yr}$.

- In the IPEEE study of the Washington Nuclear Plant 2, the Washington Public Power Supply System (WPPSS 1995) estimated that the mean core damage frequency due to external-event initiators is $2.1 \mathrm{E}-5 / \mathrm{yr}$ and that this risk is dominated by the seismic contribution.

The DOE considers that use of an annual exceedance probability for the Frequency-Category-2 design basis ground motion that is comparable to that of the safe shutdown earthquakes for nuclear power reactors is very conservative, given that the reactor seismic design bases have resulted in acceptably safe seismic designs and that a repository would be inherently less hazardous and less vulnerable to seismic shaking (or fault displacement) than is an operating nuclear power reactor. As noted by the NRC in the Section-by-Section Analysis of Section 60.136, Preclosure Controlled Area, in the Supplementary Information published with the proposed rulemaking for 10 CFR 60 (60 FR 15180):

". . in comparison with a nuclear power plant, an operating repository is a relatively simple facility in which the primary activities are in relation to waste receipt, handling, storage, and emplacement. A repository does not require the variety and complexity of systems necessary to support an operating nuclear power plant. Further, the conditions are not present at a repository to generate a radioactive source term of a magnitude that, however unlikely, is potentially capable at a nuclear power plant (e.g., from a postulated loss of 
coolant event). As such, the estimated consequences resulting from limited source term generation at a repository would be correspondingly limited."

In summary, use of a mean annual probability of exceedance of $1.0 \mathrm{E}-04$ as a reference probability for the Frequency-Category-2 vibratory ground motion is quite conservative. This probability is comparable to the probabilities of exceeding the accepted seismic design bases of more recently designed operating nuclear power reactors in the CEUS. A compilation of the mean annual exceedance probabilities of the safe shutdown earthquakes of nuclear power reactors in the western United States indicates that the average mean exceedance probability for this set of reactors exceeds $1.0 \mathrm{E}-04$ by about a factor of two. The DOE considers that use of this value for the preclosure seismic design of the geologic repository operations area is very conservative, given that a repository is inherently less hazardous and less vulnerable to seismic shaking than is an operating nuclear power reactor. The seismic safety of the operating power reactors and, by extension, the adequacy of their seismic design bases, has been confirmed by in-depth, sitespecific analyses conducted under the IPEEE program.

As noted above, the DOE intends to use design acceptance criteria that are the same as or comparable to those used in reactor designs. In particular, the DOE has evaluated the NRC standard review plans for the seismic design of nuclear power reactors and has determined that many of the acceptance criteria are applicable to the design of repository surface facilities (see Section 3.2). These facilities are anticipated to include the majority of SSCs important to safety. Acceptance criteria for underground facilities are detailed in Sections 3.3 and 3.4 of this report.

\subsubsection{Use of Reference Probabilities for Other Types of Events}

The reference probabilities proposed here for Frequency-Category- 1 and -2 design basis ground motions do not necessarily constitute appropriate frequency or likelihood criteria for the identification of other potential design basis external events such as severe winds, fires, or floods, or for design basis internal events. Different criteria may be appropriate for these other events considering relative levels of uncertainty in characterizing the frequency and severity of events, the potential consequences of exceeding design basis events, the incremental cost of increasing the basis for design, the methodology to be used to identify the design basis events, and established standards, codes, guidelines, and professional practices. The quantitative criteria given here are intended only for use in a methodology wherein the results of a probabilistic seismic hazard analysis are disaggregated at the reference probability value to identify controlling earthquakes, which are then used as a basis for the determination of design basis ground motions.

\subsection{DESIGN OF SURFACE FACILITIES FOR VIBRATORY GROUND MOTION}

The DOE has reviewed NUREG-0800, Standard Review Plan for the Review of Safety Analysis Reports for Nuclear Power Plants (NRC 1987), for potential use in repository seismic design. NUREG-0800 identifies the regulations that are applicable to the seismic design of nuclear power reactors and identifies specific criteria, regulatory guides, and industry standards that provide information, recommendations, and guidance. NUREG-0800, in general, describes a basis acceptable to NRC staff that may be used to implement requirements of the regulations. Different regulations govern the seismic design of nuclear power reactors (10 CFR 100) and mined geologic disposal systems (10 CFR 60). However, the DOE considers that specific criteria and guidance provided by NUREG- 0800 are appropriate for use in surface-facility preclosure seismic design. These are identified next. 
With exceptions as noted below, the DOE considers that Standard Review Plans 3.7.1, Seismic Design Parameters; 3.7.2, Seismic System Analysis; 3.7.3, Seismic Subsystem Analysis; and 3.10, Seismic and Dynamic Qualification of Mechanical and Electrical Equipment provide appropriate acceptance criteria for the preclosure vibratory ground motion design of repository surface facilities that are important to safety. The exceptions are as follows:

- Where differentiated in NUREG-0800, requirements for documentation to be provided in the preliminary safety analysis report to support an application for a construction permit are appropriate for the mined geologic disposal system license application for construction authorization; whereas, requirements for documentation to be included in the final safety analysis report to support an application for an operating license, are not appropriate for the mined geologic disposal system license application for construction authorization.

- Requirements for the design of specific SSCs that are present in a nuclear power reactor, but which would not be present in repository surface facilities, do not apply.

- Requirements for analyses of reactor-specific accident scenarios, such as a loss-of-coolant accident, do not apply.

- In general, the requirements of $10 \mathrm{CFR} 100$, Appendix A, for development of design basis ground motions do not apply. In particular, requirements for the operating basis earthquake and safe shutdown earthquake ground motions, do not apply. The DOE will develop Frequency-Category-1 and -2 design basis ground motions in accordance with 10 CFR 60 and the proposed 10 CFR 60 rulemaking.

- Regulatory Guide 1.60 design response spectra will not be used. Site-specific, smoothed design response spectra will be developed.

- The design earthquake motion will not be defined at the foundation level of embedded structures. Rather, it will be defined at grade, for "free field" conditions, and modified as appropriate for application to the foundation levels of any embedded structures.

- References to Category-1 SSCs will be treated as references to SSCs important to safety, in accordance with the definition of this term in the proposed rulemaking for 10 CFR 60 .

\subsection{DESIGN OF UNDERGROUND OPENINGS FOR VIBRATORY GROUND MOTION}

Underground openings in the repository consist principally of shafts, ramps, and drifts. Shafts, ramps, and main drifts provide access to and egress from repository emplacement drifts. Emplacement drifts are intended for waste disposal. Design of underground openings for vibratory ground motion includes analysis of the unsupported, as-excavated opening and the interaction of the permanent ground support system with the rock mass. Intersections of openings are areas of attention in design because wider openings can result in higher rock loads on the ground support system. Ground support systems installed in the repository emplacement drifts may include concrete or steel lining systems. Support for other openings may include concrete and steel linings or shotcrete and rockbolts.

\subsubsection{Performance Objectives and General Design Criteria}

As discussed in Section 2.1 of this report, 10 CFR 60 provides performance objectives and general design criteria for the geologic repository operations area, including underground facilities. The 
performance objectives include a requirement to design the geologic repository operations area such that any or all of the emplaced waste can be retrieved on a reasonable schedule starting at any time up to 50 years after waste emplacement operations are initiated. General design criteria include a mandate to design underground openings so that operations can be carried out safely and the retrievability option maintained. The proposed rulemaking for 10 CFR 60 (see Section 2.1.1) would add a requirement to design underground openings to reduce the potential for deleterious rock movement or fracturing of overlying or surrounding rock.

In this section, a rational seismic design methodology is presented for underground structures and is intended to satisfy the 10 CFR 60 requirements and to be consistent with the proposed rulemaking. Note that the DOE currently is assuming a retrievability period of 100 years and a design lifetime of 150 years for the main drifts and emplacement drifts (CRWMS M\&O 1995a).

\subsubsection{Load Considerations}

\subsubsection{Ground Motion Parameters}

The design basis ground motion is defined at the free-field ground surface and is modified for application at repository depths. For underground openings at the repository horizon, ground motion due to body (P and S) waves is of primary concern; shear (S) waves, in particular, are the leading cause of structural damage. For analysis, the surface ground motion typically is parameterized in terms of peak particle velocity, peak particle acceleration, duration, and frequency (spectral) content. For application at depth, the peak velocity and acceleration are modified by appropriate site-specific factors, and a propagation orientation (angle of incidence) is specified. Alternatively, the surface motion may be characterized by a time history or by a response spectrum and modified for application at depth by deconvolution or use of a site response function, respectively.

\subsubsection{Repetitive Seismic Loading}

A key technical uncertainty identified by NRC staff is the prediction of thermomechanical (including seismic-load) effects on drifts for retrievability (NRC 1995b; Appendix E). This section addresses the specific question of whether repetitive seismic loads need be explicitly considered in the preclosure design or performance analysis of emplacement drifts.

The DOE considers that the ability to monitor, inspect, and maintain emplacement drifts during the preclosure period is the only design attribute necessary to accommodate the potential for repetitive seismic loading, in addition to the requirement to design emplacement drifts for the design basis earthquake. This conclusion is based on the following considerations: (1) the likelihood that the jointed rock mass around underground openings will experience damaging seismic loads more than once or twice during the preclosure period is negligible; (2) many episodes of damaging seismic loads likely would be required to cause drift failure; (3) the ground support system will be designed to withstand thermal and seismic loads, confine the rock mass, and mitigate the potential for cumulative joint shear, regardless of the number of seismic events; and (4) inspection and, if necessary, repair of underground openings following an episode of strong ground motion will mitigate the potential for drift failure through the accumulation of seismically induced joint shear.

A suggested threshold for potential damage to underground openings from seismic loading is a peak particle velocity of $200 \mathrm{~mm} / \mathrm{s}$ at the ground surface, based on an extensive review of published studies (NRC 1991c). Using the preliminary seismic hazard results (CRWMS M\&O 1994; Figure A-7) that were used as input to the Exploratory Studies Facility design it is estimated 
that the mean annual probability of exceeding $200 \mathrm{~mm} / \mathrm{s}$ at the surface of the site is $6.5 \mathrm{E}-04$. Under the usual assumption in probabilistic seismic hazard analyses that mainshock earthquake occurrences follow a Poisson distribution, the probability of a given ground motion level being exceeded $\mathrm{n}$ times in $\mathrm{T}$ years is given by

$$
P(n)=\exp (-\lambda \cdot T) \cdot(\lambda \cdot T)^{n} / n !
$$

where $\lambda$ is the annual rate of occurrence. Setting $T$ equal to an assumed drift design lifetime of 150 years and taking $\lambda$ as $6.5 \mathrm{E}-04$, the following is obtained:

$$
\begin{aligned}
& P(0)=0.9071 \\
& P(1)=0.0884 \\
& P(2)=0.0043 \\
& P(3)=0.0001 \\
& P(4)=3.4 E-06
\end{aligned}
$$

Current information thus indicates that the likelihood of more than one episode of damaging earthquake ground motions during the design lifetime of emplacement drifts is negligible.

The preliminary seismic hazard results are, indeed, preliminary and will be updated and revised. However, even if the estimated occurrence rate were to triple (i.e., if $\lambda$ were set at $2.0 \mathrm{E}-03$ ), the calculated probabilities would be:

$$
\begin{aligned}
& P(0)=0.7408 \\
& P(1)=0.2222 \\
& P(2)=0.0333 \\
& P(3)=0.0033 \\
& P(4)=0.0002
\end{aligned}
$$

and the likelihood of exceeding the damage threshold more than twice would still be very small.

The results of the Center for Nuclear Regulatory Analyses study of mining-induced seismicity and joint slippage at the Lucky Friday Mine in the Coeur d'Alene, Idaho, mining district (Hsuing et al. 1992) suggest that, even if several episodes of seismically induced joint slip were to occur, the impact on drift stability at Yucca Mountain would be negligible and, further, that $200 \mathrm{~mm} / \mathrm{s}$ probably represents a very conservative damage threshold for Yucca Mountain.

Two drift locations were monitored in the Lucky Friday Mine study at different distances from ongoing excavation (Hsuing et al. 1992). In the proximal drift, $30-40 \mathrm{~m}$ from ongoing mining, more than $220 \mathrm{~mm}$ of horizontal closure and $113 \mathrm{~mm}$ of vertical closure were observed over about 600 days. Subtracting the seismically induced closures shown in Figure 11 of Hsuing et al. (1992) reveals a background vertical closure rate of about $35 \mathrm{~mm} / \mathrm{yr}$. The background horizontal closure rate appears to be about $70 \mathrm{~mm} / \mathrm{yr}$. These background closure rates substantially exceed the threshold rate of $0.05 \mathrm{~mm} /$ day $(18.3 \mathrm{~mm} / \mathrm{yr})$ that Bieniawski (1984) describes as quite high and dangerous for wide chambers. Several mining-induced earthquakes with peak particle velocities greater than or equal to $134 \mathrm{~mm} / \mathrm{s}$ triggered substantial joint slip in the proximal drift, resulting in as much as $60 \mathrm{~mm}$ of horizontal closure, but the joints did not respond to all events that exceeded this threshold.

In the distal drift, about $70 \mathrm{~m}$ from ongoing mining, seismically induced joint slip of a much lower magnitude was observed, albeit at a slightly lower peak-particle-velocity threshold of $104 \mathrm{~mm} / \mathrm{s}$; 
the maximum corresponding (vertical) closure appears to be about $1 \mathrm{~mm}$ (Figure 5, Hsuing et al. 1992). From Figure 10 of Hsuing et al. (1992), the background vertical closure rate of the distal drift was about $16 \mathrm{~mm} / \mathrm{yr}$. Notably, the horizontal closure stabilized at about $50 \mathrm{~mm}$ after 200 days and did not respond to any of the seismic events.

The background closure rates observed in the Lucky Friday Mine are much higher than what is anticipated for Yucca Mountain. Initial observations at convergence monitoring stations along the Exploratory Studies Facility show that a majority (56\%) of the measured average convergence rates are less than $1 \mathrm{~mm} / \mathrm{yr}$ and approximately $75 \%$ are less than $2 \mathrm{~mm} / \mathrm{yr}$ (CRWMS M\&O 1996a). The convergence rates are decreasing with time since the passage of the tunnel boring machine, and the few rates that exceed $1-2 \mathrm{~mm} / \mathrm{yr}$ are expected to drop below $1 \mathrm{~mm} / \mathrm{yr}$ during the next year (CRWMS M\&O 1996a). The observed convergence rates in the Lucky Friday Mine, thus, appear to exceed the Exploratory Studies Facility rates by one to two orders of magnitude.

The Lucky Friday Mine study demonstrated convincingly that seismically induced joint slip can and does occur in deep $(1600 \mathrm{~m})$ drifts that are highly stressed and rapidly closing. The applicability of the results to the shallow $(350 \mathrm{~m})$ emplacement drifts at Yucca Mountain, where little or no mining-induced seismicity is expected to occur and closure rates will be much lower, is problematic. However, we speculate on the basis of the Lucky Friday Mine results that co-seismic joint slip can occasionally lead to as much as a year's worth of background drift closure. (This occurred once in the proximal drift and not at all in the distal drift of the Lucky Friday Mine study). Given this speculation, accelerating the closure of emplacement drifts during the preclosure period by even a centimeter would require ten episodes of seismically induced slip, assuming a background closure rate of $1 \mathrm{~mm} / \mathrm{yr}$. As the probabilities calculated earlier indicate, the likelihood of this occurring (i.e., of exceeding the assumed damage threshold of $200 \mathrm{~mm} / \mathrm{s}$ at the ground surface ten or more times during the preclosure period) is negligible.

In addition, the assumed damage threshold of $200 \mathrm{~mm} / \mathrm{s}$ is likely very conservative for Yucca Mountain. The seismically induced joint slip at the Lucky Friday Mine occurred in highly stressed drifts that were closing at rates one to two orders of magnitude greater than what is being seen in the Exploratory Studies Facility, and it seems likely that the joint damage and weakening from such rapid convergence would render the Lucky Friday Mine drifts more susceptible to seismically induced slip than emplacement drifts at Yucca Mountain. This interpretation is supported by the observation that horizontal closure stabilized in the distal drift of the Lucky Friday Mine study and did not respond to earthquake peak-particle velocities as high as $173 \mathrm{~mm} / \mathrm{s}$ (Hsuing et al. 1992).

The conservatism of a $200 \mathrm{~mm} / \mathrm{s}$ damage threshold at Yucca Mountain should be enhanced by the thermal loading of emplacement drifts. Thermal expansion will cause some joint shear, but it will also compress the jointed rock mass around excavation drifts and substantially increase the normal stress on joints that may define key blocks (i.e., rock blocks whose geometry creates a potential for the blocks to fall into the underground opening). The increased normal stress will act to lock key blocks in place and increase resistance to seismically induced slip. At locations where the rock quality is particularly poor, the high thermally-induced compressive stresses could exceed locally the compressive strength of the rock, but the consequence likely would be minor spalling, rather than the release of a major key block. The ground support system in emplacement drifts will be designed to contain such spalling.

In the eventuality that emplaced waste must be retrieved, blast cooling of the emplacement drifts will be required to enable personnel access. To the extent that the jointed rock mass is cooled, the cooling will relax the compressive stress and increase the susceptibility of joints to seismically induced slip. However, the blast-cooling period would be a small fraction of the 150-year design 
lifetime of the drifts, and the likelihood of repeated episodes of damaging ground motion during this period would be reduced accordingly. If earthquake damage did occur in a cooled drift, it could be accessed to accomplish any necessary repairs (CRWMS M\&O 1996b, Section 9.2.3.2) and mitigate the possibility of cumulative joint slip leading to failure.

In summary, current information indicates that the likelihood of experiencing drift-damaging seismic loads more than once or twice during the preclosure period is negligible, and that many episodes of seismically induced joint slip would likely be required to lead to drift failure. The ground support system will be designed to withstand thermal and seismic loads and to keep key blocks in place, preventing the unraveling of blocks in the jointed rock mass and mitigating the potential for cumulative joint shear, regardless of the number of seismic events. Underground openings will be monitored and can be inspected following an episode of strong ground motion and repaired, if necessary, to mitigate the potential for drifts to fail through the accumulation of seismically induced joint shear. On this basis, the DOE concludes that the ability to monitor, inspect, and maintain emplacement drifts during the preclosure period is the only design attribute necessary to accommodate the potential for repetitive seismic loading, in addition to designing emplacement drifts for the applicable design basis earthquake.

\subsubsection{Combined Loads}

Loads, other than seismic, to be considered in design of the underground openings include the in situ load from pre-existing stress conditions and thermal loads from the heat generated from the nuclear waste products. In situ stress is assumed static over the time period of concern. Thermal stresses are also considered to be static in design analyses because the rate of change of thermal stresses is slow. Seismic loads, however, are inherently transient. Therefore, the design analysis of underground openings considers combinations of loads as follows:

- In situ

- In situ plus seismic stresses

- In situ plus thermal stresses

- In situ plus thermal plus seismic stresses.

These stress combinations can be modeled in quasi-static analysis of non-linear behavior of the rock mass and joints using a step sequence of loading. Specifically, nonlinear material effects, including hysteresis and damage, can be investigated by considering the effect of a sequence of load steps, with each load step defining an initial condition for the subsequent step. For dynamic analysis, the time sequence of the applied loads can be more realistically simulated.

Stress redistribution caused by excavation and thermal expansion of the rock mass and ground support components following waste emplacement is routinely modeled by numerical codes with thermomechanical capability. Seismic loads are then applied to obtain the combined stress state and combined loads that are imposed on the ground support systems.

\subsubsection{Design Approach}

Design of underground openings in jointed rock generally involves a combination of empirical methods, that is, experience-based rules summarized in design charts, and analytical methods based on solid mechanics and rock mechanics principles. The empirical methods, developed from tunneling and mining experience, provide an initial evaluation and selection of ground support but have limited application beyond static and ambient-temperature load conditions. To more accurately account for thermal and dynamic effects, analytical methods are used. Neither 
empirical nor analytical methods are fully validated under the loads and time frame of interest for repository design. Therefore, the approach adopted for repository design is to apply both methods in the selection of ground support systems.

Examples of approaches for the preliminary design of drifts and shafts at Yucca Mountain are given in reports by the Civilian Radioactive Waste Management System Management and Operating Contractor (CRWMS M\&O 1995b; 1996b) and Sandia National Laboratories (SNL 1990; SNL 1991). Underground design methods for nuclear waste repositories are summarized by the American Society of Civil Engineers (ASCE 1993).

\subsubsection{Empirical Design Approach}

Empirical observations have established that, in general, underground openings are much safer than surface structures for a given level of shaking (Dowding and Rozen 1978), and that this safety increases down to a depth of $500 \mathrm{~m}$ (Wang 1985). Sharma and Judd (1991) observed that only 94 cases of underground damage have been reported, while literally thousands of surface structures have been damaged during earthquakes. Because of this experience, it appears useful for seismic design to consider empirical methods.

Empirical techniques have been developed for underground design for static loading conditions but do not incorporate seismic loading. However, some empirical methods that deal with stress changes in mining situations (Laubscher 1984) may have application to thermal load changes and also to seismic loads. In general, empirical methods are considered to provide a qualitative means to evaluate the potential for seismic damage and to determine the need for further analysis.

The charts developed by Dowding and Rozen (1978) and shown in Figure 3-1 are a means to judge the potential for damage to underground openings at rock sites due to vibratory ground motion. Although the peak particle velocity at the surface shows a better correlation with damage than does peak ground acceleration at the surface, both parameters can be used for initial scoping, but neither should be considered a tool for design.

A more specific empirical method is the $Q$ rock mass classification method (Barton et al. 1974), which provides a preliminary estimate of the ground support components and capacities for initial excavation conditions without thermal or seismic loads. This approach is based on the determination of a $Q$ index (a measure of rock mass quality), the opening span, and the excavation support ratio. The "equivalent dimension" is defined as the span divided by the excavation support ratio. By plotting the $Q$ index versus the equivalent dimension on the design chart shown in Figure 3-2, the required type of support can be determined. Thermal and seismic loads can be considered in the stress reduction factor, one of the parameters used to determine the $Q$ index. In this way, the design chart can be used to approximate changes in rock quality and the need for additional support due to seismic loads.

The design of repository underground openings should not be determined solely by empirical methods because the case studies that form the basis for the empirical methods do not include the expected seismic and thermal loads at the repository site. In the preliminary design stages, the results of the empirical design will provide classification of the expected in situ conditions, types of ground support systems that may be required during construction, identification of the potential failure mechanisms that should be addressed analytically, and identification of loadings in combination with specific in situ conditions that could pose constructability problems and could indicate regions where wastes should not be emplaced. 


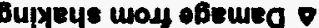

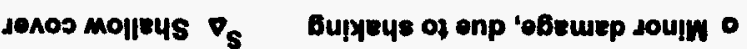
lunod deen od

eseurep on •

(8L6I) uәzoy pue simpmod jo

I X!puədde u! əses jo jəqunu jeu!p

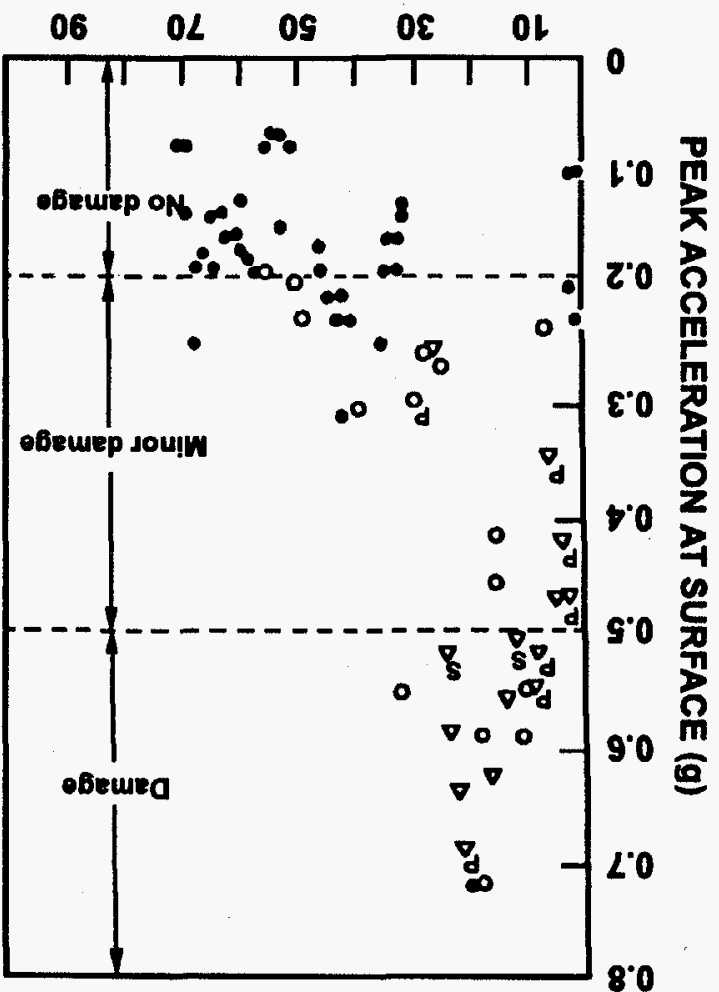

Bupyeys way obeura $\nabla$

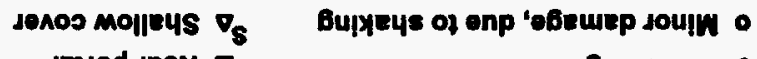
InJod IEen $\nabla_{d}$

obeurep on

(8L6I) uəzoy pue suाpмod Jo

I X!puədde u! əseo jo Iequmu ןeu!pio

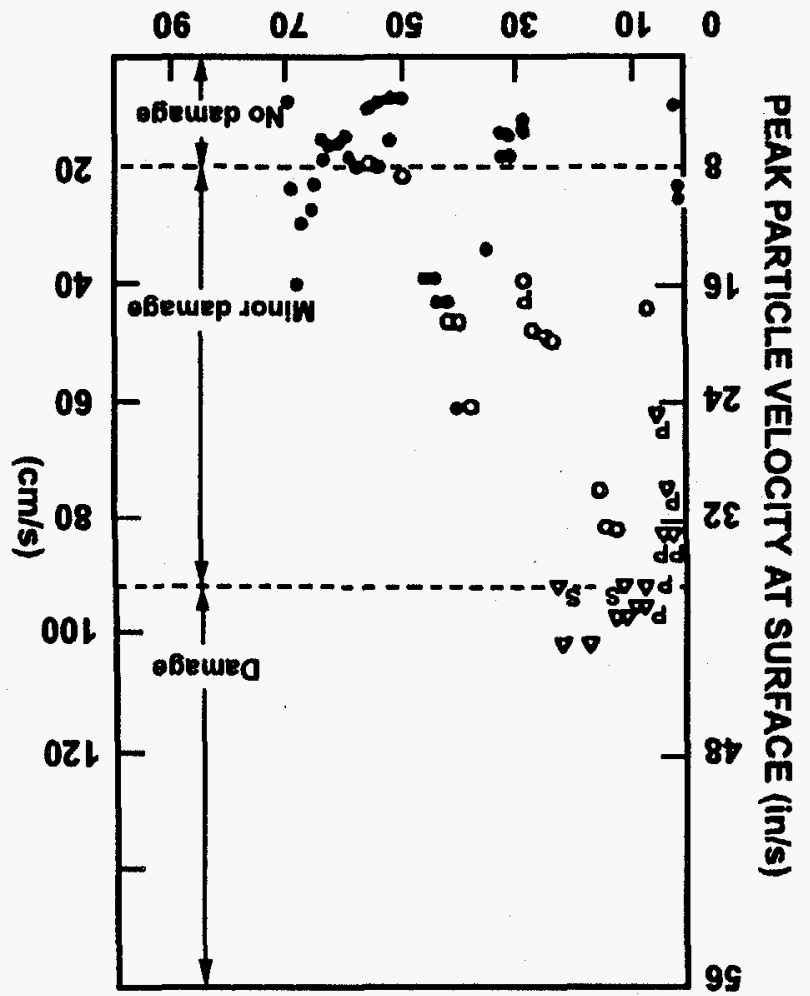




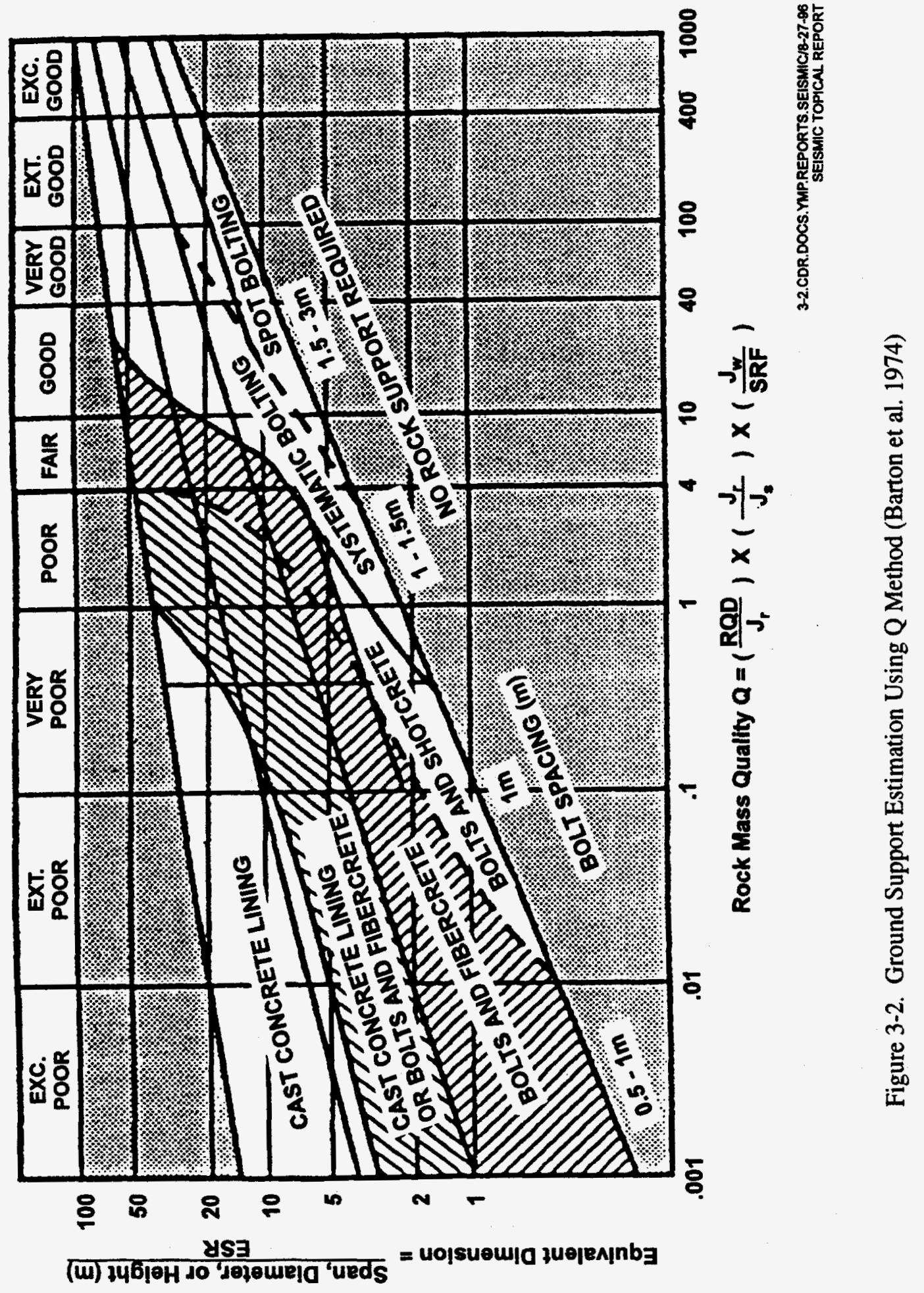




\subsubsection{Analytical Design Approach}

The interaction of a seismic wave with an underground opening depends on the ratio of the wavelength to the maximum span of the opening. For large ratios and relatively long ground motion duration, the transient ground motion caused by seismic waves produces basically quasistatic loading. For small ratios and relatively short ground motion duration, the loading is dynamic. Both loading conditions are applicable to the repository horizon and are taken into account for design analysis. In light of the complexities involved, analytical methods that include extensive numerical modeling are used for examining both quasi-static and fully dynamic loading conditions.

To model the effects of vibratory ground motion, the DOE is using four numerical programs developed by ITASCA $(1993 ; 1994 a ; 1994 b ; 1995)$ to perform numerical computations for quasistatic and fully dynamic loading. Briefly, these programs are:

- FLAC, a two-dimensional finite difference program, which simulates the fully dynamic response of continua (i.e., unjointed rock mass) to seismic loadings by an explicit finite difference solution scheme of the full equations of motion. A few isolated discontinuous geological features such as faults and weakness planes can be incorporated into the model as interfaces.

- UDEC, a two-dimensional distinct element program, which simulates the fully dynamic response of discontinua (i.e., jointed rock mass) to seismic loadings. The shear displacement and slippage of a joint are controlled by normal and shear stiffness, cohesion, friction angle, and tensile strength.

- $\quad$ FLAC $^{3 \mathrm{D}}$, a three-dimensional companion to FLAC.

- 3DEC, a three-dimensional companion to UDEC.

These codes have been verified and validated for specific applications in Yucca Mountain geologic repository operations area design analyses (see Section 1.5).

The DOE intends to perform dynamic analyses for (1) underground openings and ground support systems that must be designed for Frequency-Category-2 design basis ground motion, (2) cases where the magnitude of the peak ground acceleration for the design basis ground motion at the surface is greater than $0.5 \mathrm{~g}$, or (3) cases where the wavelength of the seismic waves with significant energy content is less than eight times the excavation diameter. The latter two criteria have been established from the empirical evidence of Dowding and Rozen (1978) and account for the dynamic interaction that is possible for short-wavelength disturbances. Some engineering judgment is required in applying the last criterion because dynamic analysis is not necessary if the energy of the high-frequency waves is low.

Intuitively, a jointed rock mass will be more susceptible to the damaging effects of seismic load than an intact rock mass. Because the repository host rock, the Topopah Spring welded 2 unit (TSw2), contains many vertical and subvertical joints, it is important to determine the influence of these joints on the seismic response of the rock mass. The effects of joints can be incorporated in continuum models, or joints can be modeled directly using a discrete block model such as that which is incorporated into the UDEC code. 
Depending on the model used (i.e., continuum or discontinuum), the strength of the rock mass or the joints is represented by a Mohr-Coulomb yield criterion. Strength and modulus, although dynamic properties, typically are determined from static tests because dynamic tests are more difficult to run, especially on jointed rock. However, the use of static strength and modulus values in dynamic analyses is conservative because the static values typically are higher than the dynamic values. For example, calculated deformations are greater when smaller (less stiff) moduli are used.

Initial analyses, based on incomplete joint data for the TSw2, have used bounding properties to examine the range of behavior. The following parameters have been input to the numerical models:

- Two dominant joint sets, with one set dipping 80 to 90 degrees and the other dipping 0 to 15 degrees

- Joint spacing ranging from 0.1 to 2 meters with both continuous and discontinuous planar joints patterns being considered

- Joint shear stiffness ranging from $10^{8}$ to $10^{12} \mathrm{~Pa} / \mathrm{m}$ and joint normal stiffness ranging from $10^{9}$ to $10^{12} \mathrm{~Pa} / \mathrm{m}$

- Joint cohesion ranging from 0.1 to $5 \mathrm{MPa}$, friction angle ranging from 15 to 50 degrees, and dilation angle ranging from 0 to 15 degrees

- Joint with Mohr-Coulomb yield or continuously yielding mode.

Lower bound values for the joint strengths given here would apply to a weaker than expected rock mass, while upper bound values approach those of an unjointed rock mass model (i.e., a continuum).

These joint strength values apply to both forward and reverse shear modes. A number of laboratory tests on jointed rock samples have revealed that joints behave differently during forward and reverse shearing motion (Jing et al. 1992; Huang et al. 1993; Qiu et al. 1993; Hsiung et al. 1993; Hsiung et al. 1994; Souley et al. 1995). Experimental evidence points out that decreases in joint shear strength and dilation effects during reverse shearing may adversely affect rock mass strength. Because such joint behavior could apply to the repository horizon rock mass, which will undergo cycles of thermal and seismic loading, jointed rock analysis will be used to evaluate the effects of lower bound joint strength and stiffness. For example, distinct element modeling, such as that done with the UDEC code, will be used to estimate the maximum extent of drift displacements due to joint degradation in the rock around emplacement drifts and other openings in the repository. Results will be used to determine internal stresses in ground support components and to provide information for design.

More details on quasi-static and dynamic approaches are provided next.

\section{Quasi-Static Approach}

The most important step in the quasi-static approach is to implement the equivalent loads that correspond to the design basis ground motion. For numerical models, the quasi-static loads are either represented as body forces and displacements acting at nodal points or as boundary pressures and displacements acting at model boundaries. 
After correctly specifying the loads, key elements for conducting a quasi-static seismic analysis are appropriate constitutive models and suitable material properties. Both the continuum and discontinuum models have application in the repository design at Yucca Mountain. The application and utility of either type model depends on the nature of the rock mass and the scale of the problem of interest. Figure 3-3 illustrates the influence of scale on the selection of an appropriate jointed rock model. Regional studies to evaluate thermally induced deformations at shaft or ramp access locations, for instance, require a regional rock model and, generally, a continuum model can be used. For local drift design, the decision to model joints discretely depends on the joint spacings relative to the dimensions of the underground opening and, to some extent, on knowledge of the joint pattern, continuity, and mechanical characteristics. Like most geotechnical material, the variation of material properties of the jointed rock mass is large. The analysis should therefore include a range of material properties, and the material properties used should consider the scale effect appropriate for the physical size of the material being analyzed.

In general, the quasi-static design analysis procedure involves:

- Calculating the strain components based on the peak particle velocities from the design basis ground motion and the propagation speeds for compressional and shear waves, and then converting those strains to stress components according to Hooke's Law.

- Superimposing the earthquake-induced quasi-static stress components onto the existing in situ and thermal loads in such a way that the least favorable directions of the incident $P$ wave and $S$ wave are accounted for, especially with respect to the orientation of joints and the alignment of underground openings.

- Evaluating the impact of the combined seismic, in situ, and thermal loads on the underground structures using appropriate constitutive models (with no ground support) to assess the extent of regions of rock yield, joint slip, and rock block movements.

- Selecting preliminary ground support components, numerically representing those components as realistically as possible in the models, and performing numerical simulation to demonstrate the appropriateness of the ground support systems in terms of limiting and stabilizing yielding rock and joints.

- Assessing the adequacy of ground support components by evaluating the safety factor (strength divided by load) for ground support components.

\section{Dynamic Approach}

The dynamic analysis method is similar to the quasi-static method in that the methodology involves analysis of unsupported openings to assess damage to the host rock, then selection of ground support components and re-analysis to assess loads on the ground support components. The analysis loads and material properties differ between the quasi-static and dynamic methods, as discussed next.

Dynamic analysis differs from quasi-static analysis in that mass-acceleration terms are included in the equilibrium equation and, in some numerical algorithms, rate-dependent properties are considered. Dynamic seismic loads are exerted at the equilibrated state after the static in situ and thermal loads have been applied. The procedure for dynamic analysis for repository underground structures involves the following: 


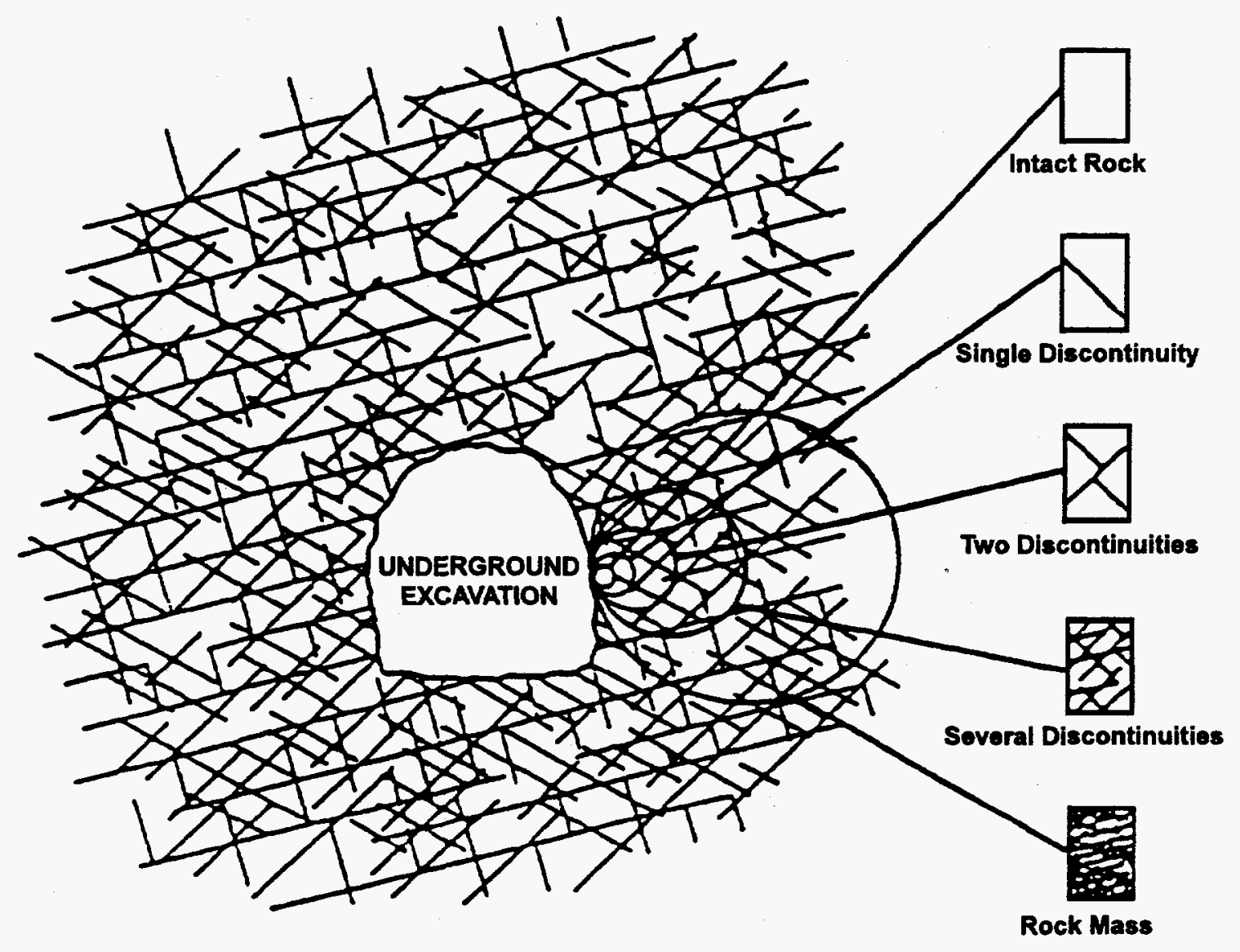

3-3.CDR. MP.REPORTS.SEISMC/B-27-96 SEISMIC TOPICAL REPORT

Figure 3-3. Idealized Diagram Showing the Transition from Intact Rock to a Heavily Jointed Rock Mass with Increasing Sample Size (Hoek and Brown 1980) 
- Analysis of the in situ equilibrium state for the excavation.

- Thermomechanical analysis that considers the effects of heat from the emplaced waste. (Omit this step for the load combination without thermal load.)

- Dynamic simulation of seismic waves traveling through the rock mass surrounding the underground opening.

Seismic loads are numerically approximated and are applied to the models being analyzed. Seismic waves are characterized by their amplitude values (acceleration, velocity, or pressure), wavetype ( $\mathrm{P}$ or $\mathrm{S})$, duration, frequency, and propagation direction with respect to the emplacement drifts, in conjunction with depth attenuation and the damping effect from the rock mass. Shown below are assumed lower and upper values that have been used in preliminary analyses:

- Peak ground acceleration at the surface: 0.2 to $0.6 \mathrm{~g}$

- Peak particle velocity at the surface: 20 to $40 \mathrm{~cm} / \mathrm{s}$

- Frequency: 1 to $10 \mathrm{~Hz}$

- Duration: 1 to 3 seconds

- Depth attenuation multiplier: 0.7 to 1.0

- Wavetype: vertically incident $P$ and $S$ waves.

The dynamic loading is input to a numerical model of an underground opening as a ground acceleration history, velocity history, pressure wave history, or dynamic force history. The history data are expressed either in tables or as analytical functions that have the appropriate duration time. The functional expressions are constructed from combinations of sinusoidal and exponential functions. If time histories are not provided as design inputs, they can be generated to be consistent with specified peak particle motions, duration, and frequency content.

A factor for consideration in seismic modeling is the incidence angle of the largest-amplitude seismic waves at the repository horizon. Seismic waves typically originate at depth in rock of higher density, stiffness, and strength than that of near-surface strata. As seismic waves propagate toward the ground surface through rocks of decreasing density and stiffness, the incidence angle steepens, according to Snell's Law regarding wave transmission at boundaries. A vertically propagating wave (incidence angle of zero) is therefore considered most representative and is used in most numerical dynamic modeling.

For analysis of deep underground structures, non-reflecting boundaries are used to simulate the surrounding infinite medium. Benchmarking the non-reflecting boundaries using a simple harmonic wave propagating in an infinite medium is conducted before performing a full-scale dynamic analysis. For analysis of shallow underground structures, a stress-free reflecting surface models the earth's surface. Wave reflection from the surface can have an important impact on the loading of the underground structures.

Mesh construction needs to account for boundary effects in modeling excavation, thermal loading, and seismic loading. In general, a mesh boundary three to five diameters away from the opening is sufficient to model the static loading due to excavation. It is advantageous to use symmetrical conditions as much as possible in considering the mesh boundary location for the thermal loading condition. For the boundary to be as realistic as possible, seismic loading requires the largest mesh, even though viscous boundary conditions are used. Viscous boundary conditions are used at the base and top of the FLAC model to prevent the outwardly propagating waves from reflecting 
back into the model at those boundaries. The two vertical lateral boundaries are set either to have free field or viscous conditions.

Seismic loads are imposed on the model after equilibrium has been reached under both the in situ stress field and subsequent thermal loadings generated by emplaced waste packages. Therefore, the initial velocity for each grid point before the application of dynamic loads is zero. The velocity history of the $\mathrm{P}$ wave or $\mathrm{S}$ wave is applied at the bottom boundary and propagates upwards through the drift-bearing rock. The $S$ wave causes horizontal ground shaking, and the $\mathrm{P}$ wave causes oscillating vertical compression and tension.

Figure 3-4 illustrates a FLAC model that was constructed for the Mined Geologic Disposal System Advanced Conceptual Design Report (CRWMS M\&O 1996b, Figure B-2). This model simulates the rock strata at the repository horizon as a continuum with a Mohr-Coulomb yield criterion. Uniformly spaced emplacement drifts are located in the middle. The center drift is supported with a 150-mm-thick concrete liner. The model is brought to equilibrium following drift excavation, subjected to 50 years of thermal loading, and then loaded by seismic waves propagating upwards from the model bottom. Figure 3-5 (CRWMS M\&O 1996b, Figure B-21[b]) shows the input wave and emerging wave after propagation through the 189-m-thick TSw2 rock unit. Dynamic drift closures are shown in Figure 3-6 (CRWMS M\&O 1996b, Figure B-25 [b]).

Table 3-1 (from CRWMS M\&O 1996b, Tables B-10 and B-13) shows maximum changes in displacement and load caused by the seismic waves. These changes are considerably smaller than the predicted thermal displacements and stresses and would not significantly affect the design. This result is consistent with the expectation that seismically induced rock and support deformations and stresses will be small because seismic wavelengths typically are longer than drift dimensions and, hence, induce little differential motion in the opening. The results are also consistent with the empirical evidence of low damage levels in underground openings relative to surface structures.

To further illustrate the dynamic approach when the rock is modeled as a discontinuum containing a pattern of joints, a UDEC model is shown in Figure 3-7. Two sets of joints, one dipping nearly vertically and the other dipping nearly horizontally, are simulated in the rock mass surrounding the emplacement drifts. Figure 3-8 shows the rock and joint movements after seismic waves propagate through the model, following drift excavation and 50 years of thermal loading at a loading density of 83 metric tons of uranium/acre. Joint stiffness and strength values correspond to the lower bounds described earlier, and the results are, therefore, conservative.

\subsubsection{Acceptance Criteria}

Stability and material performance goals for underground repository openings are a mix of qualitative and quantitative goals that together form the basis for underground structure design criteria. An adequate ground support system is one that meets safety and functional requirements, is constructable, and is both practical and economical to install. However, for the design of underground support system components there is neither a universally accepted standard for assessing the loads on the components nor for selecting the safety factor for design. Thus, specific safety factors or load factors are not proposed in this report.

To achieve ground support stability and performance goals, the unique aspects of underground structures will be considered in choosing appropriate load factors and safety factors. For example, the selection of safety factors depends on the anticipated variation of the ground and construction 


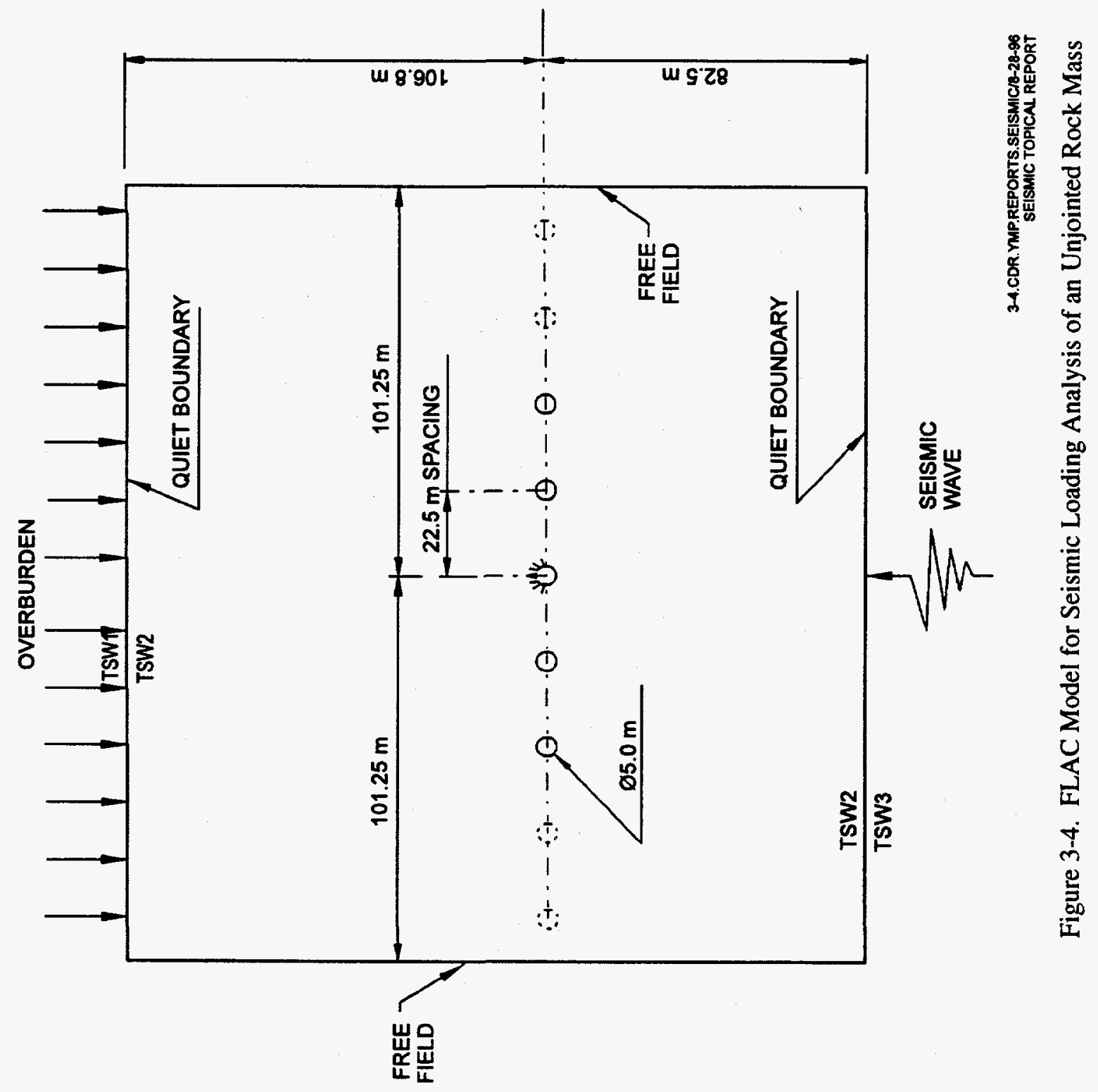




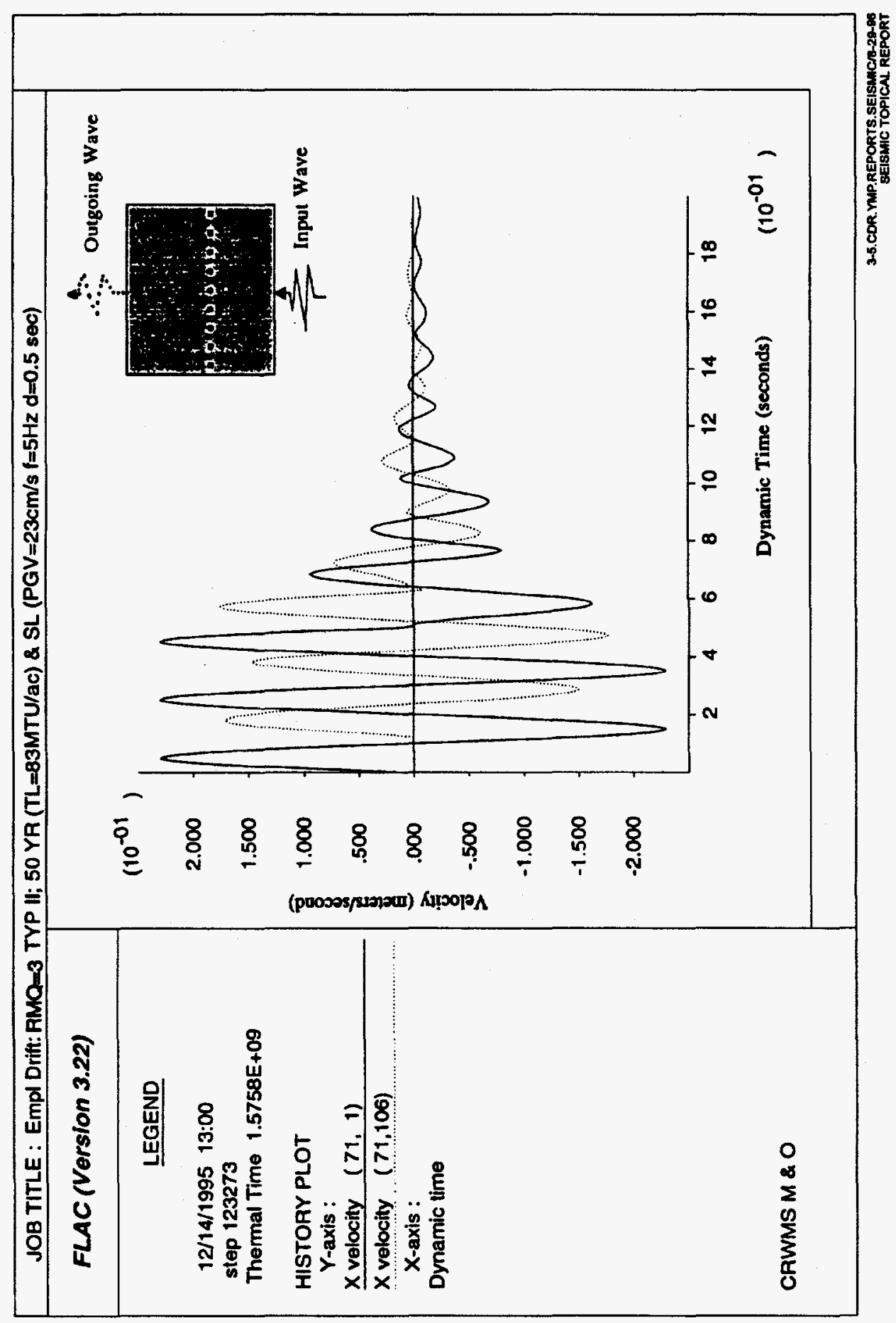


JOB TITLE : Empl Drift: RMQ=3 TYP II; 50 YR (TL=83MTU/ac) \& SL (PGV=23cm/s f=5Hz d=0.5 sec)

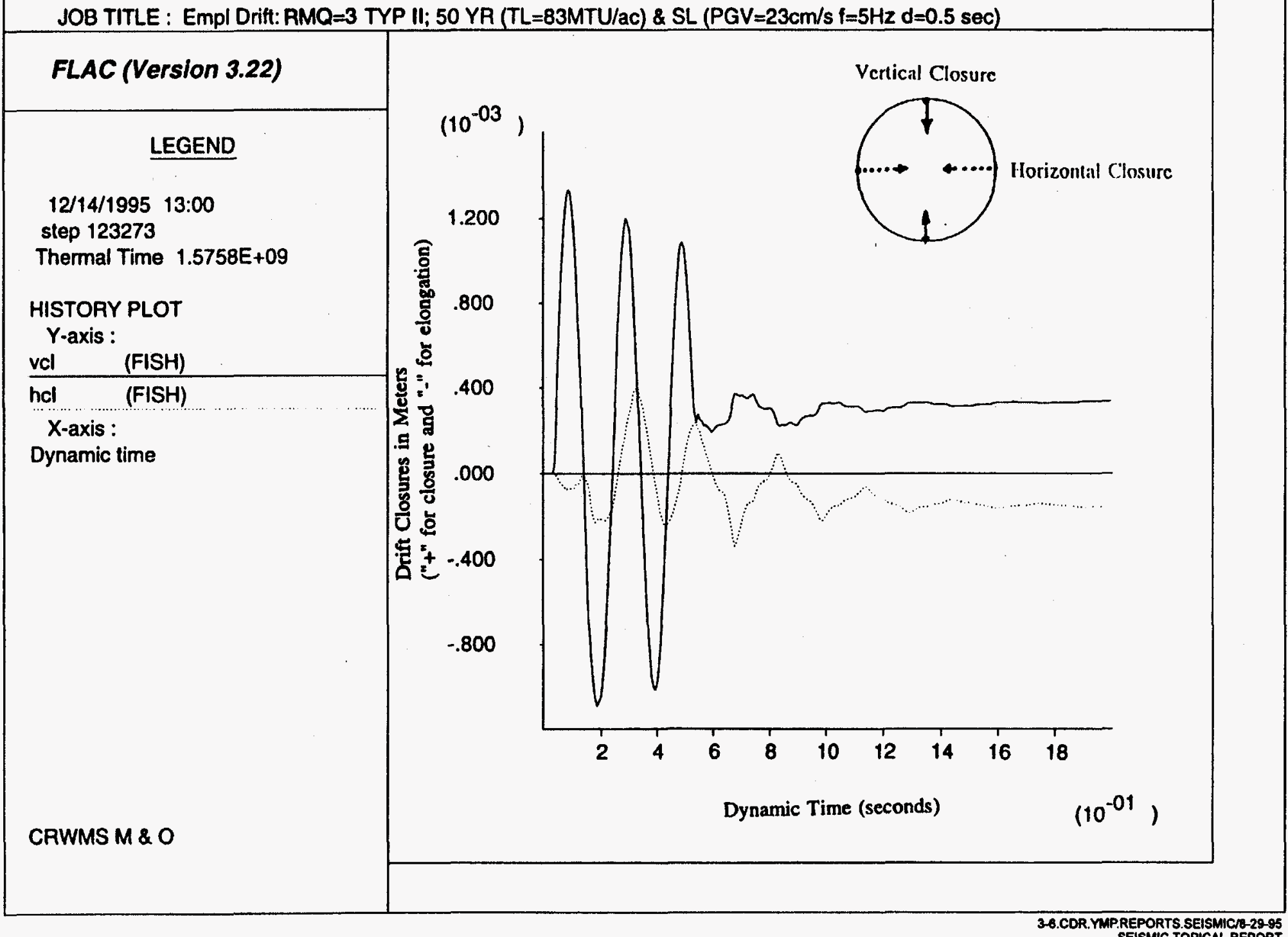

Figure 3-6. Horizontal and Vertical Closures for the Center Drift under Seismic Loading 
Table 3-1. Summary of Numerical Results for Seismic Load for Concrete Liner

\begin{tabular}{|l|c|c|c|}
\hline & \multicolumn{2}{|c|}{ Numerical Results with RMQ=3 and E=12.67 GPa for TSw2 } \\
\hline $\begin{array}{l}\text { Selected Output Items } \\
\begin{array}{l}\text { Horizontal Closure at the } \\
\text { Springline Level }\end{array}\end{array}$ & $\begin{array}{l}\text { After 50 Years of } \\
\text { Heating (A) }\end{array}$ & $\begin{array}{l}\text { During Seismic } \\
\text { Loading (B) }\end{array}$ & $\begin{array}{c}\text { Change } \\
\text { [B-A]/A) }\end{array}$ \\
\hline $\begin{array}{l}\text { Vertical Closure between } \\
\text { Crown and Invert }\end{array}$ & $10.5 \mathrm{~mm}$ & $10.5 \pm 0.4 \mathrm{~mm}$ & $\pm 4 \%$ \\
\hline $\begin{array}{l}\text { Circumferential Stress at } \\
\text { Crown }\end{array}$ & $-3.6 \mathrm{~mm}$ & $-3.6 \pm 1.3 \mathrm{~mm}$ & $\pm 35 \%$ \\
\hline $\begin{array}{l}\text { Radial Stress above Crown } \\
\text { Maximum Tensile Load in } \\
\text { Concrete Liner }\end{array}$ & $-30.1 \mathrm{MPa}$ & $-30.9 \mathrm{MPa}$ & $3 \%$ \\
\hline $\begin{array}{l}\text { Maximum Compressive } \\
\text { Load in Concrete Liner }\end{array}$ & $24.8 \mathrm{MPa}$ & $-3.5 \mathrm{MPa}$ & $7 \%$ \\
\hline
\end{tabular}

Note: (1) Peak temperature at drift wall $=160^{\circ} \mathrm{C}$.

(2) Compressive stress is negative.

(3) Positive closure is convergence; negative closure is elongation.

loads and possible variations in lining capacity. If the highest loads are used for analysis, a safety factor is inherent in the design. On the other hand, if typically expected loads are used, safety factors are needed to cover possible variations and uncertainties. Less reliance is given to the use of structural design codes for establishing safety factors than would be the case for surface facilities, in part because the codes have been developed for the design of surface structures, but also because of the influence of the construction method and the considerable self-supporting and confining effects of the rock mass.

For ground support components such as concrete linings and steel sets that are subjected to both axial thrust and bending moment, combined stresses will be considered. The DOE intends to base acceptance criteria for concrete on comparisons between moment and thrust combinations and a moment-thrust failure envelope or interaction diagram as described by the Underground Technology Research Council (O'Rourke 1984). For steel, the DOE intends to develop analogous acceptance criteria based on requirements such as those given by the American Institute of Steel Construction (AISC 1989). 







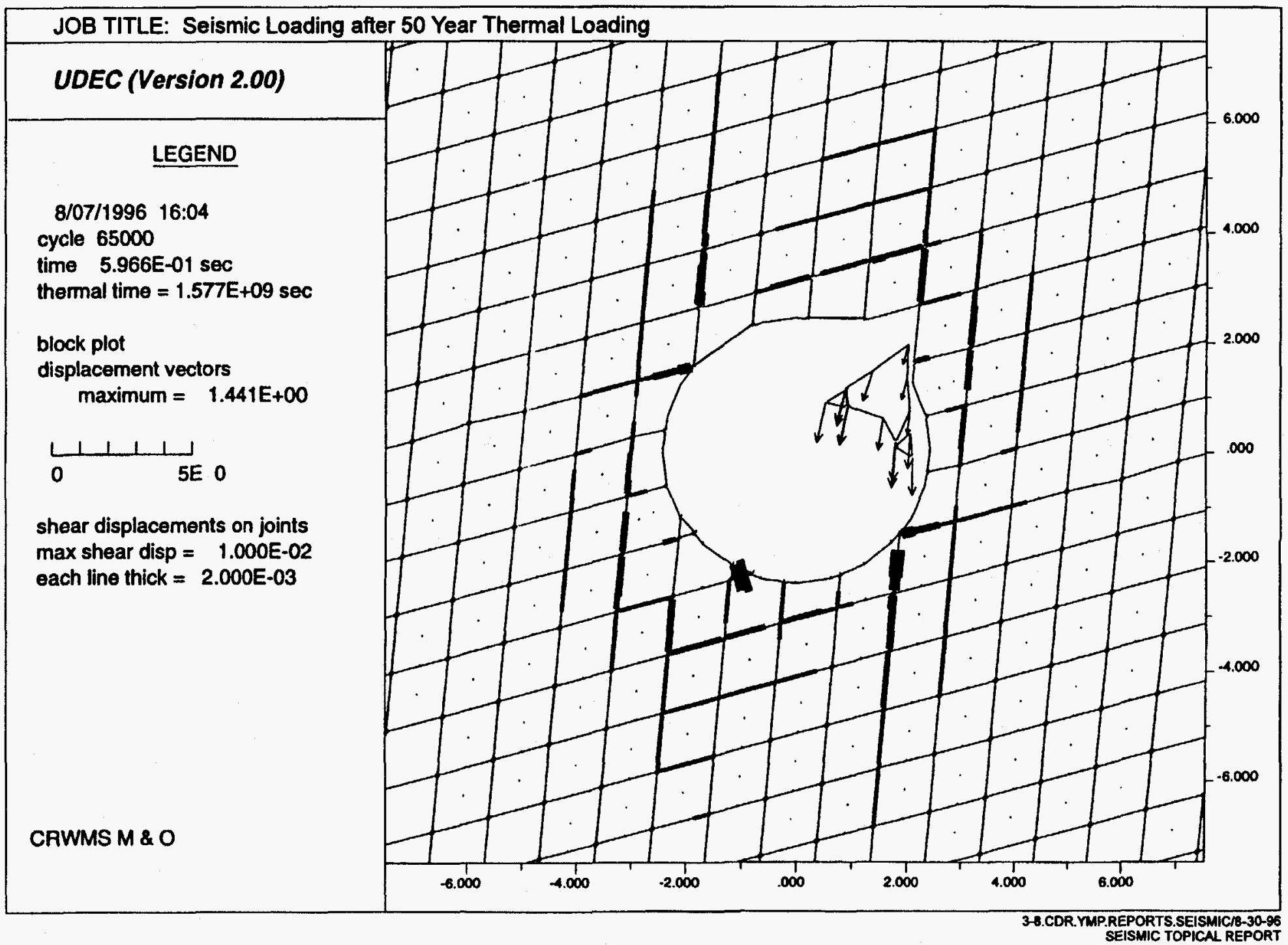

O
$\frac{8}{0}$
$\frac{0}{1}$
$\frac{0}{0}$

Figure 3-8. Rock and Joint Displacements by Seismic Loading after 50-Year Thermal Loading 


\subsection{DESIGN OF OTHER UNDERGROUND SSCs FOR VIBRATORY GROUND MOTION}

In addition to underground openings and ground support systems, subsurface repository areas will have other SSCs that will need to be designed to withstand seismic ground motion. Such SSCs are those associated with ventilation systems; waste package transportation systems; electrical cable tray and conduit systems; instrumentation, monitoring, and alarm systems; shielding doors; and waste packages. With the exception of the waste package and transportation systems, these SSCs will either be anchored directly to the rock or supported from frame-type structures anchored to the rock. Waste package seismic design is discussed separately in Section 5.

\subsubsection{Performance Requirements and Design Criteria}

Systems associated with underground items are generally similar to the systems in repository surface facilities, and some are extensions of the surface systems. Examples include the cask handling and transportation system, ventilation system, cable tray system, and radiation monitoring system. Those systems that are important to safety will be identified in the same manner as surface systems (see Section 3.1) and will be designed for Frequency-Category-1 and -2 design basis ground motions, as appropriate.

The seismic adequacy of these SSCs, like the equipment and components in the surface facilities, will be ensured either by analytical evaluation or by shake table testing. The design criteria and analysis considerations are similar to those described in Section 3.2 for the surface system (i.e., they will be based mostly on existing NRC staff guidance documents for the seismic design of nuclear power reactors).

\subsubsection{Load Considerations}

Design loads and responses will be determined for SSCs anchored directly to the rock and SSCs supported from structures anchored to the rock. For SSCs anchored directly to rock, the design basis ground motions will be defined at the ground surface and modified for application at depth using appropriate techniques that account for site-specific conditions. For SSCs supported by structures anchored to rock, design loads will be modified to account for the dynamic response of the supporting structures using appropriate criteria in Standard Review Plans 3.7.2, Seismic System Analysis and 3.7.3, Seismic Subsystem Analysis (see Section 3.2).

Non-seismic demands may be different for surface and subsurface subsystems (e.g., subsurface systems will be subjected to thermal effects of emplaced waste). Thermal effects, excavationinduced loads, effects of material creep (if any), and effects of humidity changes will be considered in the design of underground SSCs. As for underground openings and ground support systems, thermally induced stresses will be treated as static in the analytical evaluation. 


\subsection{DESIGN OF REPOSITORY SSCS FOR FAULT DISPLACEMENT}

\subsection{INTRODUCTION}

This section describes the methods, procedures, and criteria that the DOE intends to use to provide reasonable assurance that SSCs important to safety will meet the pertinent $10 \mathrm{CFR} 60$ preclosure safety performance objectives with respect to fault displacements. Three approaches are available: fault avoidance, geotechnical engineering isolation techniques, and structural engineering design to increase structural ductility or to provide for structural modularization. The choice of approaches to be implemented for a particular SSC depends on the intended function of the SSC, its characteristics, and the geotechnical characteristics of the materials on which it is positioned.

In establishing the seismic safety design criteria for the Yucca Mountain geologic repository operations area described in this section, the DOE intends to follow and implement the guidance provided in NUREG-1494, Staff Technical Position on Consideration of Fault Displacement Hazards in Geologic Repository Design (NRC 1994a). The Staff Technical Position recommends that Type I faults within the geologic repository operations area be avoided when reasonably achievable, but recognizes that fault avoidance may not be possible for all SSCs, especially those that are spatially extended. Thus, the primary seismic safety design criterion for fault displacement will be fault avoidance to the extent reasonably achievable by facility layout and placement of SSCs important to safety. When the fault avoidance criterion cannot reasonably be achieved, geotechnical engineering and/or structural engineering design criteria or repair and rehabilitation actions will be provided to reasonably ensure that preclosure seismic safety performance goals are met.

\subsection{BACKGROUND}

\subsubsection{Experience in Design of Surface SSCs to Accommodate Fault Displacement}

The specific issue of whether a nuclear facility can safely accommodate fault offset has been extensively evaluated by NRC staff and the Atomic Safety and Licensing Board in the review of the General Electric Company Test Reactor (GETR) (Reed et al. 1979; EDA 1980a; EDA 1980b; ASLB 1982). The GETR at Vallecitos, California, is located on the surface trace of a thrust fault called the Verona Fault. Investigations conducted by the General Electric Company and reviewed by NRC staff concluded that the Verona Fault could have one meter of surface displacement coseismically with vibratory ground motion from a magnitude 6.5 earthquake. Therefore, the GETR facility was analyzed for vibratory ground motion defined by an NRC Regulatory Guide 1.60 response spectrum anchored at $0.6 \mathrm{~g}$ and combined with a $1.0-\mathrm{m}$ fault displacement beneath the reactor building on a plane dipping at an angle of 15 degrees to the horizontal. The stress loads induced by the combined vibratory ground motion and fault displacement were found to be below the conservative cracking threshold capacity of the concrete reactor building. The analysis further showed that, for the geotechnical properties of the GETR facility foundation, the fault displacement would be deflected around the heavy, embedded containment structure. Based on these analyses, NRC staff concluded that the GETR SSCs important to safety would perform their intended functions under the combined fault displacement and vibratory ground motion loading. These conclusions and evaluations were reviewed in a public hearing before the Atomic Safety and Licensing Board and found to be in compliance with NRC seismic safety regulations (ASLB 1982).

Other analytic studies of the effects of fault displacement on structures have been reported by Duncan and Lefebvre (1973), Berrill (1983), and SNL (1989). These studies concluded that 
structures can be designed to withstand earth pressure loads that result from fault displacements by providing assurance of the proper level of ductile performance. For heavy embedded structures, the studies performed by Duncan and Lefebvre (1973) and Berrill (1983) indicate that fault displacement will deflect around the structure. SNL (1989) performed a simplified analysis of the main waste handling building proposed for the Yucca Mountain facility for combined vibratory ground motion and fault displacement loads. They concluded that for a $0.4 \mathrm{~g}$ vibratory ground motion design (and no specific fault displacement design), the conditional probability of the waste handling building exceeding a moderate damage state is $2 \times 10^{-3}$ and $5 \times 10^{-2}$ for fault vertical displacement of $1 \mathrm{~cm}$ and $10 \mathrm{~cm}$, respectively. These results show that well-designed SSCs conservatively can withstand small fault displacements without loss of function.

Experience of a building response to vibratory ground motion and a co-seismic fault displacement has been studied by Niccum (1976), Selna and Cho (1973), and Wyllie (1973), who reported investigations of fault displacement through the Banco Central de Nicaragua building during the December 23, 1972, Managua, Nicaragua, earthquake. These investigations revealed that a fault displacement of 10 to $17 \mathrm{~cm}$, measured at the ground surface, deflected around the bank's heavy substructure vault. This observation is consistent with the analytical results reported by Duncan and Lefebvre (1973), Berrill (1983), and the GETR analysis (ASLB 1982).

Simplified analyses performed by Kennedy et al. (1977) show that well-designed shallow buried piping placed in loose to moderately dense cohesionless soil can withstand fault displacements as large as $6 \mathrm{~m}$.

\subsubsection{Experience in Design of Tunnels to Accommodate Fault Displacement}

Examples of tunnel design and performance through faults are detailed in Appendix D. Rather than provide a tunnel support structure that has the strength and stiffness to resist fault movement, the approach in a number of cases has been to provide a flexible structure that allows deformation without undue disruption of the drift function. An enlarged tunnel cross section may also be indicated as part of the design solution. In addition to flexibility, the support structure must maintain stability, as rock quality in the vicinity of a fault often is low enough to require stabilization. Either rockbolts and mesh or lining systems are typically used.

\section{Rockbolts and Mesh}

Rockbolts, wire mesh, and straps form an inherently flexible ground support system that is relatively easy to maintain and repair. An example of the flexibility in a bolt and mesh system subjected to large ground displacement is the rock reinforcement used in a deep gold mine in Zambia (Russell 1983). In that case, mined openings in rock, highly fractured as a result of rockbursts, have been maintained with a system of fully grouted steel dowels (rockbolts), wire mesh, and steel cable lacing stretched across the tunnel walls in a diamond pattern between the dowels. During large ground displacements, this structural system provides sufficient supporting pressure to confine the rock mass, thereby maintaining its self-supporting capacity.

\section{Lining Systems}

Lining systems, especially in civil tunnels, usually are designed to fulfill another function, such as water conveyance or transportation, in addition to the function of providing long-term ground support. These linings are often reinforced cast-in-place concrete, which is considered too stiff and unyielding to accommodate movement at the specific location of a fault. In this regard, for design of the Bay Area Rapid Transit tunnel through the Berkeley Hills, where displacement on 
the Hayward fault was a consideration, a flexible lining design was implemented by keeping the tunnel lining as thin as practicable (Brown et al. 1981).

A more elaborate flexible lining design has been proposed by Desai et al. (1989). Their design uses a conduit or pipe, placed within the drift and surrounded with a low modulus backpacking. The design uses segmented precast pipe with joints configured to accommodate extensional and compressional strains. The pipe maintains the function of the opening and is protected from significant damage because discrete fault displacements are not transmitted by the surrounding backpacking. Instead, lateral and longitudinal forces resulting from the faulting are distributed along the enclosed pipe and absorbed by deformation of the segmented pipe.

As in the case of the segmented pipe-in-tunnel design, a drift lining can be designed with flexible joints to accommodate fault displacement and avoid undue damage to the lining. Frame (1995) has described a lining design for the tunnel outlet at the Coyote Dam, which is constructed across the Calaveras fault zone. A section of lining 56.5-m long was designed to withstand expected displacement on a fault interpreted to be subordinate to the Calaveras Fault. The lining was designed for an estimated $0.2-\mathrm{m}$ single event displacement using articulated joints placed at 3-m centers, each designed to withstand a $0.3-\mathrm{m}$ displacement in any direction without failure.

\subsection{IMPLEMENTATION OF THE NRC STAFF TECHNICAL POSITION ON SEISMIC DESIGN FOR TYPE I FAULTING AT YUCCA MOUNTAIN}

NUREG-1451, the NRC Staff Technical Position on an acceptable process and criteria to identify Type I faults (NRC 1992) is discussed in Section 2.2.1. A two-step process is described:

(1) identification of faults that are subject to displacement, and (2) assessment of whether such faults may affect repository design and/or performance. Specific criteria and guidance are given in NUREG-1451 for implementing the first step of the process; the primary criterion for identifying faults subject to displacement is evidence of movement during the Quaternary Period. To implement the second step, it is stated that fault length can be used as a measure to assess the possible effects of fault displacement on repository design or performance. It is further recommended that the DOE develop technically defensible criteria based on fault length for identifying faults or fault zones that may affect repository design and/or performance, assuming displacement will occur.

The DOE approach to characterizing Type I faults and the fault-displacement hazard is detailed in the first seismic topical report (DOE 1994). The approach is fully compliant with the approach identified in NUREG-1451 as providing sufficient data for input to fault-displacement hazard assessments for both the preclosure and the postclosure periods of performance. In accordance with staff guidance, this approach includes:

- A description of the character of the fault or fault zone, including its three-dimensional geometry.

- A description of the relationship of the fault or fault zone to other tectonic structures in the controlled area and within the boundaries of the component(s).

- Nature, magnitude, and geologic history (e.g., slip rates) of displacements along the fault or fault zone, including particularly the estimated Quaternary-age displacement. For each event, the estimated length of rupture, amount of displacement, and area or rupture surface is described. 
- Correlation of hypocenters, or locations of highest intensity, of historically reported and instrumentally recorded earthquakes with faults or fault zones, any parts of which are within the component boundaries.

- Consideration of alternative tectonic models at the scale of the controlled area or larger area, as they may affect alternative interpretations of the character and significance of Type I faults.

These investigations apply to both Type I faults expressed at the surface and those with no surface expression (i.e., those faults identified or inferred in the subsurface).

Site characterization studies performed to date have shown that individual displacements on faults in the Yucca Mountain geologic repository operations area during the Quaternary Period have been small, and cumulative displacements typically have been less than $200 \mathrm{~cm}$ during the past 100,000 to 200,000 years (Menges et al. 1995). Rates of movement are very low, in the range of $10^{-2} \mathrm{~mm}$ per year to $10^{-3} \mathrm{~mm}$ per year, and average earthquake recurrence intervals are 20,000 to more than 100,000 years. In addition, consistent with the results reported by Wells and Coppersmith (1994) obtained from an analysis of worldwide data on fault displacement versus fault length, the displacement per event for the faults at Yucca Mountain is strongly a function of fault length. While characterization of the faults in the Yucca Mountain geologic repository operations area is not yet complete, the data relating fault displacement to length of faulting should provide a basis for the assessment of whether faults subject to movement may affect repository design or performance. Results of this assessment are planned to be documented in the third seismic topical report.

\subsection{CRITERIA FOR IMPLEMENTATION OF FAULT DISPLACEMENT DESIGN}

The DOE design considerations to accommodate fault displacements follow the intent of NUREG-1494 (NRC 1994a). As discussed in Section 2.2.2 of this report, NUREG-1494 specifically recognizes that the presence of Type I faults inside the geologic repository operations area does not, by itself, disqualify a candidate site for a geologic repository. However, strong guidance is given to avoid Type I faults where avoidance can reasonably be achieved. Consistent with NUREG-1494, the principal fault displacement design action will be fault avoidance for SSCs important to safety. Fault avoidance will be accomplished to the extent reasonably achievable through the facility layout. However, also consistent with NUREG-1494, the DOE recognizes that it likely will not be reasonably feasible to avoid all Type I faults. This situation is particularly the case for spatially extended SSCs. For such cases, reasonable assurance of safe performance will be demonstrated by design of these SSCs to withstand the design basis fault displacement hazard.

\subsubsection{Criteria for Fault Avoidance}

Fault avoidance is the preferred approach to accommodating potential fault displacements. For clustered SSCs that are important to safety, the design requirement will be fault avoidance, except (1) when a compelling reason exists (e.g., fault avoidance reduces overall system safety) and it can be conservatively demonstrated that the SSC can withstand design basis fault displacement loads, or (2) when it can be demonstrated that the consequences of SSC failure due to fault displacement loads are well within acceptance criteria. For spatially extended SSCs that are important to safety, the design requirement also will be fault avoidance to the extent reasonably achievable. However, when fault avoidance is not reasonably achievable, design criteria and procedures will be 
implemented to reasonably ensure that the SSC will continue to perform its safety function, if subjected to the design basis fault displacement.

To implement the fault avoidance approach, criteria for when fault avoidance has been achieved are needed. Given the randomness inherent in faulting processes and uncertainty about the nature of previous displacement episodes on local faults, the DOE considers that a probabilistic definition of fault avoidance is the most appropriate. A probabilistic definition of fault avoidance also takes advantage of and will use the results of the DOE's planned probabilistic fault displacement hazard assessment and is consistent with the probabilistic definition of design basis fault displacements discussed in the next section.

The DOE considers that a Type I fault can be deemed to be avoided or, for an important-to-safety SSC that crosses a fault, a fault can be deemed to not be a Type I fault when the mean annual probability of displacement for which there is negligible engineering concern is less than $1.0 \mathrm{E}-04$ for SSCs that must be designed for Frequency-Category-1 design basis events, and 1.0E-05 for SSCs that must be designed for Frequency-Category-2 design basis events. As discussed in the next section, these are the probability levels that the DOE considers to be appropriate for use in establishing design basis fault displacements where fault avoidance is not feasible.

An implication of this probabilistic, SSC-specific approach to fault avoidance is that setback distances will be strongly fault-specific and SSC-specific. For example, an SSC with a specified fault avoidance threshold that is proximate to two Type I faults likely would have to be set back different distances from each to achieve the same probability of experiencing the threshold fault displacement. Two different SSCs with different avoidance thresholds would have to set back different distances from the same Type I fault to satisfy the avoidance criterion for each. The DOE plans to document setback distances in the third seismic topical report.

In addition to establishing minimum setback distances, the DOE will follow conservative layout guidelines when locating important to safety SSCs relative to Type I faults. For instance, when practical layout requirements make it necessary to place spatially extended SSCs across a Type I fault, the layout will be configured such that the SSC crosses the fault trace at a steep angle, minimizing the exposure of the SSC to faulting-induced damage.

Some guidance for determining fault setback can be obtained from engineering evaluations of expected responses of SSCs to fault displacement. Analyses performed by Kennedy and Kincaid (1985), for example, have shown that total strain induced in a pipeline by fault displacement decreases by about 60 percent at a distance of 20 feet from the locus of displacement and by about 80 percent at a distance of 100 feet.

\subsubsection{Criteria for Fault Displacement Design}

\subsubsection{Determination of Design Basis Fault Displacements}

When fault avoidance is not feasible for SSCs important to safety, these SSCs will be designed to withstand the design basis fault displacement without loss of their required safety functions. As for design basis vibratory ground motion, the DOE considers that probabilistic criteria for design basis fault displacements are most appropriate. Specifically, the DOE considers that fault displacements having mean annual exceedance probabilities of $1.0 \mathrm{E}-04$ and $1.0 \mathrm{E}-05$ are appropriate for the Frequency-Category-1 and Frequency-Category-2 design basis fault displacements, respectively. These values are a factor of ten lower than the exceedance probabilities of the corresponding Frequency-Category-1 and -2 design basis vibratory ground 
motions, reflecting the more limited experience with engineering design of facilities for fault displacement.

The motivation and justification for using a probabilistic rather than deterministic description of design basis fault displacements are the same as for design basis vibratory ground motions. Specifically, the advantages are that a properly done probabilistic faulting hazard analysis captures and reflects both randomness and uncertainty and accounts for both the magnitude and the likelihood of occurrence of the hazard. Faulting displacement hazards will be determined using the methodology described in the first seismic topical report (DOE 1994a), as discussed in Section 1.2.

\subsubsection{Acceptance Criteria for Fault Displacement Design}

Fault displacement loads depend on the magnitude and direction of the fault movement and on the ease with which the two segments of the SSC on two sides of the fault can move relative to each other. The latter depends on the following:

- The stiffness (or flexibility) of the SSC, especially in the vicinity of the fault

- The stiffness (or flexibility) of the ground around the buried segment or foundation of the SSC, especially in the vicinity of the fault

- The configuration of the SSC.

Once the design basis fault displacements are determined, the resulting loads (or stresses) and deformations (or strains) in the SSC will be calculated using analytical models that will consider the above three parameters. When similar loads/stresses and deformations/strains are calculated for vibratory ground motion, it is customary to use stress-based acceptance criteria to establish design adequacy assuming essentially linear elastic behavior, which is the basis for industry codes and standards. Unlike vibratory ground motion loads, however, fault displacement loads are generally localized and often cause inelastic response of SSCs, unless the SSC and the ground medium are very flexible, in which case the SSC can undergo large deformation and stay within elastic limits. For this reason, the DOE intends to use strain-based acceptance criteria to establish the design adequacy of SSCs subjected to fault displacement loads.

In establishing strain-based acceptance criteria for the Yucca Mountain repository facilities, nuclear power plant and other industry experiences with the use of strain-based criteria will be used. Examples are the strain criteria used for designing pipe rupture restraint systems and for designing SSCs subject to accidental impact and impulse loads such as those resulting from tornado missiles, turbine missiles, aircraft crashes, cask drops, reactor vessel head drops, and others that may be applicable. Some similarities also exist between localized inelastic response of SSCs when subject to fault displacement loads and localized stresses well beyond linear elastic limit of materials permitted by the American Society of Mechanical Engineers Boiler and Pressure Vessel Code (ASME 1991). Because of uncertainties in the fragilities of SSCs, however, the design acceptance criteria for fault displacement loads will not permit strain levels up to the ultimate or failure strain limit of the material. Instead, the limiting strain will be determined by considering the parameters that influence the fragility of the SSC. Explicitly, these are the configuration of the SSC, the SSC failure mode, the SSC material characteristics (brittle versus ductile), the stiffness of the SSC, and the stiffness of the ground material in the vicinity of the fault. Considering these parameters, strain limits will be established on a case-by-case basis to provide reasonable assurance that the seismic safety goal established for the SSC will be achieved. 
Some specific considerations for establishing strain limits for different kinds of SSCs are discussed next.

\section{Near-Surface Buried Piping}

As noted previously, piping is highly ductile; consequently, piping systems are able to withstand significant displacements causing large strains, without loss of function. Generally, piping performance will depend on whether tensile or compressive distortion is imposed. Analyses and observed performance show that piping is able to withstand significantly larger tensile strains than compressive strains. Whether the piping deforms in tension or compression in a fault displacement depends on the angle of the piping with respect to the faulting direction at the fault crossing. Therefore, whenever possible, pipeline alignment at a fault crossing will be such that the piping will be subjected to tension. Alignments that would place the piping in compression will be avoided whenever reasonably possible.

Acceptable analysis procedures for the design of piping systems for fault displacement are given in Guidelines for the Seismic Design of Oil and Gas Pipeline Systems (ASCE 1984). These analysis procedures and the design acceptance criteria described above will be followed for the fault displacement design of the Yucca Mountain piping system.

\section{Ventilation Shafts and Ducts}

Ventilation shafts and ducts, as well as underground openings, will control the movement, distribution, amount, and quality of air through the facility. The NRC requires in 10 CFR $60.133(\mathrm{~g})(3)$ that the underground facility ventilation system separate the ventilation of the excavation and waste emplacement areas. A final ventilation design concept has not been adopted at this time. However, a concept of two fully independent ventilation systems that have no operational impacts on one another is favored because of safety considerations. According to the current conceptual design given in the Mined Geologic Disposal System Advanced Conceptual Design Report (CRWMS M\&O 1996b), this concept will require two exhaust shafts with inside diameters on the order of $6 \mathrm{~m}$.

For ventilation ducts crossing Type I faults, the design action will be installation of flexible connections on the duct on each side of the fault to accommodate the design basis displacement. The flexible connection will be conservatively designed to provide reasonable assurance that the ventilation duct will retain its function.

If practical repository layout considerations require that a ventilation shaft be placed across a Type I fault, the design basis fault displacement will be accommodated by adding a flexible metal liner along the sector crossing the fault. The flexible metal liner will span a distance on either side of the fault such that reasonable assurance is provided that the shaft will maintain its function if subjected to the design basis fault displacement.

\section{Surface Facilities}

As discussed in Section 4.2.1, analyses and observations have shown that well-designed embedded structures can withstand vibratory ground motion and co-seismic fault displacement without loss of safety function. Appropriate procedures for calculating earth pressures are given by Duncan and Lefebvre (1973). The design analysis will take due account of the structure's design and layout, including embedment and subsystems, and will assume shipping cask drops from a crane or rail inside the surface structure. Fault displacement loads will be considered in combination 
with vibratory ground motion loads, and sufficiently conservative strain limits will be set to ensure safe performance.

\section{Ground Supports}

Actions that will be taken to ensure safe performance of drifts at crossings of Type I faults consist of (1) excavation of an oversize section through the fault zone and use of flexible support systems, or (2) incorporation of a flexible coupling, when the drift is lined. Investigations of faulting in the vicinity of the geologic repository operations area to date show that fault displacements are small, and intervals between displacements range from about 20,000 years to 100,000 years (Menges et al. 1995). Although tunnels are generally designed for higher recurrence rate events than these, the general practices of the tunneling industry will be adopted for analysis and design for fault displacement. 


\subsection{SEISMIC DESIGN OF THE WASTE PACKAGE}

The waste package is discussed separately because of its unique safety functions, postclosure performance requirements, and the requirement to perform safety functions both at the repository surface and subsurface. The waste package has a key role in providing substantially complete containment, waste isolation, criticality control, and waste retrievability. The following is a description of current waste package plans, performance requirements, and seismic design considerations. Although the objective of this topical report is to address preclosure seismic design, a discussion of the postclosure performance objectives of the waste package is also provided to illustrate how preclosure and postclosure design are integrated. As the waste package design is in the preliminary phase, the information discussed here is also preliminary.

The waste package consists of a waste form in a sealed disposal container, possibly surrounded by shielding, packing, and absorbent materials. Three waste package design configurations are under consideration. These configurations accommodate the three varieties of waste forms that will be placed inside the waste packages and emplaced in the repository. The three proposed waste package configurations are:

- Canistered spent fuel, placed inside outer containment barriers

- Uncanistered spent fuel supported by basket members, placed inside outer containment barriers

- Vitrified high-level defense waste, placed inside outer containment barriers.

Current waste package conceptual design configurations are not self-shielding. Worker radiation protection during emplacement will be accomplished by a shielded transporter and remote handling. Radiation protection during the caretaker phase will be accomplished by restricting access to the emplacement drifts. During the postclosure phase, worker radiation protection will not be an issue because of the absence of workers in the repository.

Horizontal, in-drift emplacement is the current design assumption for waste package emplacement. The large, high thermal output waste package is not well suited to borehole emplacement.

The preferred system for supporting the waste package in the repository is under development. Unlike most underground SSCs, the waste package may not be anchored directly to the rock or supported from frame-type structures anchored to the rock. The method currently being considered is to support the waste package by cradling it on a pedestal.

\subsection{WASTE PACKAGE PERFORMANCE REQUIREMENTS}

The waste package is unique because of the multiple safety functions it serves. These safety functions are performed during emplacement, during the caretaker phase, and during postclosure. Key performance requirements for the waste package are:

- Substantially complete containment (postclosure)

- Criticality control (preclosure and postclosure)

- Waste isolation (postclosure)

- Radiation protection (preclosure)

- Retrievability (preclosure). 
The waste package is required to provide substantially complete containment of the waste for 300 to 1,000 years after permanent closure. The current performance goal is to achieve mean waste package lifetimes well in excess of 1,000 years. The waste package configurations under consideration use robust, multiple containment barriers to achieve the waste containment performance objective.

Criticality control must be provided throughout the emplacement, containment, and waste isolation periods, beginning with loading of the waste into the waste package at the repository surface. The waste package will be required to provide this safety function for the spent nuclear fuel and defense high-level waste. The waste package will be designed to meet this performance requirement using the following methods:

- The canister internals, uncanistered spent fuel supporting structure, and vitrified waste form will maintain waste in a geometry that is not favorable to criticality.

- Neutron absorbing materials will be incorporated into the spent fuel waste package internals.

- Multiple containment barriers will prevent the presence of a moderator.

- Credit will be taken for a portion of the reduced reactivity of the fuel due to burnup.

The waste package is required to contribute to the performance of the engineered barrier system and repository such that the long-term waste isolation performance requirement is accomplished. Each of the waste package concepts under consideration are robust waste package designs that use multiple containment barriers. The use of multiple containment barriers is consistent with the well-accepted defense-in-depth approach. The multiple containment barriers will also serve to distribute waste package breaches over time, thereby enhancing compliance with the waste isolation phase's performance requirement for the gradual release of radionuclides. The waste package will contribute to the performance of the engineered barrier system such that following the 1,000-year substantially complete containment period, the radionuclide release rate will be less than or equal to 1 part in 100,000 per year of inventory at 1,000 years.

Current plans call for the repository to be designed to allow the waste to be retrieved for a period of up to 100 years after initial emplacement. The waste package will provide waste containment during the caretaker phase to meet this performance requirement.

\subsection{SEISMIC DESIGN CONSIDERATIONS}

The DOE has tentatively identified waste packages as Quality Assurance Classification 2-Important to Waste Isolation (DOE 1994d). A final determination will be made in accordance with the Civilian Radioactive Waste Management System.Management and Operating Contractor procedure for classifying permanent items (discussed in Appendix B). Postclosure design requirements for waste packages, including postclosure seismic design requirements, will be established accordingly through the systems engineering process discussed in Section 1.3 and Appendix A. For postclosure items, this process is based on iterating total system and subsystem performance assessments and developing design solutions until all postclosure performance requirements are met.

Although a definitive determination has not yet been made, it is likely that waste packages will also be determined to be Quality Assurance Classification 1-Important to Radiological Safetyi.e., to provide functions necessary to meet preclosure radiation protection requirements. As 
discussed in Appendix A, safety importance is assessed through analyses of potential accident scenarios and resulting public and worker radiation exposures. If found to be important to safety, waste packages will be designed to withstand Frequency-Category-1 or Frequency-Category-2 design basis ground motions, as appropriate. The preclosure seismic design methodology presented in Section 3 is applicable to the waste package. While at the surface, the waste package will be subject to the aboveground seismic loading conditions and will meet the seismic design criteria described in Section 3.2. While in the subsurface facility, the waste package will be subject to the underground seismic loading conditions and will meet the seismic design criteria described in Section 3.4.

If multiple seismic design criteria apply, the most stringent will control the design. For example, if it is determined that the waste package must be designed for the Frequency-Category-2 design basis ground motion on the surface and at depth, as well as for postclosure seismic loads, the most severe design basis ground motion will control the seismic design.

Seismic design loading considerations contemplated for the waste package include the following surface and subsurface situations and conditions:

- Rockfall onto the waste package during or after emplacement in the repository

- Overturning of the waste package from the emplacement support in the repository or while being handled in the surface facilities

- Integrity of the waste package internals (vitrified waste form, multipurpose canister, or uncanistered fuel basket) to maintain waste geometry and control criticality

- Seismically induced drop scenarios for waste package handling situations in surface and subsurface facilities

- Seismically induced shaking while in surface and subsurface facilities.

Current conceptual design configurations call for a robust waste package using multiple containment barriers. The waste package will be designed for appropriate combinations of seismic and non-seismic (accident and normal) loads. Non-seismic loading conditions contemplated for the waste package include the following:

- Emplaced loads

- Spent nuclear fuel and high-level waste loads

- Differential thermal stresses

- Residual thermal stresses

- Internal structural loads

- Imposed loads such as rockfall and backfill loads

- Repository operational loads

- Transportation loads

- Spent nuclear fuel and high-level waste loads

- Differential thermal stresses

- Internal structural loads

- Handling accidents (slap down)

- Transporter induced loads 
- Hot cell loads

- Handling

- Waste package loading.

It is expected that meeting the design requirements for non-seismic loads will render waste packages extremely resistant to inertial seismic loads. For example, a preliminary analysis of the seismic capacity of the conceptual waste package design for uncanistered spent fuel (Ceylan et al. 1995 ) indicated that the basket structure could withstand a 2-g seismic load with no yielding and with very large margins of safety.

A two-purpose (transportation and disposal) canister has additional design requirements -in particular, the transportation loading requirements from 10 CFR 71 -that should render it even more resistant to inertial seismic loads. These requirements include:

- Maintaining the required geometric spacing of the spent nuclear fuel assemblies to maintain a subcritical array configuration for all conditions as specified in 10 CFR 71 (transportation) and 10 CFR 72 (storage).

- Being designed for loading combinations, stress limits, and other structural criteria contained in Nuclear Regulatory Commission Regulatory Guides 7.6 (NRC 1978) and 7.8 (NRC 1989b).

- No yielding or buckling of the spent nuclear fuel basket under the loading conditions specified in 10 CFRs 71 and 10 CFR 72.

- A canister minimum service life of 100 years. 


\subsection{SUMMARY}

\subsection{INTRODUCTION}

This topical report is the second in a series of three reports being developed by the DOE to document the preclosure seismic design of SSCs important to the radiological safety of the geologic repository operations area at Yucca Mountain, Nevada. The first topical report, Methodology to Assess Fault Displacement and Vibratory Ground Motion Hazards at Yucca Mountain (DOE 1994a), was submitted to NRC staff for review and comment in 1994 and has been accepted by staff. The DOE plans to implement this methodology in fiscal year 1997 to develop probabilistic descriptions of the vibratory ground motion hazard and the fault displacement hazard at the Yucca Mountain site. The second topical report (this report) describes the DOE methodology and acceptance criteria for the preclosure seismic design of SSCs important to safety. Development of seismic design inputs is planned to begin in fiscal year 1997 and to be documented in a Seismic Design Report during fiscal year 1998. For formal NRC staff review, the DOE plans to develop a third seismic topical report that would document the results of the probabilistic seismic hazard assessment and the development of design inputs.

This report addresses preclosure seismic design methodology only, but SSCs important to safety must, ultimately, be built to a single design that meets all requirements, including those for postclosure performance. To ensure that all SSCs meet all of their design requirements, and to avoid sub-optimalization with respect to any single design requirement, the $\mathrm{DOE}$ is employing a systematic approach to the development, integration, and management of all site characterization, development, and operational activities. This approach, summarized here in Appendix A, is specifically intended to result in a one-pass design for the repository, which requires that all functions of the repository throughout its life cycle be understood and all aspects of the repository be designed in advance. To illustrate the design integration process, Appendix A examines the linkage between preclosure seismic design criteria for emplacement drifts and postclosure performance considerations related to seismic loading. This examination concludes that the preclosure seismic design criteria are expected to control the emplacement drift seismic design.

\subsection{REGULATORY PERSPECTIVE}

Preclosure seismic design must meet the NRC requirements in 10 CFR 60. Subpart A, General Provisions, of 10 CFR 60 requires the DOE to identify SSCs important to safety (i.e., those SSCs that are essential to the prevention of radiation doses in excess of regulatory limits). Subpart B, Licenses, requires the DOE to identify principal geologic repository operations area design criteria and their relationship to general performance objectives, geologic repository operations area design bases and their relationship to the principal design criteria, and codes and standards to be applied to geologic repository operations area design and construction. Subpart B also obligates the DOE to describe and analyze the design and performance requirements of SSCs important to safety under normal and anticipated operational conditions and under accident conditions, including those caused by natural phenomena. Subpart E, Technical Criteria, requires the DOE to demonstrate that the repository can be operated without unreasonable risk to the health and safety of the public. Subpart E also provides the important qualification that, while the performance objectives and criteria "are generally stated in unqualified terms, it is not expected that complete assurance that they will be met can be presented. A reasonable assurance, on the basis of the record before the Commission, that the objectives and criteria will be met is the general standard that is required." The Performance Objectives section of 10 CFR 60 requires the geologic repository operations area to be designed meet the radiation protection requirements of 10 CFR 20 during the preclosure period and to preserve the option of retrieving all emplaced waste on a 
reasonable schedule starting at any time up to 50 years after waste emplacement operations are initiated.

10 CFR 60 also provides general design criteria for the geologic repository operations area and for the waste package, but it does not specify or provide guidance regarding acceptable seismic design methodologies or design acceptance criteria. Therefore, the DOE produced this topical report to document proposed methodologies and acceptance criteria for preclosure seismic design. The report is being submitted for NRC staff review and comment to reach agreement on acceptable preclosure seismic design approaches before DOE implements the license application design.

This topical report has been written to comply with pending NRC requirements in a proposed rulemaking (60 FR 15180) for 10 CFR 60 that newly creates two categories of design basis events. These events are defined by qualitative descriptions of their likelihood of occurrence before closure of the geologic repository operations area. The DOE refers to the two categories of design basis events as Frequency-Category-1 and Frequency-Category-2 and proposes in this topical report target annual probabilities of exceedance for design basis vibratory ground motions and design basis fault displacements. Under the proposed rulemaking, SSCs important to safety are required to meet 10 CFR 20 radiation protection requirements for workers and members of the public, assuming the occurrence of Frequency-Category-1 design basis events, and meet a 5 rem limit for the total effective dose equivalent to an individual at or beyond the boundary of the preclosure controlled area, assuming the occurrence of a Frequency-Category-2 design basis event. The DOE process for identifying those SSCs important to safety is summarized in Appendix B of this report.

\subsection{HAZARD LEVELS FOR DESIGN BASIS GROUND MOTIONS}

The identification of SSCs important to safety and the characterization of design basis events requires a quantitative interpretation of the qualitative descriptions in the proposed rulemaking for 10 CFR 60 of the likelihood of occurrence of Frequency-Category-1 and -2 design basis events. The DOE intends to use mean annual exceedance probabilities of $1 . \mathrm{E}-03$ and 1.0E-04, respectively, as reference values in determining the Frequency-Category-1 and -2 design basis vibratory ground motions. These reference values will be used in the disaggregation of probabilistic seismic hazard estimates to identify those earthquakes that control the seismic hazard at the reference probabilities. This procedure and the DOE determination of the design basis ground motions would be detailed in the third seismic topical report.

The definition of Category 1 design basis events in the proposed 10 CFR 60 rulemaking is "those natural and human-induced events that are reasonably likely to occur regularly, moderately frequently, or one or more times before permanent closure of the geologic repository operations area." The DOE considers that a reasonable annual probability of occurrence to assign to this qualitative description of likelihood, given the 100-year time frame of preclosure operations, is 1.0E-02. However, model building codes recommend using ground motion values having a return period of about 500 years for the design of new facilities, and the DOE intends to use ground motion values having a return period of about 1,000 years (reference mean annual probability of exceedance of 1.0E-03) in determining the Frequency-Category-1 design basis ground motion, reflecting the fact that SSCs important to safety must function to prevent significant radiological impacts on public health and safety.

The DOE considers that a reference mean annual exceedance probability of $1.0 \mathrm{E}-04$ for Frequency-Category-2 design basis ground motion is appropriate and conservative based on the observations that (1) it is comparable to the mean exceedance probabilities of the seismic design 
bases of operating nuclear power reactors in the United States, (2) these accepted reactor design bases and their associated design-acceptance criteria have resulted in acceptably safe seismic designs, (3) design-acceptance criteria will be used in repository design that are the same as or comparable to those used in reactor designs, and (4) an operating mined geologic disposal system is inherently less hazardous and less vulnerable to earthquake-initiated accidents than is an operating nuclear power reactor.

As a check on the reasonableness of using a mean annual exceedance probability of $1.0 \mathrm{E}-04$, the DOE compiled published information on the annual probability of exceeding the accepted seismic design bases of nuclear power plants in the western United States. Results of the compilation are presented in Appendix C. The average mean annual probability of exceeding the safe shutdown earthquake of each plant is $2.0 \mathrm{E}-04$, which is twice the value of the reference probability to be used in determining the Frequency-Category- 2 design basis ground motion.

\subsection{DESIGN OF FACILITIES FOR VIBRATORY GROUND MOTION}

The DOE general policy is to use existing NRC guidance documents where they can appropriately be applied to the design and operation of geologic repository operations area facilities.

Accordingly, the DOE reviewed NUREG-0800, Standard Review Plan for the Review of Safety Analysis Reports for Nuclear Power Plants, for potential use in repository seismic design. With certain exceptions, the DOE considers that Standard Review Plans 3.7.1, Seismic Design Parameters; 3.7.2, Seismic System Analysis; 3.7.3, Seismic Subsystem Analysis; and 3.10, Seismic and Dynamic Qualification of Mechanical and Electrical Equipment, provide appropriate acceptance criteria for the preclosure vibratory ground motion design of repository surface facilities important to safety.

Underground openings in the repository consist principally of shafts, ramps, and drifts. Design of underground openings for vibratory ground motion includes analysis of the unsupported, as-excavated opening as well as the permanent ground support system and its interaction with the rock mass. Intersections of any of these openings are areas of attention in design because wider openings can result in higher rock loads on the ground support system. Ground support systems installed in the repository emplacement drifts may include concrete or steel lining systems. Support for other openings may include concrete and steel linings, or shotcrete and rockbolts.

The general design criteria in 10 CFR 60 require that underground openings be designed so that operations can be carried out safely and the retrievability option maintained. Although the requirement in 10 CFR 60 is to design the geologic repository operations area such that any or all of the emplaced waste can be retrieved on a reasonable schedule starting at any time up to 50 years after waste emplacement operations are initiated, the DOE is currently assuming a 100-year retrievability period and a main drift and emplacement drift design lifetime of 150 years.

To analyze the response of underground openings to seismic loading, the input ground motion must be defined. Design basis ground motions for underground openings are defined at the ground surface and are modified for application at depth using appropriate techniques that account for site-specific conditions.

The DOE has concluded that the ability to monitor, inspect, and maintain emplacement drifts during the preclosure period is the only design attribute necessary to accommodate the potential for repetitive seismic loading, in addition to designing emplacement drifts for the design basis earthquake. The likelihood of experiencing drift-damaging seismic loads more than once or twice during the preclosure period is negligible and many episodes of seismically induced joint slip 
would likely be required to lead to drift failure. The ground support system will be designed to withstand thermal and seismic loads and to keep key blocks in place, preventing the unraveling of blocks in the jointed rock mass and mitigating the potential for cumulative joint shear, regardless of the number of seismic events. Underground openings can be inspected following an episode of strong ground motion and repaired, if necessary, to mitigate the potential for drifts to fail through the accumulation of seismically induced joint shear.

Loads, other than seismic, to be considered in design of the underground openings include the in situ load from pre-existing stress conditions and thermal loads resulting from heat generated from the nuclear waste products. In situ stress is assumed static over the time period of concern. Thermal stresses are also considered to be static in design analyses because the rate of change of thermal stresses is slow.

Design of underground openings in jointed rock generally involves a combination of empirical methods, that is, experience-based rules summarized in design charts, and analytical methods based on solid mechanics and rock mechanics principles. Empirical methods, developed from tunneling and mining experience, provide an initial evaluation and selection of ground support but have limited application beyond static and ambient-temperature load conditions. To more accurately account for thermal and dynamic effects, analytical methods are used. Neither empirical nor analytical methods are fully validated under the loads and time frame of interest for repository design. Therefore, both methods are utilized here in the selection of ground support systems.

A preliminary dynamic analysis of emplacement drifts shows that the maximum changes in displacement and load caused by seismic waves are considerably smaller than the predicted thermal displacements and stresses and would not significantly affect the design. This result is consistent with the expectation that seismically induced rock and support deformations and stresses will be small because seismic wavelengths typically are longer than the drift dimensions and, hence, induce little differential motion in the opening. This result also is consistent with the empirical evidence of low damage levels in underground openings relative to surface structures.

In addition to underground openings and ground support systems, the subsurface repository areas will have other SSCs that will need to be designed to withstand seismic ground motion. Those systems that are important to safety will be identified in the same manner as surface systems and will be designed for Frequency-Category-1 and -2 design basis ground motions, as appropriate. The design criteria and analysis considerations are similar to those for the surface systems and will be based mostly on existing NRC staff guidance documents for the seismic design of nuclear power reactors. Design loads and responses will be determined for SSCs anchored directly to the rock and SSCs supported from structures anchored to the rock. For SSCs anchored directly to rock, the design basis ground motions will be specified at the depth of the SSC and will be developed by deconvolving or applying a site-specific correction factor to design basis ground motions that are defined for free-field conditions on the ground surface. For SSCs supported by structures anchored to the rock, design loads will be determined as for seismic subsystems.

\subsection{DESIGN OF FACILITIES FOR FAULT DISPLACEMENT}

In establishing fault displacement design criteria for the Yucca Mountain geologic repository operations area, the DOE intends to follow and implement NRC guidance provided in NUREG-1494, Staff Technical Position on Consideration of Fault Displacement Hazards in Geologic Repository Design. This document recommends that Type I faults within the geologic repository operations area be avoided when reasonably achievable. Type I faults are defined in 
NUREG-1451, NRC Staff Technical Position on Investigations to Identify Fault Displacement Hazards and Seismic Hazards at a Geologic Repository, as faults or fault zones that are subject to displacement and of sufficient length and located such that they may affect repository design or performance. NUREG-1494 recommends fault avoidance but explicitly recognizes that fault avoidance may not be possible for all SSCs, especially those that are spatially extended. To the extent reasonably achievable, the DOE will avoid Type I faults in the design of geologic repository operations area SSCs important to safety. When this cannot reasonably be achieved, the potential for fault displacement will be accommodated through design or repair and rehabilitation actions to provide reasonable assurance that all seismic safety requirements will be met.

There is a strong technical basis for fault displacement design, although such design is not as common as design for vibratory ground motion. The specific issue of whether a nuclear facility can safely accommodate fault offset has been extensively evaluated by NRC staff and the Atomic Safety and Licensing Board in a previous licensing proceeding. Other studies have shown that structures can be designed to withstand earth pressure loads that result from fault displacements by providing the proper level of ductile performance. Examples of tunnel design and performance through faults are detailed in Appendix D; the approach in a number of cases has been to provide a flexible structure that allows deformation without undue disruption of the drift function. An enlarged tunnel cross section may also be indicated as part of the design solution.

As for design basis vibratory ground motion, the DOE considers that probabilistic criteria for design basis fault displacements are most appropriate. Specifically, the DOE considers that fault displacements having mean annual exceedance probabilities of $1.0 \mathrm{E}-04$ and $1.0 \mathrm{E}-05$ are appropriate for the Frequency-Category-1 and Frequency-Category-2 design basis fault displacements, respectively. These values are a factor of ten lower than the exceedance probabilities of the corresponding Frequency-Category-1 and -2 design basis vibratory ground motions, reflecting the more limited experience with engineering design of facilities for fault displacement.

The DOE will use strain-based acceptance criteria to establish the design adequacy of SSCs that may be subjected to fault displacement loads. In establishing these criteria, nuclear power plant and other industry experiences with the use of strain-based criteria will be used. Examples are the strain criteria used for designing pipe rupture restraint systems and SSCs that may be subject to accidental impact and impulse loads. Because of uncertainties in the fragilities of SSCs, the design acceptance criteria for fault displacement loads will not permit strain levels up to the ultimate or failure strain limit of the material.

Consistent with NUREG-1494, fault avoidance is the DOE preferred approach to accommodating potential fault displacements. To implement this approach, criteria for when fault avoidance has been achieved are needed. Given the randomness inherent in faulting processes and uncertainty about the nature of previous displacement episodes on local faults, a probabilistic definition of fault avoidance is the most appropriate. Specifically, the DOE considers that a fault can be deemed to be avoided or, for an important-to-safety SSC that crosses a fault, a fault can be deemed to be not a Type I fault, when the mean annual probability of displacement for which there is negligible engineering concern is less than 1.0E-04 for SSCs that must be designed for FrequencyCategory-1 design basis events, and 1.0E-05 for SSCs that must be designed for FrequencyCategory- 2 design basis events. These are the probability levels that the DOE considers to be appropriate for use in establishing design basis fault displacements where fault avoidance is not feasible. Fault setback distances under this approach will be highly SSC- and fault-specific. 


\subsection{SEISMIC DESIGN OF WASTE PACKAGES}

The waste package consists of a waste form in a sealed disposal container, possibly surrounded by shielding, packing, and absorbent materials. Three waste package design configurations are under consideration: canistered spent fuel, uncanistered spent fuel supported by basket members, and vitrified high-level defense waste. All configurations include outer containment barriers. Horizontal, in-drift emplacement is the current design assumption for waste package emplacement. The preferred system for supporting the waste package in the repository has not been determined. Unlike most underground SSCs, the waste package may not be anchored directly to the rock or supported from frame-type structures anchored to the rock. The method currently being considered is to support the waste package by cradling it on a pedestal.

The DOE has tentatively identified waste packages as Quality Assurance Classification 2-Important to Waste Isolation (DOE 1994d). A final determination will be made in accordance with the Civilian Radioactive Waste Management System Management and Operating Contractor procedure for classifying permanent items, as described in Appendix B. Postclosure design requirements for waste packages, including postclosure seismic design requirements, will be established accordingly through the systems engineering process. For postclosure items, this process is based on iterating total system and subsystem performance assessments and developing design solutions until all postclosure performance requirements are met.

Although a definitive determination has not yet been made, it is likely that waste packages will also be determined to be Quality Assurance Classification 1-Important to Radiological Safety-i.e., to provide functions necessary to meet preclosure radiation protection requirements. If confirmed to be important to safety, waste packages will be designed to withstand FrequencyCategory-1 or Frequency-Category-2 design basis ground motions, as appropriate.

If multiple seismic design criteria apply, the most stringent will control the design. For example, if it is determined that the waste package must be designed for the Frequency-Category- 2 design basis ground motion on the surface and at depth, as well as for postclosure seismic loads, the most severe design basis will control the seismic design.

The waste package will be designed for appropriate combinations of seismic and non-seismic loads. Non-seismic loads contemplated for the waste package include a number of structural, operational, thermal, transportation, and accident-induced loads. Meeting the design requirements for non-seismic loads is expected to render waste packages extremely resistant to inertial seismic loads. The two-purpose (transportation and disposal) canister has additional design requirements-in particular, the transportation loading requirements from 10 CFR 71-that should render it even more resistant to inertial seismic loads. 
APPENDIX A

INTEGRATION OF PRECLOSURE AND POSTCLOSURE

REQUIREMENTS IN SEISMIC DESIGN 


\section{APPENDIX A}

\section{INTEGRATION OF PRECLOSURE AND POSTCLOSURE REQUIREMENTS IN SEISMIC DESIGN}

Structures, systems, and components (SSCs) important to safety must, ultimately, be built to a single design that not only meets preclosure seismic design requirements, but all requirements, including those for postclosure seismic design. The integration of preclosure and postclosure seismic design requirements to develop a single seismic design is illustrated schematically in Figure 1-1. To ensure that all SSCs meet all of their design requirements, and to avoid suboptimalization with respect to any design requirement, the U.S. Department of Energy (DOE) is employing a systematic approach to the development, integration, and management of all site characterization, development, and operational activities. This approach is specifically intended to result in a one-pass design for the repository which requires that all life cycle functions of the repository be understood and all aspects be designed in advance. Integrating activities to accomplish these objectives currently are described in existing program- and project-level systems engineering plans. These plans are being consolidated and augmented by the DOE and the Civilian Radioactive Waste Management System Management and Operating Contractor (CRWMS M\&O) in a Technical Management Implementation Plan (in preparation); here highlights that are germane to the integration of preclosure and postclosure seismic design are presented. In addition, to illustrate how linkages between preclosure and postclosure seismic design are explored, the issue of repetitive seismic loading and long-term drift stability is examined. Finally, some specific activities are identified that demonstrate how postclosure impacts of tectonic activity and postclosure seismic design requirements are being identified.

\section{A.1 OVERVIEW OF THE INTEGRATED TECHNICAL MANAGEMENT PROCESS}

Development of the mined geologic disposal system (MGDS) involves defining performance expectations, requirements, and criteria for the natural and engineered systems and integrating the results of the scientific method and the design process to formulate and develop solutions. The scientific method formulates hypotheses for the natural system and material components of engineered systems and then confirms the hypotheses and performance predictions through analyses, using data collected through site investigations and process modeling. The design process is a structured approach to developing an operational concept, defining system functions, conducting trade studies, and evaluating alternatives to develop design solutions that meet all requirements and criteria. Verification, validation, total system performance assessment, and performance confirmation are then used to ensure that the design, operating in the natural system, satisfies performance requirements and criteria.

A systems engineering process, modeled after commercial industry processes, is being used to develop the system and subsystem performance and operational criteria and to integrate, control, and verify the development of the CRWMS. These processes have been tailored for the CRWMS to facilitate the development and integration of design, scientific investigations, and performance assessment using a top-down analysis of systems requirements and of design and scientific solutions. The systems engineering process provides a logical application of technical skills, creativity, and communication methods to generate an integrated set of solutions to the system requirements. Figure A-1 depicts the systems engineering process in the context of MGDS development. Activities associated with this process are evaluated and controlled in accordance with applicable quality assurance procedures. Some of the documents and processes that support the systems engineering process are discussed next. 


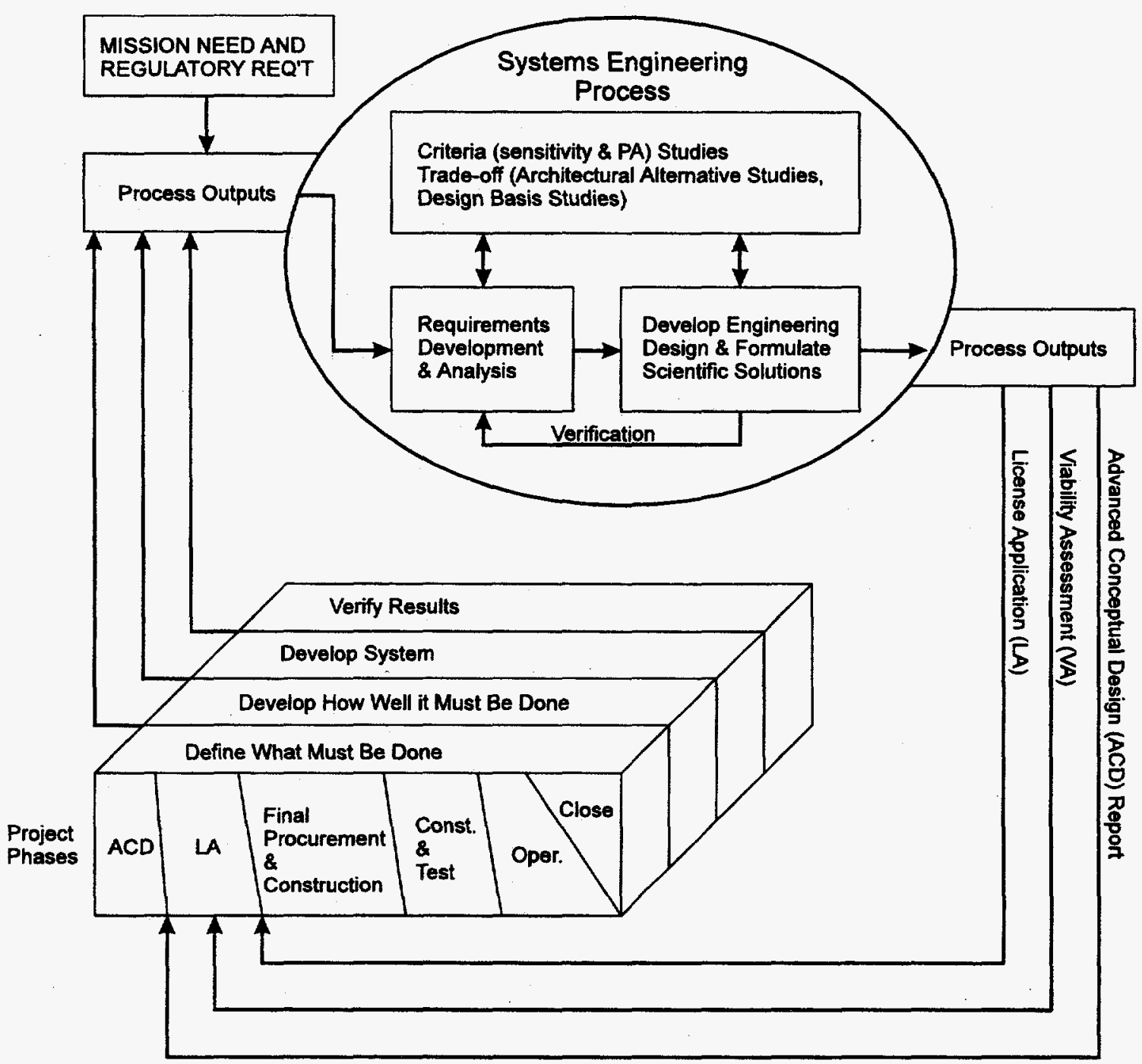

A-1.CDR. YMP.REPORTS.SEISMICI8-2-96 SEISMIC TOPICAL REPORT

Figure A-1. MGDS Development Process 
Top-level constraints and requirements are captured in the Civilian Radioactive Waste Management System Requirements Document (CRD) (DOE 1995b) and project-level design requirements documents. The system and project-level design requirements documents provide the technical requirements that must be satisfied by the engineered and scientific solutions for an operational CRWMS. The requirements are based on applicable laws, regulations, and guidelines. These top-level constraints and requirements are used to develop the conceptual designs and concept of operations and are being used in the development of the MGDS, waste acceptance, interim storage, transportation, and waste isolation strategies. Requirements and conceptual designs are then used to develop performance and design criteria for the engineered SSCs and performance allocations for the natural system. The performance criteria and allocations establish what the engineered SSCs and natural system must be capable of accomplishing, how well they must perform in measurable terms, and under what conditions they must operate.

For the MGDS, the Controlled Design Assumptions Document (CDA) (CRWMS M\&O 1995a) captures the assumptions that were required to complete the conceptual design phase; this document will be updated frequently to capture evolving design criteria, including requirements and assumptions, until those criteria can be incorporated into the system description documents.

Use of Integrated Product Teams is a key integration tool in the development of the CRWMS. These teams, with representation from all interfacing and impacted areas, will be used to develop the primary criteria and expectations for the engineered SSCs and natural system. The first step in criteria development is the determination of the functions needed to satisfy the CRD and project-level design requirements documents, based on the current conceptual design and concept of operations. As the functions are identified, they are defined, bounded, and documented. For the MGDS, the functions are documented in the MGDS Functional Analysis Document (CRWMS $M \& O$ 1996c). Performance and operational attributes and criteria are then developed by the Integrated Product Team for each function. The performance criteria are derived from the higherlevel requirements based on the waste isolation strategy, process models, performance assessment sensitivity studies, MGDS systems studies, and professional experience. As criteria are allocated to the functional structure, concepts are developed for accomplishing the functions in a manner that meets the performance criteria.

The synthesis process is used to develop integrated solutions that achieve performance and operational criteria. The functions and criteria, initially at the upper levels, are grouped into key systems or structures, including the natural system. By grouping key functions, the SSCs are identified through conceptualization of the architecture required to perform the functions, allowing allocation of the performance criteria to the natural system and engineered SSCs that provides a discrete set of criteria for each development effort. Key interfaces between the natural system, engineered SSCs, and other elements of the CRWMS are captured through interface controls. The SSCs are developed based on groupings of functions and the Mined Geologic Disposal System Advanced Conceptual Design Report (CRWMS M\&O 1996b). System description documents are then developed for identified SSCs. Once the functions have been grouped, a combination of the design process and the scientific method is used to develop viable solutions.

The design process is based on objectives, criteria, and concepts. For the MGDS, these are documented in the CRD and project-level design requirements documents, the CDA, and the Mined Geologic Disposal System Advanced Conceptual Design Report. The criteria are allocated to SSCs and further decomposed to define the technical and performance criteria needed to support design activities. For the MGDS, these criteria are documented in system description 
documents that are developed and controlled in accordance with applicable quality assurance procedures.

The three primary design inputs for the MGDS design are the requirements (as captured in the design requirements documents and the system description documents), design assumptions (i.e., CDA), and technical data. Design inputs are then translated into design output products such as technical reports, design analyses, drawings, and specifications. All design output products are developed, reviewed, and controlled in accordance with appropriate procedures.

Design guides and/or implementing procedures are written when needed to ensure standardized and licensable development of specific SSC designs. The design guides are developed for systems or groups of systems that have applications in more than one area or facility. These guides provide a standardized methodology for designing the SSCs and guidance on how the design can be tailored depending on its specific application. Design guides will draw heavily upon U.S. Nuclear Regulatory Commission (NRC) precedents, and development will begin with a comprehensive review of existing applicable codes and standards (DOE and commercial) for the given systems or groups of systems. These design guides will provide a design methodology with the flexibility to be applied in unique applications in terms with which the NRC is familiar.

As the design process is conducted for the MGDS, operational descriptions are developed for each SSC and documented in the appropriate system description document. The operational descriptions provide the basis for design criteria development, analysis, and design. These operational descriptions describe not only how the SSCs will operate (including processes, procedures, and personnel), but also how the SSCs may fail and how they will be maintained.

The MGDS design process generates detailed physical performance models based on the current design. These physical performance models provide part of the basis of simplified or abstracted models for conducting criteria (sensitivity) studies and total system performance assessments.

The scientific method is used to understand and quantify the performance of the natural system and material components of engineered systems. Based on existing scientific data, system performance predictions, and the waste isolation strategy, scientific hypotheses are formulated for the natural system and material component properties. Data needs are then identified to support the hypotheses testing, and the required testing and modeling are identified, assigned, and documented in Study Plans or Scientific Investigation Plans. The data collected from these tests are used to develop conceptual, framework, and process-level models to test the validity of the hypotheses. Integrated Product Teams develop detailed data needs documents that identify key information exchanges between scientific investigations and design activities. Total system performance assessments identify information needs from site characterization. The intersection between site and performance assessment is facilitated by the joint abstraction process of performance assessment modelers and site process modelers.

Competing or contradictory requirements or expectations for design and scientific solutions are resolved through the systems analysis process. This process consists of system and design studies. System studies are used to provide technical bases for the resolution of program- or project-wide issues. Generally, system studies provide results that may be used to develop a set of recommended scientific or design requirements or criteria and a feasible solution to those requirements and criteria that consider all relevant system-wide factors, instead of optimizing the solution for a given sub-element at the sacrifice or expense of another element. Design studies provide technical bases for design decisions. Design studies will evaluate different alternatives to meeting a set of requirements for a given element of design, without forcing requirement changes 
elsewhere in the system to accommodate the options, although consolidation of requirement changes may be recommended. Design studies will evaluate performance implications and margin tradeoffs for specific elements.

\section{A.2 POSTCLOSURE SEISMIC DESIGN}

\section{A.2.1 Repetitive Seismic Loads and Drift Stability}

To illustrate the design integration process, the link is examined between the preclosure seismic design approach to repetitive seismic loading of the emplacement drifts (i.e., reliance on design for a single design basis event and the ability to inspect and maintain the drifts) and postclosure performance considerations related to repetitive seismic loading.

Over thousands of years, an MGDS at Yucca Mountain likely would experience multiple episodes of moderate to strong ground shaking from earthquakes (Lee et al. 1991) and could experience adjacent or throughgoing fault displacement. The DOE is evaluating, therefore, postclosure effects of tectonic processes and events, including seismically induced rockfalls, on the natural and engineered barrier systems (DOE 1994c; Gauthier et al. 1995; SNL 1996). These studies, in conjunction with systems studies (e.g., CRWMS M\&O 1996d), total system performance assessments (e.g., Gauthier et al. 1995), and design studies will address the prediction of thermal-mechanical-hydrological effects on emplacement drifts to provide input for waste package design and performance assessments, which is one of the key technical uncertainties that has been identified by NRC staff (NRC 1995b; Appendix E).

Predicting the postclosure time-dependent behavior of emplacement drifts at Yucca Mountain would require modeling the dynamic response of jointed rock masses to slowly varying thermal stresses and to occasional seismic loads. The welded tuffs at Yucca Mountain, including the welded Topopah Spring tuff that would be the host rock for emplacement drifts, are highly fractured. Through research conducted by the Center for Nuclear Waste Regulatory Analyses and others, significant progress has been made recently in understanding the seismic behavior of jointed rock masses and in developing rock joint models for cyclic loads (e.g., Fishman 1988; Jing et al. 1992; Huang et al. 1993; Qiu et al. 1993; Wibowo et al. 1993; Hsiung et al. 1994a; Hsuing et al. 1994b; Ghosh et al. 1995; Kana et al. 1995; Souley et al. 1995). However, this research has also clearly shown that dynamic joint behavior is a complex nonlinear phenomenon that depends on the joint boundary conditions, joint surface characteristics, and joint slip history. In particular, research has shown that an opening in a jointed rock mass will weaken with time if it is unsupported and if it experiences sufficient permanent joint deformation that has accumulated from a number of episodes of seismic loading (Brown and Hudson 1974; Hsuing et al.1992; Kana et al. 1995).

Because of the complexities and uncertainties just noted, the DOE presently does not intend to rely on rockfalls not occurring in emplacement drifts for any period of time to achieve acceptable postclosure performance (CRWMS M\&O 1996d). Rather, the DOE intends to bound the effects of postclosure rockfalls on postclosure performance and, if necessary, to design to mitigate their consequences. Therefore, preclosure seismic design requirements are expected to control the seismic design of emplacement drifts.

Information is not available that would enable an accurate prediction of rockfall frequency with time. Such time-distribution predictions rely on empirical databases of events, which are lacking for rockfall. However, plausible "what-if" probability distributions for time-dependent rockfall parameters (e.g., Gauthier et al. 1995; Ahola et al. 1995) may be constructed to support 
performance sensitivity studies. The DOE does consider it to be feasible to determine a distribution of probable rock-block sizes (e.g., Gauthier et al. 1995; CRWMS M\&O 1996d) and to use this probability distribution to model the consequences of rockfalls onto waste packages at various times during the postclosure period (CRWMS M\&O 1996d).

To summarize, the DOE does not intend to rely on rockfalls not occurring in emplacement drifts during the postclosure period and, therefore, does not intend to design emplacement drifts to withstand single or multiple episodes of seismic loading during the postclosure period. Consequently, preclosure seismic design requirements are expected to control the seismic design of emplacement drifts. However, a number of episodes of earthquake ground motion can be expected during the postclosure period, and the DOE intends to characterize the postclosure seismic environment to support analyses of the effects of seismic loading and other tectonic processes and events on the performance of natural and engineered barriers.

\section{A.2.2 Technical Basis for Postclosure Seismic Design}

As part of the integrated technical management process, the DOE has been evaluating potential postclosure impacts of tectonic activity and developing the technical basis for the postclosure seismic design of SSCs that are important to waste isolation. Scenarios for the effects of tectonic processes on postclosure repository performance are being developed (SNL 1996). A preliminary total system performance assessment of the impacts of seismic activity on long-term repository performance at Yucca Mountain has been conducted (Gauthier et al. 1995), and follow-on assessments are planned. Gauthier et al. (1995) specifically considered rockfall induced by thermal-mechanical and seismic loads in unbackfilled emplacement drifts, container damage caused by fault displacement within the repository, and flow-path changes caused by changes in strain. A preliminary seismic structural analysis of a conceptual waste package design has been performed (Ceylan et al. 1995), and analysis of the capacity of waste packages to withstand rockfalls is ongoing. The issue of repetitive seismic loading and long-term drift stability is examined in this report.

Results of the DOE activities to evaluate the postclosure impacts of tectonic events will be used within the iterative, systems engineering process to update repository system models, design inputs, designs, and requirements to achieve a single design for all SSCs that will meet all requirements, including requirements for preclosure and postclosure seismic design. 


\author{
APPENDIX B \\ PROCESS FOR IDENTIFYING STRUCTURES, SYSTEMS, AND \\ COMPONENTS IMPORTANT TO RADIOLOGICAL SAFETY
}




\section{APPENDIX B}

\section{PROCESS FOR IDENTIFYING STRUCTURES, SYSTEMS, AND COMPONENTS IMPORTANT TO RADIOLOGICAL SAFETY}

The U.S. Department of Energy (DOE) will design repository structures, systems, and components (SSCs) important to radiological safety to withstand design basis events. Contingent on the proposed rule being finalized, the DOE will use the criteria provided in the proposed $10 \mathrm{CFR} 60$ rulemaking at 60 FR 15180 to identify these design basis events; i.e.:

"(1) those natural and human-induced events that are reasonably likely to occur regularly, moderately frequently, or one or more times before permanent closure of the geologic repository operations area; and

"(2) other natural and man-induced events that are considered unlikely, but sufficiently credible to warrant consideration, taking into account the potential for significant radiological impacts on public health and safety."

The DOE will refer to events meeting these criteria as Frequency-Category-1 and Frequency-Category-2 design basis events, respectively.

The DOE defines important to radiological safety in accordance with the proposed rulemaking's definition of important to safety; i.e.:

"Important to safety, with reference to structures, systems, and components, means those features of the repository whose function is:

"(1) to provide reasonable assurance that high-level waste can be received, handled, packaged, stored, emplaced, and retrieved without exceeding the requirements of $\$ 60.111$ (a) for Category 1 design basis events; or

"(2) to prevent or mitigate Category 2 design basis events that could result in doses equal to or greater than the values specified in $\$ 60.136$ to any individual located on or beyond the nearest boundary of the preclosure controlled area."

The classification of permanent repository SSCs (or items) is accomplished by the Civilian Radioactive Waste Management System Management and Operating Contractor using Quality Administrative Procedure QAP-2-3, Classification of Permanent Items. This procedure provides checklists of criteria for determining what quality assurance classification to assign to permanent items, including Classification 1-Important to Radiological Safety. The Classification 1 criteria include:

- Whether the item is required to mitigate the consequences of a credible accident that could result in a dose in excess of regulatory limits

- Whether the item is required to monitor or control important-to-radiological-safety SSCs

- Whether the failure of the item can initiate a credible accident that could result in a dose in excess of regulatory limits. 
Assessing whether an item meets any of these criteria requires the identification of credible events and credible event-initiated accidents. Potential external events such as earthquakes, volcanoes, tornadoes, floods, and internal events such as a fuel-handling drop are identified, and their likelihood of occurrence and potential severity is assessed. The consequences of events are then analyzed to determine how the site and facilities would respond to the event and, when radiological releases are postulated, predicted releases, radiation levels, and exposures are compared to regulatory limits. The applicable regulatory limits depend on the frequency or likelihood of occurrence of the initiating event. As discussed in Sections 3 and 4 of this topical report, the DOE intends to use reference mean annual exceedance probabilities of $1.0 \mathrm{E}-03$ and $1.0 \mathrm{E}-04$ to determine Frequency-Category-1 and -2 design basis vibratory ground motions, respectively, and to use mean annual exceedance probabilities of 1.0E-04 and $1.0 \mathrm{E}-05$ to determine Frequency-Category- 1 and -2 design basis fault displacements, respectively. To comply with the proposed rulemaking for $10 \mathrm{CFR} 60$, SSCs must meet the requirements of proposed $\$ 60.111(\mathrm{a})$ - which incorporates by reference the radiation protection requirements of $10 \mathrm{CFR} 20$-when subjected to frequency-Category-1 design basis events and the requirements of proposed $\$ 60.136$ - which limits potential doses to a person at the boundary of the preclosure controlled area-when subjected to Frequency-Category-2 design basis events. Any SSC whose continued functionality is required to ensure compliance with any of these regulatory limits is classified as important to radiological safety.

Procedure QAP-2-3 also requires the evaluation of permanent items to determine whether they are Classification $5^{*}$-Important to Potential Interaction. The continued function of Classification 5 items is not required, but their failure during a design basis event could impair the capability of other items to perform their intended radiological safety or waste isolation function. Thus, interactions between SSCs will be evaluated to ensure that the seismic response of any SSC to a Frequency-Category-1 or Frequency-Category-2 design basis earthquake will not preclude the continued functioning of SSCs important to radiological safety.

As part of good engineering practice, the DOE intends to evaluate the response of repository systems to low-probability, potentially high-consequence events that exceed the nominal design basis. Such events will include earthquake ground motions more severe than and less likely than the design basis ground motions. Analysis of beyond-design-basis events may lead to changes in design or operating practices that will further decrease the probability of event-initiated failures or the consequences of such failures.

In addition to Classifications 1 and 5, QAP-2-3 defines Classification 2-Important to Waste Isolation, Classification 3-Important to Radioactive Waste Control, Classification 4-Important to Fire Protection, Classification 6-Important to Physical Protection of Facility and Materials, and Classification 7Important to Occupational Radiological Exposure. 


\begin{abstract}
APPENDIX C
PROBABILITIES OF EXCEEDING THE SEISMIC DESIGN BASES OF NUCLEAR POWER PLANTS IN THE WESTERN UNITED STATES
\end{abstract}




\section{APPENDIX C \\ PROBABILITIES OF EXCEEDING THE SEISMIC DESIGN BASES OF NUCLEAR POWER PLANTS IN THE WESTERN UNITED STATES}

This appendix documents estimated composite mean annual probabilities of exceeding the accepted seismic design bases of nuclear power plants in the western United States. Specifically, it documents the exceedance probabilities and seismic design bases of the Diablo Canyon Power Plant (DCPP), the Palo Verde Nuclear Generating Station (PVNGS), the San Onofre Nuclear Generating Station (SONGS) (Units 2 and 3), the Washington Nuclear Plant 2 (WNP-2), and the Washington Nuclear Plant 3 (WNP-3). With the exception of WNP-3, these are currently operating plants whose seismic design bases were reviewed and accepted by U.S. Nuclear Regulatory Commission (NRC) staff, then adjudicated and found acceptable by NRC licensing boards. WNP-3 was partially constructed and then canceled, but its seismic design basis was reviewed and provisionally accepted by NRC staff. In accordance with NRC guidance in Draft Regulatory Guide DG-1032 (NRC 1995a), the composite exceedance probability is defined as the arithmetic average of the probabilities of exceeding the design basis response spectral ordinates at 5 and $10 \mathrm{~Hz}$, for $5 \%$ damping. The composite probability is intended to be used as a reference probability for the identification of controlling earthquakes that are used to define the design basis earthquake ground motion. Mean, rather than median, probabilities are used for the reasons discussed in Section 3.1.2.1 of this report.

Plant-specific evaluations are presented in the following sections.

\section{C.1 DIABLO CANYON POWER PLANT}

The two units of the DCPP in Port San Luis, California, are operated by the Pacific Gas and Electric Company (PG\&E). PG\&E conducted a probabilistic seismic hazard analysis of the DCPP site under its Long Term Seismic Program (PG\&E 1988). Results of this study were input to the seismic risk assessment that PG\&E conducted for the Individual Plant Examination of External Events (IPEEE) program, described in Section 3.1.2.2 of this report. The Long Term Seismic Program estimated the probability of exceeding the average spectral accelerations at the DCPP site over the 3- to $8.5-\mathrm{Hz}$ frequency range. The mean hazard results, taken from the IPEEE report (PG\&E 1994) are shown in Figure C-1.

The accepted earthquake for the seismic evaluation of Diablo Canyon Units 1 and 2 is a postulated magnitude 7.5 event on the Hosgri fault, generating a peak horizontal acceleration at the site of $0.75 \mathrm{~g}$ (PG\&E 1978). Both Newmark and Blume standard design spectral shapes were "anchored to" this peak acceleration value to provide a basis for evaluating the DCPP seismic design, as shown in Figures C-2 and C-3 (PG\&E 1985). From these figures, the 3- to 8.5-Hz (0.12- to 0.33-sec period) average spectral acceleration for $5 \%$ damping for both spectral shapes is approximately $2.0 \mathrm{~g}$.

Referring to Figure $\mathrm{C}-1$, the estimated mean probability of exceeding $2.0 \mathrm{~g}$ for the $3-$ to $8.5-\mathrm{Hz}$ average spectral acceleration is approximately $1.7 \mathrm{E}-04 / \mathrm{yr}$. Exceedance probabilities for the spectral values at 5 and $10 \mathrm{~Hz}$ are not available. However, the calculated average probability of exceeding the DCPP design spectra at 5 and $10 \mathrm{~Hz}$ should differ little from the calculated probability of exceeding the 3- to $8-\mathrm{Hz}$ average acceleration. Therefore, it is estimated that the 5and $10-\mathrm{Hz}$ composite (average) mean exceedance probability for the DCPP is about $1.7 \mathrm{E}-04 / \mathrm{yr}$, and it can safely be concluded that it is greater than $1.0 \mathrm{E}-04 / \mathrm{yr}$. 


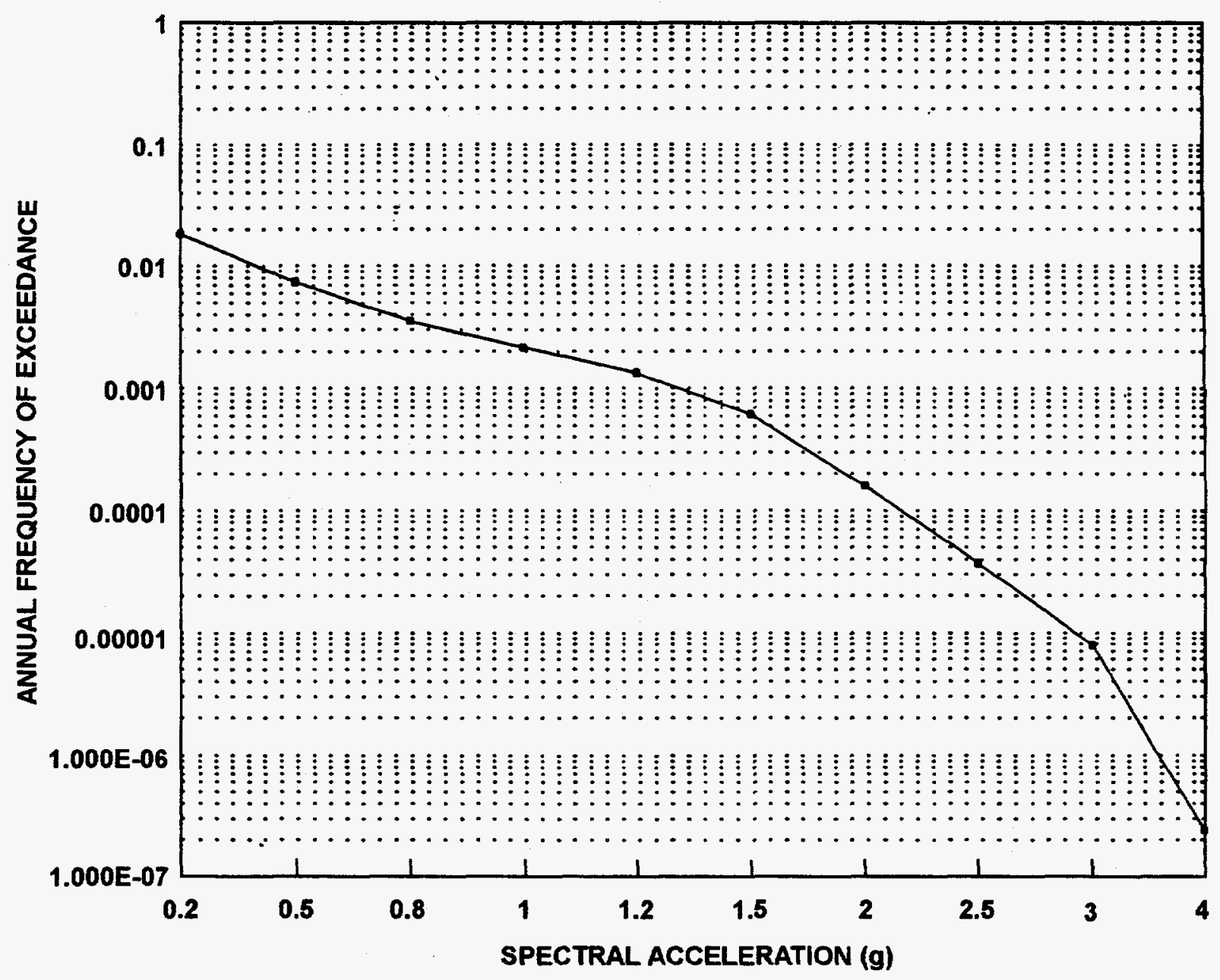

B-1.CDR.YMP.REPORTS.SEISMIC/Q-27-98 SEISMIC TOPICAL REPORT

Figure C-1. Seismic Hazard (3.0-8.5 Hz), Diablo Canyon Site 


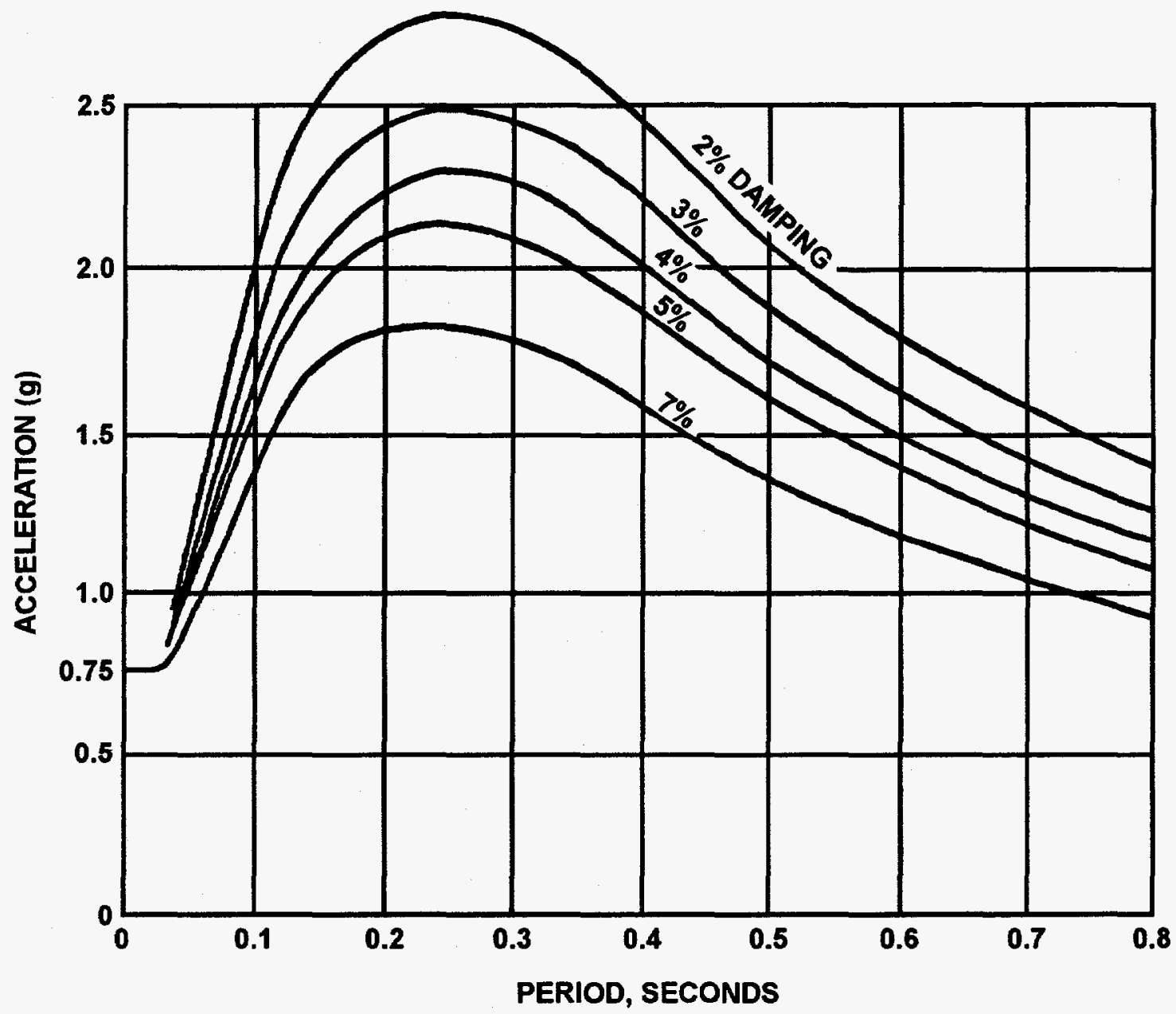

B-2.CDR.YMP.REPORTS.SEISMIC/6-20-96 SESMIC TOPICAL REPORT

Figure C-2. Horizontal Hosgri/Blume Design Spectrum, Diablo Canyon Power Plant 


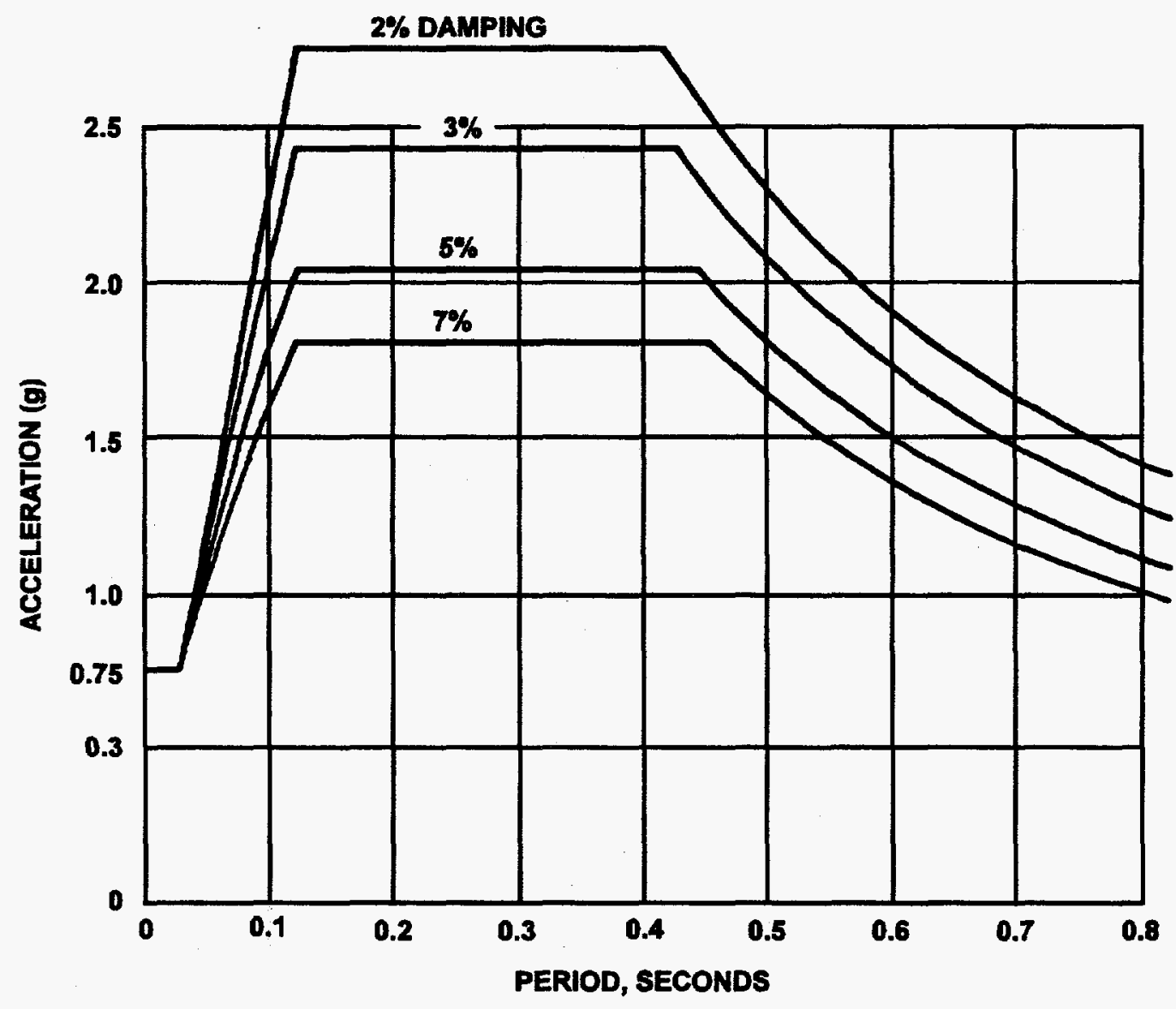

B-3.CDR.YMP.REPORT8.8ERMIC/2-21-96 SEISMIC TOPICN RGPORT

Figure C-3. Horizontal Hosgri/Newmark Design Spectrum, Diablo Canyon Power Plant 


\section{C.2 PALO VERDE NUCLEAR GENERATING STATION}

The PVNGS in Wintersburg, Arizona, is operated by the Arizona Public Service Company (APS). The PVNGS site is in a region where the seismic hazard is lower than in most other regions of the western United States, and the free-field horizontal design-basis response spectrum for the PVNGS is anchored at $0.25-\mathrm{g}$ peak ground acceleration (APS 1978). The free-field, horizontal-component design response spectra for the PVNGS are shown in Figure C-4. From this figure, it is estimated the design-basis spectral velocities at $5 \mathrm{~Hz}$ and $10 \mathrm{~Hz}$, for $5 \%$ damping, are $7.5 \mathrm{in} / \mathrm{sec}(17.55 \mathrm{~cm} / \mathrm{sec})$ and $3.2 \mathrm{in} / \mathrm{sec}(7.5 \mathrm{~cm} / \mathrm{sec})$, respectively.

Risk Engineering, Inc. (1993), conducted a probabilistic seismic hazard evaluation of the PVNGS site. The resulting seismic hazard curves for $5-\mathrm{Hz}$ and $10-\mathrm{Hz}$ spectral velocities ( $5 \%$ damping) are shown in Figures C-5 and C-6. Comparing the design response spectrum with the hazard curves, it can be seen that the mean probabilities of exceeding the PVNGS seismic design basis at $5 \mathrm{~Hz}$ and $10 \mathrm{~Hz}$ are approximately $4.5 \mathrm{E}-05 / \mathrm{yr}$ and $3.2 \mathrm{E}-05 / \mathrm{yr}$, respectively. Thus, the composite mean probability of exceeding the design-basis spectrum at 5 and $10 \mathrm{~Hz}$ is $3.8 \mathrm{E}-05 / \mathrm{yr}$. This low exceedance probability is consistent with the low seismic hazard at the PVNGS site.

\section{C.3 SAN ONOFRE NUCLEAR GENERATING STATION}

The SONGS is located on the Southern California coast, between San Diego and Los Angeles, and is operated by Southern California Edison (SCE).

To support the IPEEE study, SCE conducted a probabilistic seismic hazard analysis of the SONGS site. Figure C-7 (SCE 1995) shows mean and fractile seismic hazard curves for the average spectral acceleration over the frequency band from 1 to $10 \mathrm{~Hz}$, and Table C-1 (SCE 1995) provides the estimated mean and median horizontal spectral accelerations at various probabilities of exceedance. (The probability value of $1.386 \mathrm{E}-04 / \mathrm{yr}$ in Table C-1 is labeled "SSE" because it corresponds to the probability of exceeding the safe shutdown earthquake peak horizontal ground acceleration, $0.67 \mathrm{~g}$.)

The horizontal-component design-basis earthquake for SONGS (Units 2 and 3) is specified as a smoothed (modified Newmark) response spectrum that is anchored to $0.67 \mathrm{~g}$. This spectrum, for $5 \%$ damping, is plotted in Figure C-8 (modified from SCE 1995). From this figure, the design basis spectral accelerations at 5 and $10 \mathrm{~Hz}$ are $1.5 \mathrm{~g}$ and $1.1 \mathrm{~g}$, respectively.

Using the slope of the mean hazard curve in Figure C-7 to interpolate the $5-\mathrm{Hz}$ and $10-\mathrm{Hz}$ exceedance probabilities provided in Table $\mathrm{C}-1$, it is estimated that the mean probability of exceeding the SONGS design-basis spectral acceleration value of $1.5 \mathrm{~g}$ at $5 \mathrm{~Hz}$ is $3.0 \mathrm{E}-04 / \mathrm{yr}$. Similarly, it is estimated that the mean probability of exceeding $1.1 \mathrm{~g}$ at $10 \mathrm{~Hz}$ is also $3.0 \mathrm{E}-04 / \mathrm{yr}$. Thus, the composite mean probability of exceeding the SONGS design-basis spectrum at 5 and $10 \mathrm{~Hz}$ is estimated to be $3.0 \mathrm{E}-04 / \mathrm{yr}$. 
Topical Report YMP/TR-003-NP, Rev. 1

Seismic Design Methodology for a Geologic Repository at Yucca Mountain

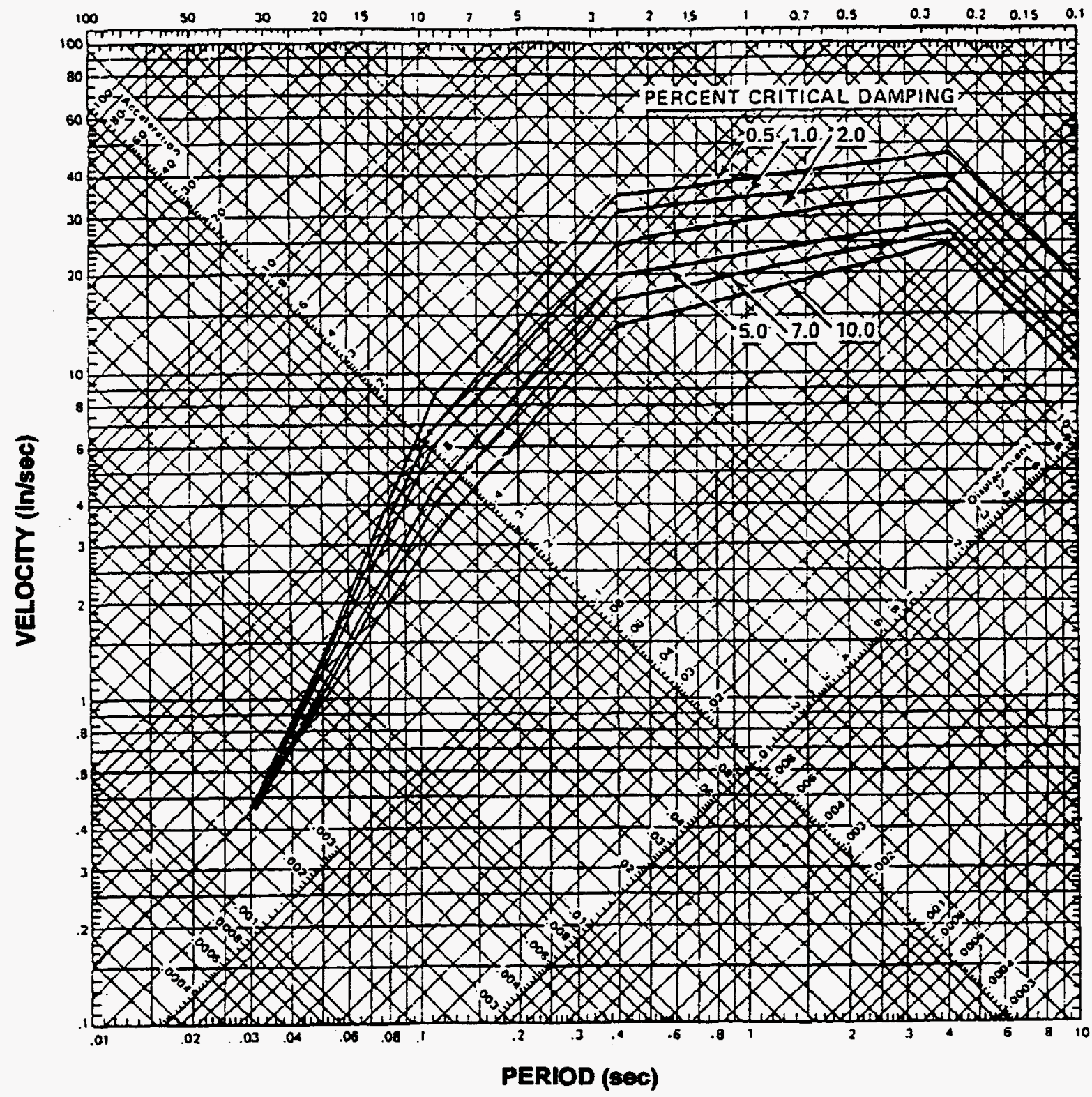

B-4.CDR.YMP.REPORTS.SEBMCT-1068 BEISMIC TOPICAL REPORT

Figure C-4. Horizontal Design Spectra, Palo Verde Nuclear Generating Station 
PALO VERDE - SOIL (5-Hz PSV)

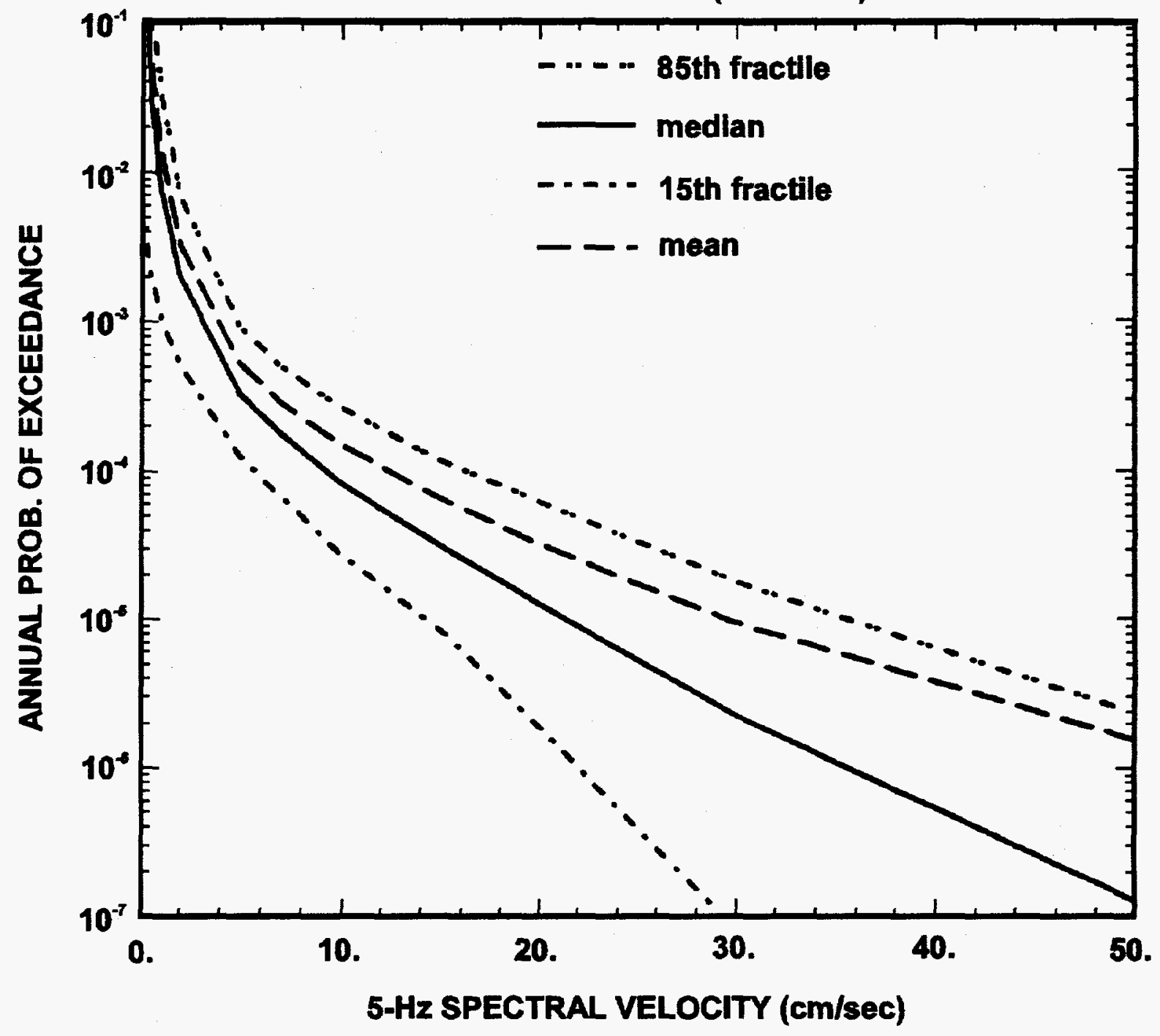
B-5.COR.YMP.REPORTS.8EISMICA-2405
SEISIML TOPICAL REPORT

Figure C-5. Seismic Hazard (5 Hz), Palo Verde Site 


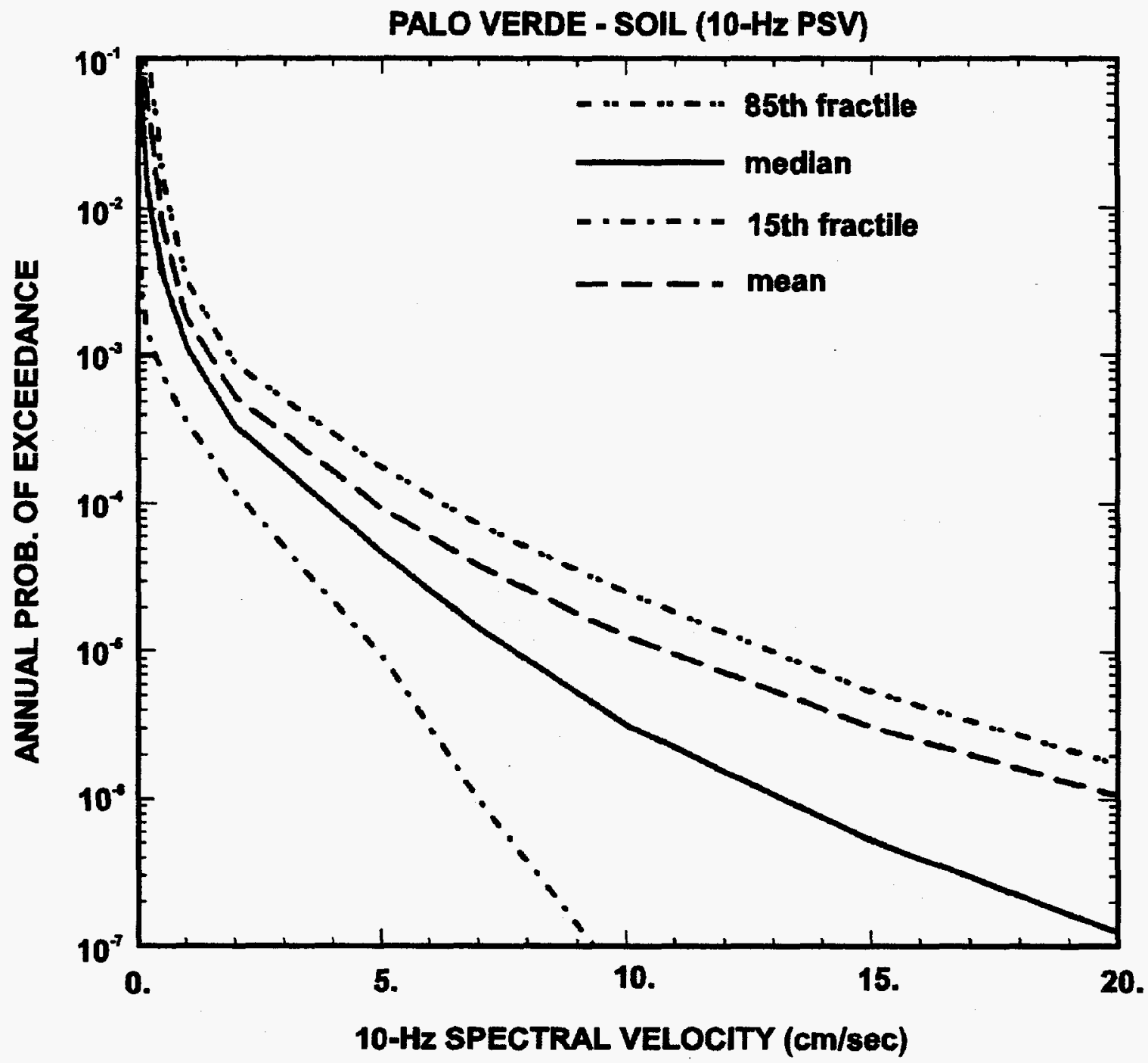

Q-8.CDR.YMP.REPORTE.6EISAICN-24-95 SEISMIC TOPICAL REPORT

Figure C-6. Seismic Hazard $(10 \mathrm{~Hz})$, Palo Verde Site 


\section{HORIZONTAL HAZARD CURVES AVERAGE $1 \mathrm{~Hz}$ TO $10 \mathrm{~Hz}$}

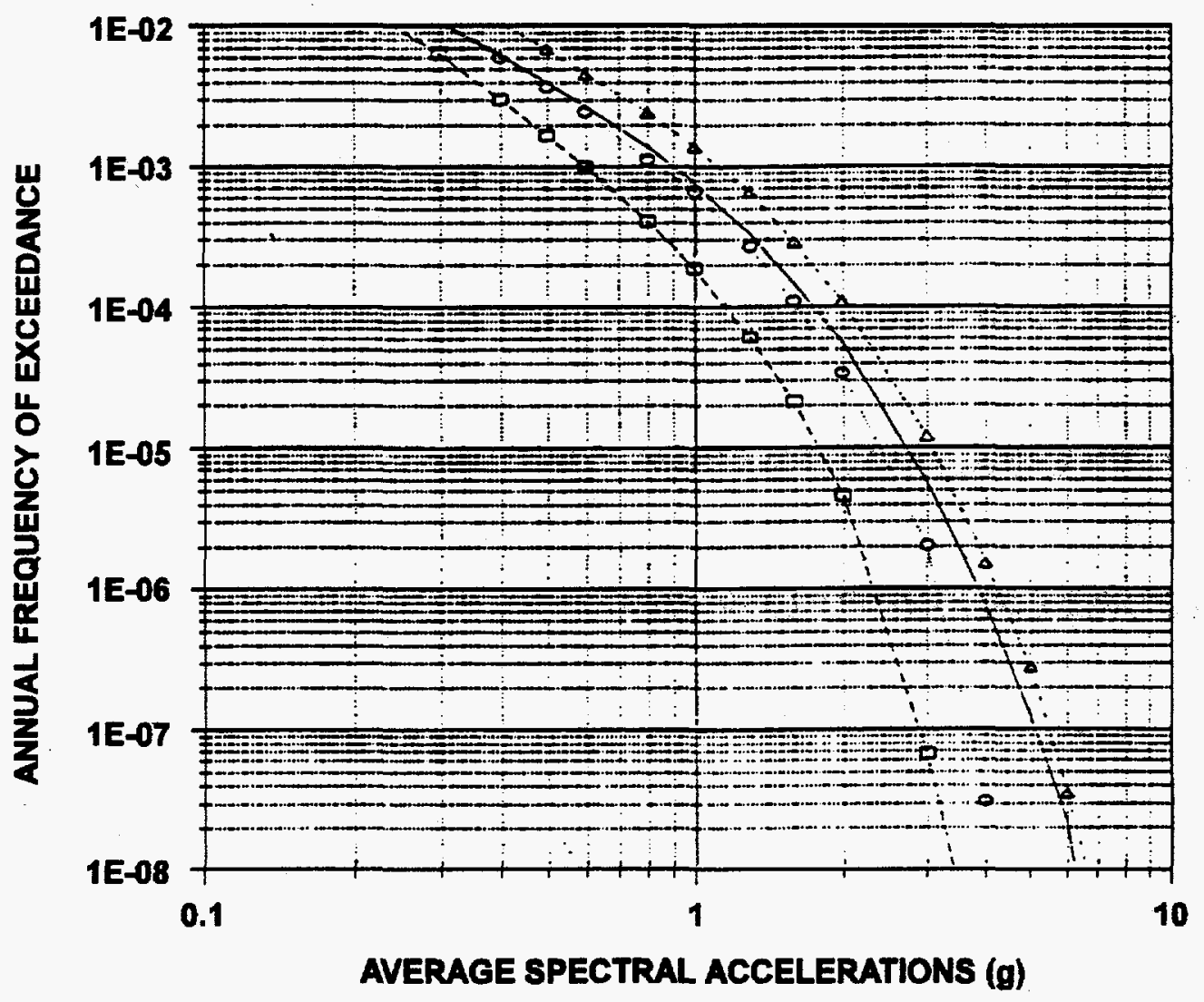

Mean

Figure C-7. Seismic Hazard (1-10 Hz), San Onofre Site 


\begin{tabular}{|c|c|c|c|c|c|c|c|}
\hline Probability & & $\mathrm{S}_{\mathrm{a}}(25 \mathrm{~Hz})$ & $S_{2}(10 \mathrm{~Hz})$ & $\mathrm{S}_{\mathrm{a}}(5 \mathrm{~Hz})$ & $\mathrm{S}_{\mathrm{a}}(2.5 \mathrm{~Hz})$ & $S_{a}(1 \mathrm{~Hz})$ & $\mathrm{S}_{\mathrm{z}}(0.5 \mathrm{~Hz})$ \\
\hline $1 \mathrm{E}-08$ & $\begin{array}{c}\text { mean } \\
\text { median }\end{array}$ & $\begin{array}{l}2.712 \\
2.002 \\
\end{array}$ & $\begin{array}{l}5.315 \\
3.050\end{array}$ & $\begin{array}{l}6.962 \\
4.132\end{array}$ & $\begin{array}{l}6.816 \\
4.049\end{array}$ & $\begin{array}{l}4.938 \\
3.727 \\
\end{array}$ & $\begin{array}{l}2.109 \\
1.913\end{array}$ \\
\hline $1 \mathrm{E}-5$ & $\begin{array}{c}\text { mean } \\
\text { median }\end{array}$ & $\begin{array}{l}1.198 \\
1.072\end{array}$ & $\begin{array}{l}2.157 \\
1.913\end{array}$ & $\begin{array}{l}3.044 \\
2.662\end{array}$ & $\begin{array}{l}2.714 \\
2.491\end{array}$ & $\begin{array}{l}1.550 \\
1.526\end{array}$ & $\begin{array}{l}.858 \\
.832\end{array}$ \\
\hline $2 \mathrm{E}-5$ & $\begin{array}{c}\text { mean } \\
\text { median }\end{array}$ & $\begin{array}{c}1.071 \\
.973\end{array}$ & $\begin{array}{l}1.919 \\
1.726\end{array}$ & $\begin{array}{l}2.696 \\
2.415\end{array}$ & $\begin{array}{l}2.443 \\
2.266\end{array}$ & $\begin{array}{l}1.376 \\
1.368\end{array}$ & $\begin{array}{l}.758 \\
.736\end{array}$ \\
\hline $1 E-4$ & $\begin{array}{c}\text { mean } \\
\text { median }\end{array}$ & $\begin{array}{l}.795 \\
.730\end{array}$ & $\begin{array}{l}1.402 \\
1.311\end{array}$ & $\begin{array}{l}1.964 \\
1.804\end{array}$ & $\begin{array}{l}1.799 \\
1.963\end{array}$ & $\begin{array}{l}1.007 \\
1.018\end{array}$ & $\begin{array}{l}.543 \\
.528\end{array}$ \\
\hline $2 \mathrm{E}-4$ & $\begin{array}{c}\text { mean } \\
\text { median }\end{array}$ & $\begin{array}{l}.674 \\
.630\end{array}$ & $\begin{array}{l}1.195 \\
1.129\end{array}$ & $\begin{array}{l}1.652 \\
1.544\end{array}$ & $\begin{array}{l}1.542 \\
1.467\end{array}$ & $\begin{array}{l}.857 \\
.866\end{array}$ & $\begin{array}{l}.448 \\
.446\end{array}$ \\
\hline $1 \mathrm{E}-3$ & $\begin{array}{c}\text { mean } \\
\text { median }\end{array}$ & $\begin{array}{l}.423 \\
.400\end{array}$ & $\begin{array}{l}.729 \\
.710\end{array}$ & $\begin{array}{c}1.029 \\
.976\end{array}$ & $\begin{array}{l}.985 \\
.952\end{array}$ & $\begin{array}{l}.544 \\
.548\end{array}$ & $\begin{array}{l}.283 \\
.278\end{array}$ \\
\hline $2 \mathrm{E}-3$ & $\begin{array}{c}\text { mean } \\
\text { median }\end{array}$ & $\begin{array}{l}.334 \\
.320\end{array}$ & $\begin{array}{l}.552 \\
.531\end{array}$ & $\begin{array}{l}.783 \\
.750\end{array}$ & $\begin{array}{l}.755 \\
.733\end{array}$ & $\begin{array}{l}.423 \\
.431\end{array}$ & $\begin{array}{l}.221 \\
.217\end{array}$ \\
\hline $\begin{array}{l}1.715 \times 10^{-6} \\
\left(2 \times \mathrm{SSE}^{*}\right)\end{array}$ & $\begin{array}{c}\text { mean } \\
\text { median }\end{array}$ & $\begin{array}{l}1.516 \\
1.293 \\
\end{array}$ & $\begin{array}{l}2.813 \\
2.384 \\
\end{array}$ & $\begin{array}{l}3.972 \\
3.280 \\
\end{array}$ & $\begin{array}{l}3.461 \\
3.034 \\
\end{array}$ & $\begin{array}{l}2.060 \\
1.933 \\
\end{array}$ & $\begin{array}{l}1.128 \\
1.081 \\
\end{array}$ \\
\hline $\begin{array}{l}1.386 \times 10^{-4} \\
\left(\mathrm{SSE}^{*}\right)\end{array}$ & $\begin{array}{c}\text { mean } \\
\text { median }\end{array}$ & $\begin{array}{l}.735 \\
.681\end{array}$ & $\begin{array}{l}1.301 \\
1.227\end{array}$ & $\begin{array}{l}1.810 \\
1.676\end{array}$ & $\begin{array}{l}1.673 \\
1.583\end{array}$ & $\begin{array}{l}.934 \\
.945\end{array}$ & $\begin{array}{l}.522 \\
.507\end{array}$ \\
\hline
\end{tabular}

* safe shutdown earthquake 


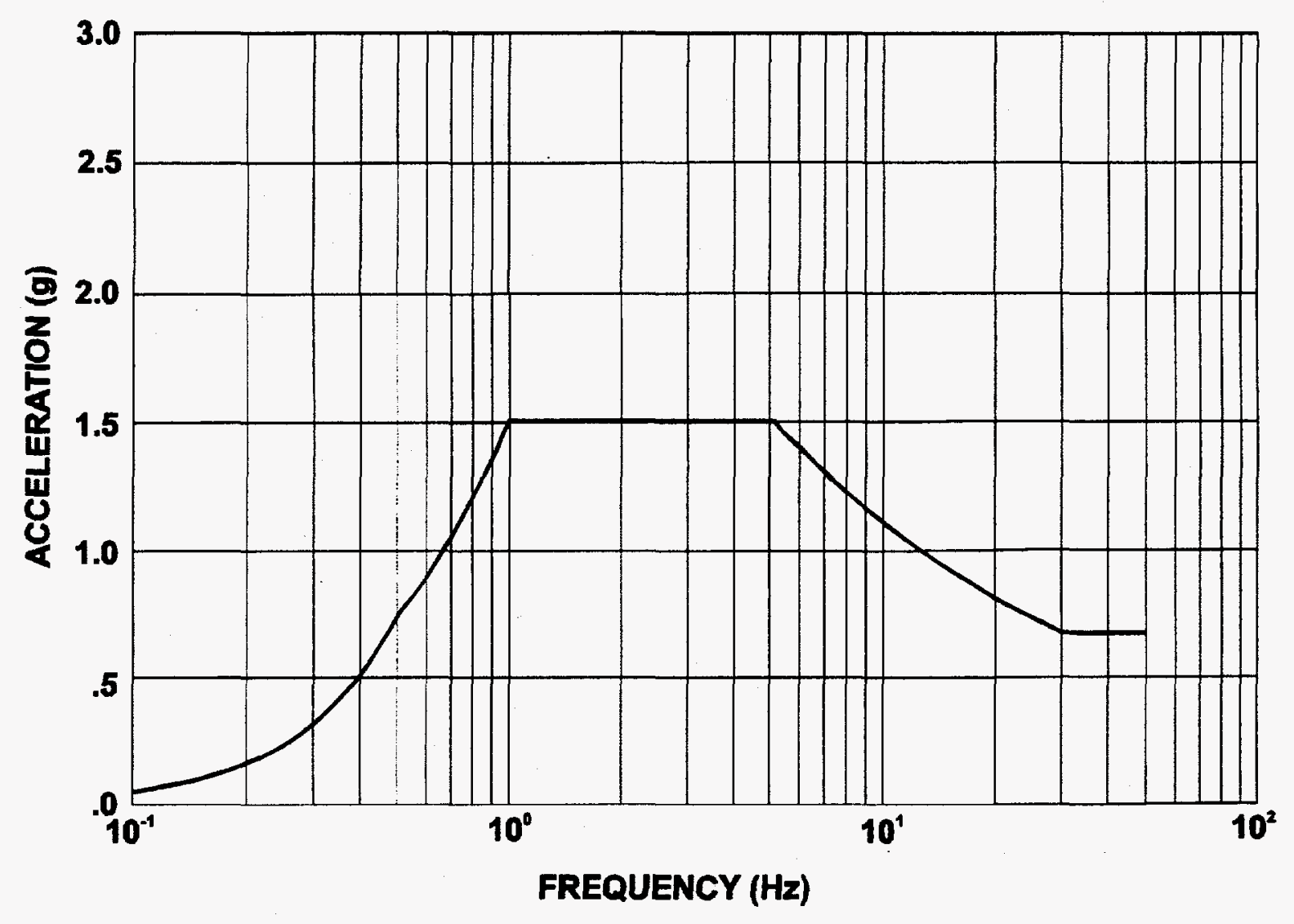

(Modified from SCE, 1995)

B-8.CDR. YMP.REPORTB.8EBMICA-13-08 SEISIMC TOPICNL REPORT

Figure C-8. Horizontal Design Spectrum, San Onofre Nuclear Generating Station 


\section{C.4 WASHINGTON NUCLEAR PLANT 2}

WNP-2 is located near Hanford, Washington, and is operated by the Washington Public Power Supply System (WPPSS).

As an input to the IPEEE study for WNP-2, Geomatrix Consultants (1994) conducted a probabilistic seismic hazard analysis of the site. The resulting mean uniform hazard spectra $(5 \%$ damping) are plotted in Figure C-9.

The horizontal-component design basis response spectra for WNP-2 are shown in Figure C-10, taken from the WNP-2 IPEEE report (WPPSS 1995). From this figure, the design basis spectral accelerations (5\% damping) at $5 \mathrm{~Hz}$ and $10 \mathrm{~Hz}$ are $0.6 \mathrm{~g}$ and $0.4 \mathrm{~g}$, respectively.

Figure C-9 shows that the return period for $0.6 \mathrm{~g}$ spectral acceleration at $5 \mathrm{~Hz}$ is about $4500 \mathrm{yr}$ (i.e., the exceedance probability is approximately $2.2 \mathrm{E}-04 / \mathrm{yr}$ ). Similarly, the return period of 0.4 $\mathrm{g}$ spectral acceleration at $10 \mathrm{~Hz}$ is about $2950 \mathrm{yr}$, for an exceedance probability of approximately $3.4 \mathrm{E}-04 / \mathrm{yr}$. Taking the average of the two probabilities, the composite mean exceedance probability is approximately $2.8 \mathrm{E}-04 / \mathrm{yr}$.

\section{C.5 WASHINGTON NUCLEAR PLANT 3}

WNP-3 at Satsop, Washington, was only partially constructed and has now been canceled. However, it is included in this analysis because its seismic design basis was provisionally accepted by NRC staff (NRC 1991a). (NRC acceptance was given with the caveat that the safe shutdown earthquake would be reviewed again should the request for an operating license be reactivated, in light of any new information that becomes available.)

Geomatrix Consultants (1988) developed fractile seismic hazard curves for peak horizontal ground acceleration and spectral accelerations at periods of $0.15,0.80$, and 2.00 seconds. The hazard curves for peak ground acceleration and $0.15-\mathrm{sec}(6.67 \mathrm{~Hz})$ spectral velocities are shown in Figures $\mathrm{C}-11$ and $\mathrm{C}-12$.

The design basis response spectrum for WNP-3 was a Regulatory Guide 1.60 (AEC 1973) standard response spectral shape anchored to a peak horizontal ground acceleration of $0.32 \mathrm{~g}$ (WPPSS 1982). The Regulatory Guide 1.60 horizontal-component design spectra, scaled to $1-\mathrm{g}$ horizontal acceleration, are reproduced in Figure C-13. The peak spectral velocity of the $5 \%$ damped standard spectrum at $6.67 \mathrm{~Hz}$ (corresponding to a period of $0.15 \mathrm{sec}$ ) is close to $30 \mathrm{in} / \mathrm{sec}$. Scaling this value by 0.32 and converting to metric units, $22.5 \mathrm{~cm} / \mathrm{sec}$ is obtained for the WNP-3 design basis spectral velocity at $6.67 \mathrm{~Hz}$.

Figure $\mathrm{C}-11$ indicates that the median probability of exceeding $0.32-\mathrm{g}$ peak horizontal acceleration at the WNP-3 site is about $1.3 \mathrm{E}-03 / \mathrm{yr}$. Figure C-12 shows that the median probability of exceeding $22.5 \mathrm{~cm} / \mathrm{sec}$ peak spectral velocity at $0.15 \mathrm{sec}(6.67 \mathrm{~Hz})$ is about $2.2 \mathrm{E}-$ 04/yr. The median probabilities of exceeding the design-basis spectral velocities at $5 \mathrm{~Hz}$ and 10 $\mathrm{Hz}$ are expected be close to this value, with the $10-\mathrm{Hz}$ value probably being higher, given that the exceedance probability appears to increase between $6.67 \mathrm{~Hz}$ and the high frequency that is represented by the peak ground acceleration. In addition, mean values are expected to be higher than median values. It is concluded, therefore, that the composite mean probability of exceeding the WNP-3 design basis spectrum at 5 and $10 \mathrm{~Hz}$ is greater than $2.2 \mathrm{E}-04 / \mathrm{yr}$. 


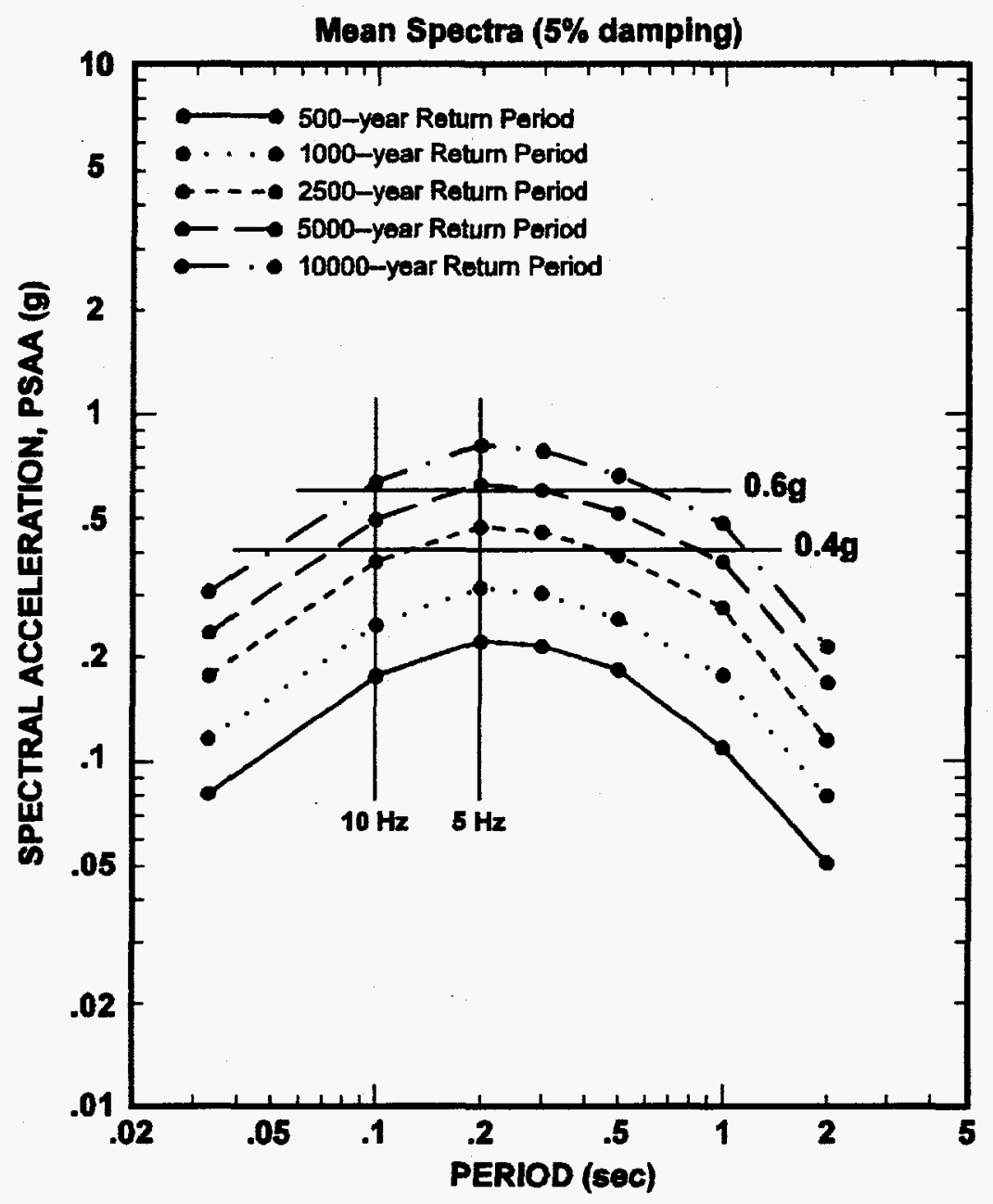

B-C.CDR.YMP.REPORTB. 8EIBMIC6-25-66 SEISMIC TOPICAL REPORT

Figure C-9. Uniform Hazard Spectra, Washington Nuclear Plant 2 Site 


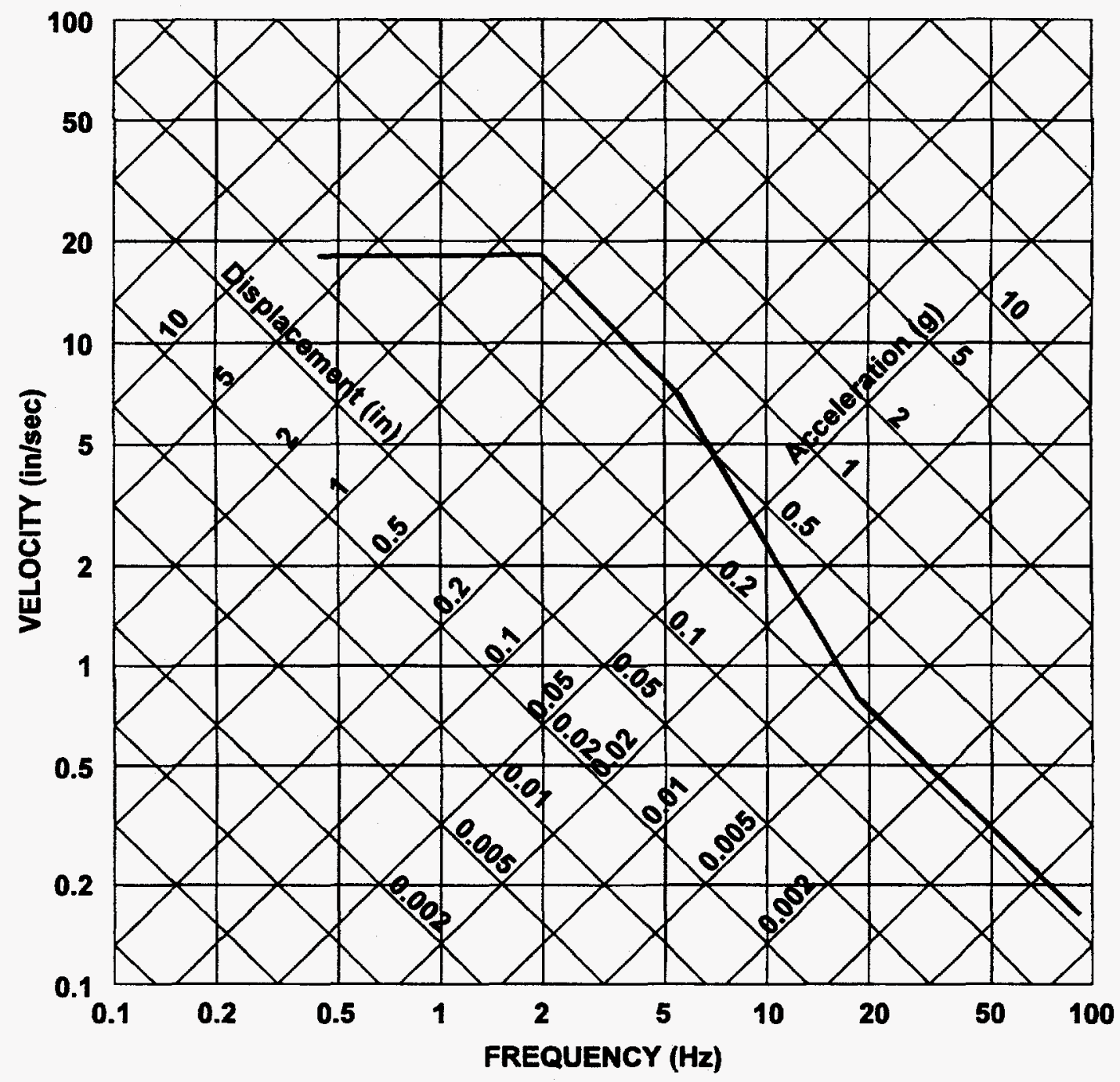

C-10.CDR.YMP.REPORTS.SEISMIC/8-30-98 SEISMIC TOPICAL REPORT

Figure C-10. Horizontal Design Spectrum, Washington Nuclear Plant 2 Site 


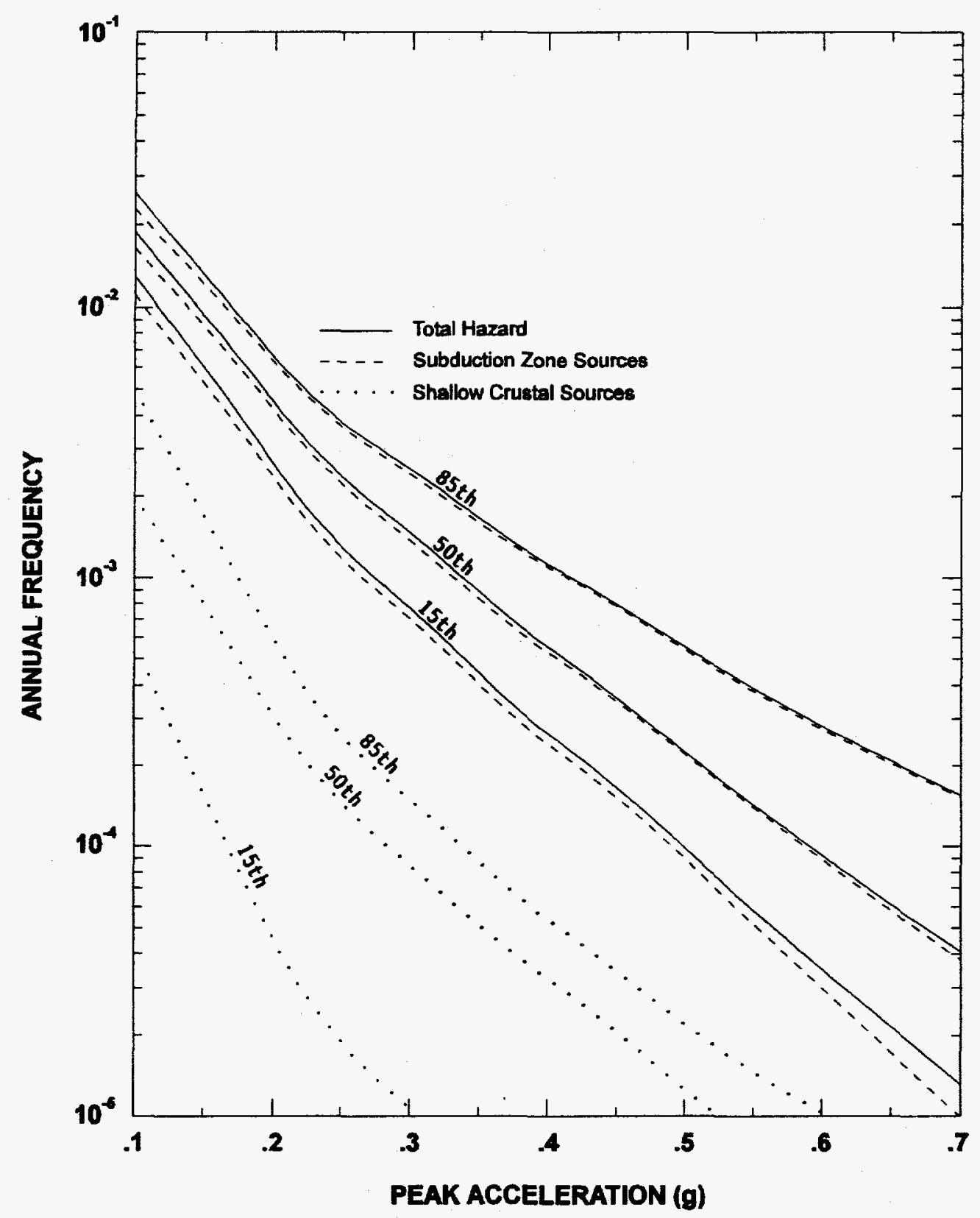
B-11.COR.YMP.REPORTS. BEISMIC/6-25-68
SEISMIC TOPICAL REPORT

Figure C-11. Seismic Hazard (PGA), Washington Nuclear Plant 3 Site 


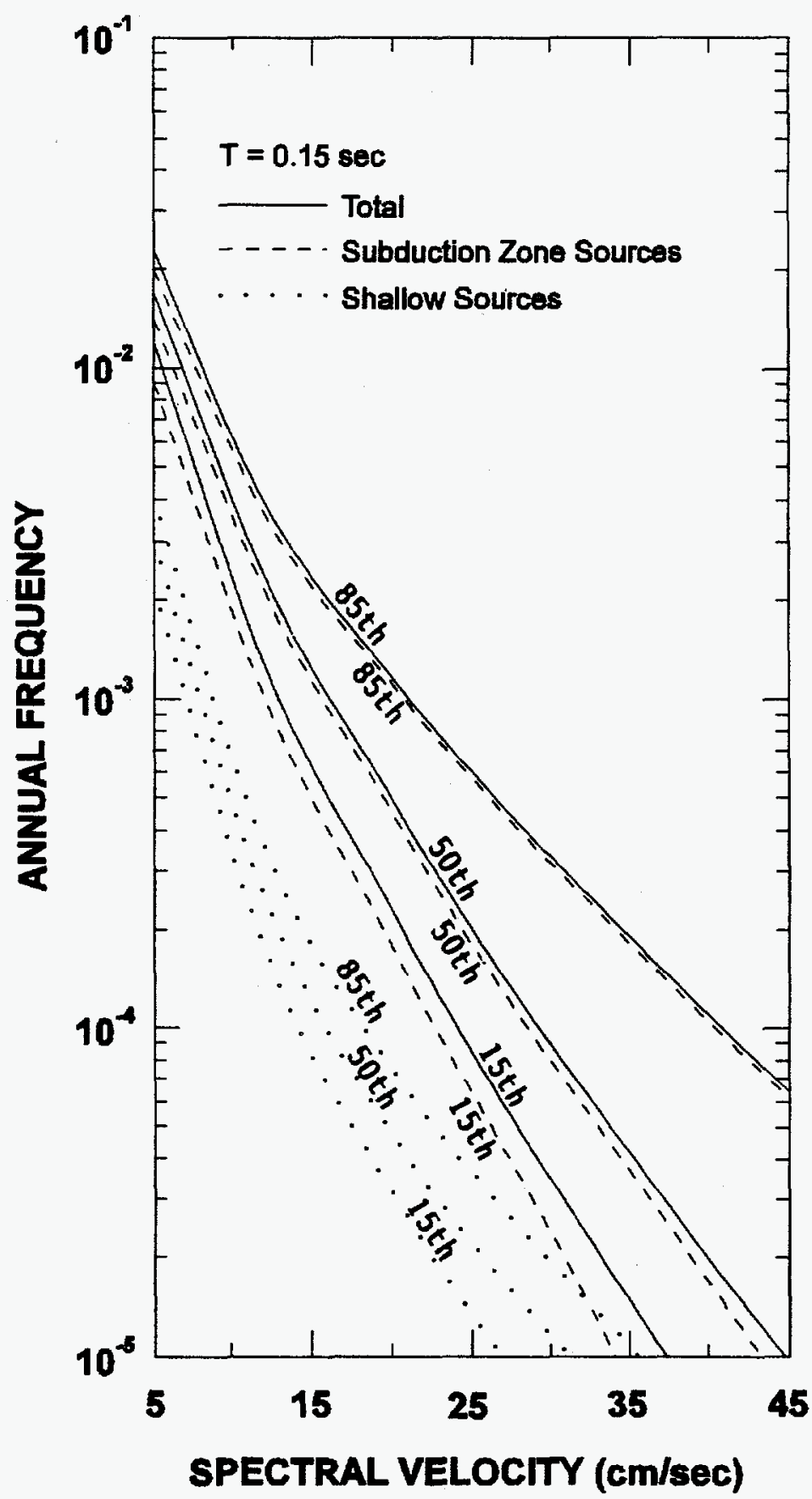

B-12.CDR.YMP.REPORTS.SEISMICT-26-96 SEISMIC TOPICAL REPORT

Figure C-12. Seismic Hazard $(0.15 \mathrm{sec})$ Washington Nuclear Plant 3 Site 




B-13.CDR.YMP.REPORTS.8EISMMC7-1000 SEISMIC TOPICAL REPORT

Figure C-13. Regulatory Guide 1.60 Horizontal Design Spectra, Scaled to $1 \mathrm{~g}$ Horizontal Ground Acceleration 


\section{C.6 SUMMARY}

Published information was compiled regarding the probabilities of exceeding the NRC-accepted $5 \%$-damped design response spectra of nuclear power plants in the western United States. From this information, the composite (arithmetic average) mean probability of exceeding the design basis spectra at 5 and $10 \mathrm{~Hz}$. was calculated or estimated. Table C-2 summarizes results of the compilation.

Table C-2. Summary of Composite Mean Exceedance Probabilities for Nuclear Power Plants in the Western United States

\begin{tabular}{|l|c|}
\hline \multicolumn{1}{|c|}{ Plant Name } & Composite Mean Exceedance Probability \\
\hline Diablo Canyon & $\approx 1.7 \mathrm{E}-04 / \mathrm{yr}$ \\
\hline Palo Verde & $3.8 \mathrm{E}-05 / \mathrm{yr}$ \\
\hline San Onofre & $3.0 \mathrm{E}-04 / \mathrm{yr}$ \\
\hline Washington Nuclear Plant 2 & $2.8 \mathrm{E}-04 / \mathrm{yr}$ \\
\hline Washington Nuclear Plant 3 & $>2.2 \mathrm{E}-04 / \mathrm{yr}$ \\
\hline Sample Mean & $>2.0 \mathrm{E}-04 / \mathrm{yr}$ \\
\hline Sample Median & $>2.2 \mathrm{E}-04 / \mathrm{yr}$ \\
\hline
\end{tabular}




\author{
APPENDIX D \\ EXAMPLES OF TUNNEL DESIGN AND PERFORMANCE THROUGH FAULTS
}




\section{APPENDIX D}

\section{EXAMPLES OF TUNNEL DESIGN AND PERFORMANCE THROUGH FAULTS}

This appendix reviews case histories of tunnels that have been, or may potentially be, subjected to earthquake-induced fault displacement. Although the database is limited and consists mainly of transportation and water tunnels, the cases provide information for the fault-displacement design of proposed underground facilities at Yucca Mountain, as discussed in Section 4 of this report. Many of these cases, up to about the end of the $1970 \mathrm{~s}$, were reviewed and presented by Brown et al. (U.S. Department of Transportation 1981). Most examples are of civil tunnels along the coast of California and in Japan, a geographic bias that apparently reflects the frequent coincidence of active faults and civil structures in those regions. A few examples are given of the support of deep African mine tunnels subjected to induced seismicity.

Fault displacement in most of the case histories is due to rupture during an earthquake, although a few cases are given where fault creep is the primary source of movement. Emphasis in this review is on reporting the manner of faulting and the extent of damage to the structure. In addition, design and construction methods used for dealing with potential displacement are discussed.

\section{D.1 EXAMPLES FROM NORTHERN CALIFORNIA}

\section{D.1.1 Southern Pacific Railroad Tunnel, Santa Clara County}

A 1,890-m long Southern Pacific Railroad tunnel extends through the Santa Cruz Mountains and crosses the San Andreas Fault near Wright Station. Damage to the tunnel by movement along the San Andreas Fault during the 1906 San Francisco earthquake is discussed by Louderback (1950) and Brown et al. (U.S. Department of Transportation 1981). The San Francisco earthquake is estimated to have had a magnitude of 8.25. Associated with the earthquake, a right-lateral displacement of $1.4 \mathrm{~m}$ occurred along a shear zone intersecting the tunnel about $120 \mathrm{~m}$ from the northeast portal. During reconstruction, a survey found that horizontal displacement of the tunnel decreased from this maximum offset near one end to zero about $1,500 \mathrm{~m}$ further into the tunnel. Damage in the vicinity of the maximum offset included crushing of timber supports, heaving of rails, and rockfall. Some railroad ties were broken in the middle. Other shear zones of similar orientation had minor offsets; and at the ground surface immediately above the tunnel, larger displacements were found along the San Andreas fault trace than were observed underground. At present the tunnel is closed, although apparently it remains functional, as a current study is considering the feasibility of using the tunnel for a commuter rail line (ENR 1994).

\section{D.1.2 San Andreas Dam Overflow Tunnel, Santa Clara County}

During the 1906 San Francisco earthquake, fault displacement occurred in ground forming the left abutment of the San Andreas dam. A 2.1- to 2.4-m diameter overflow tunnel with 432-mm thick brick and concrete walls was cut in two by the fault movement. The fault displacement at the tunnel was $1.5 \mathrm{~m}$, and the tunnel was "badly crushed" for $8.5 \mathrm{~m}$ at its outlet end (Louderback 1950, p. 147). No mention is made of repair or reconstruction. 


\section{D.1.3 Coyote Dam Outlet Tunnel, Santa Clara County}

Frame (1995) describes a lining design for the tunnel outlet at the Coyote Dam on Coyote Creek. Coyote Dam is an earthfill dam constructed in 1935 to 1936 and operated by the Santa Clara Valley Water District. Modifications, completed in 1991, included the construction of a new water outlet tunnel approximately $215 \mathrm{~m}$ long and $3 \mathrm{~m}$ in diameter to replace an existing outlet endangered by siltation. The tunnel, excavated through sandstone, conglomerate, and shale, passes through a potentially active fault zone composed of clayey gouge which is considered to be a splay of the nearby Calaveras Fault. Although the tunnel has experienced no fault rupture, the Calaveras Fault has an overall slip rate of about $15 \mathrm{~mm}$ per year and is considered the source of historic earthquakes, the maximum of which was a magnitude 6.6 event that occurred in 1911 .

The outlet tunnel has a reinforced concrete lining. A 56-m long section of the lining was designed to cope with potential movement along the fault zone by the use of articulated joints at 3-m centers. Each joint has been constructed to withstand $0.3 \mathrm{~m}$ of fault displacement in any direction without failure of the lining. Some features of this construction are (1) the concrete joint itself which is formed as an open joint to allow movement, (2) sealant in the joint and a PVC waterstop across the joint to prevent water penetration, and (3) reinforcing bars installed with bond breakers to permit longitudinal slip along the bars.

\section{D.1.4 Berkeley Hills Tunnels, Alameda and Contra Costa Counties}

The four tunnels discussed below are all affected by fault creep on the Hayward Fault. Fault creep has been defined by Burford et al. in a 1978 U.S. Geological Survey publication (U.S. Department of Transportation 1981) as "gradual, aseismic slip that is apparently produced by viscous yielding within a relatively weak fault gouge." The word "slippage" is considered by Brown et al. (ibid.) to be the more appropriate term since "creep" refers to the material behavior phenomenon of plastic flow under a sustained load. However, fault creep is used here since the term is less ambiguous.

\section{D.1.4.1 Bay Area Rapid Transit Tunnels, Alameda County}

In the San Francisco Bay Area, the Bay Area Rapid Transit twin tunnels pass through the Berkeley Hills. The tunnels were constructed in 1967 and are $4,950 \mathrm{~m}$ long, $30 \mathrm{~m}$ apart, and have an inside diameter of $5.3 \mathrm{~m}$. They have about $70 \mathrm{~m}$ of cover where they cross the Hayward Fault near the west portal. The behavior of the tunnels due to fault creep on the Hayward Fault since construction in 1967 has been examined and evaluated in detail by Brown et al. (ibid.). Survey data and observations have indicated that fault creep of 6 to $8 \mathrm{~mm}$ a year is associated with a shear zone about $215 \mathrm{~m}$ wide.

During tunnel excavation in the Hayward Fault zone, squeezing ground broke support timbers and distorted steel sets, even though invert struts were used on $610-\mathrm{mm}$ centers. As a consequence, a substantial supporting structure was installed at the fault zone, resulting in a relatively stiff tunnel section. Consideration of long-term rock loads led to a circular section for the final tunnel lining, although a horseshoe-shaped tunnel was initially excavated. A drainage system was included to reduce possible long-term hydrostatic loading.

Neither the circular lining section nor the drainage system specifically pertained to a seismic design. However, in consideration of fault offset potential, Brown et al. (ibid.) state that "It was also considered desirable to have a flexible lining; consequently, the final lining was kept as thin as practicable $(457 \mathrm{~mm})$." Longitudinal reinforcement steel was added, presumably for added 
strength. Although it is stated, "... to accommodate possible movement along the Hayward Fault during an earthquake, a tunnel section larger than that required for the operation of BART [Bay Area Rapid Transit] trains was constructed ...," other reasons, having to do with rolling stock clearances, are given for actually having an inside radius larger than that used in other parts of the system. Also, sufficiently large fault displacements (design displacements of "two feet horizontal and one foot vertical") were believed to be accommodated with no change in the designed tunnel radius if fault movement were distributed over about $100 \mathrm{~m}$ of tunnel rather than on a single plane. For these reasons, it is doubtful the tunnel was ever constructed with an enlarged section just for the purpose of accommodating fault displacement.

Of particular interest, since fault creep on the Hayward Fault is now well documented, is that fault creep along the Hayward Fault was not considered at the time of design of the Bay Area Rapid Transit tunnels. During construction this aspect of fault behavior was brought to the attention of the designers, and the track was laid on wooden ties to allow future realignment. At the same time it was decided to instrument the section of the northern tunnel where it crosses the Hayward Fault (ibid.).

\section{D.1.4.2 Claremont Tunnel, Alameda County}

The Claremont tunnel example is similar to that of the Bay Area Rapid Transit tunnels, the west portals of which are located $245 \mathrm{~m}$ south of the Claremont tunnel. The Claremont tunnel was constructed just prior to 1929 to transport water through the Berkeley Hills to the east side of the San Francisco Bay. The tunnel is 5,507 $\mathrm{m}$ long and has a horseshoe-shaped cross section about $2.74 \mathrm{~m}$ high and $2.74 \mathrm{~m}$ wide. Most of the tunnel is lined with unreinforced concrete at least $355 \mathrm{~mm}$ thick, where placed over initial timber supports, and $300 \mathrm{~mm}$ thick where untimbered. Heavy timber and reinforced concrete were used in some sections, especially where squeezing ground was encountered. The tunnel crosses the Hayward Fault near the west portal. A 1964 inspection found that the concrete lining in the fault zone was cracked and the invert was buckled. A survey determined that $168 \mathrm{~mm}$ of right lateral offset had occurred since construction. In response to the fault-related damage, the tunnel section in the Hayward Fault was relined.

\section{D.1.4.3 San Pablo Tunnel, Contra Costa County}

The San Pablo tunnel was constructed between 1917 and 1920 to transport water from the San Pablo reservoir through the Berkeley Hills to the east side of the San Francisco Bay. The tunnel is $4,134 \mathrm{~m}$ long and in cross section is $2.29 \mathrm{~m}$ high and $2.44 \mathrm{~m}$ wide. The tunnel crosses two major active fault zones, the Hayward and the Wildcat, as well as several unnamed faults. The Hayward Fault was encountered during construction at a depth between 70 and $100 \mathrm{~m}$. The fault zone material was described as serpentine that was so sheared that it flowed into the tunnel under its own weight and was difficult to control.

Repairs and inspections made between construction and the late 1970 s demonstrate the continuous nature of the deformation to which the tunnel has been subjected. In 1933 a major break occurred at a distance between 625 and $687 \mathrm{~m}$ from the west portal near the Hayward Fault crossing. A heavily reinforced concrete lining was constructed at that location to repair the tunnel. From 1952 to 1953 , the tunnel invert was replaced and a new lining constructed inside the existing lining. During inspection in 1969, a circumferential crack was noted at $981 \mathrm{~m}$ and longitudinal cracks were seen at $1,945 \mathrm{~m}$ and $2,015 \mathrm{~m}$. Inspection in 1978 found apparent horizontal distortion between 2,637 and $2,652 \mathrm{~m}$. 


\section{D.2 EXAMPLES FROM SOUTHERN CALIFORNIA}

\section{D.2.1 Southern Pacific Railroad Tunnels, Kern County}

In 1952 the Arvin-Tehachapi earthquake of magnitude 7.7 resulted from reverse or thrust fault movement on the White Wolf Fault (Kupfer et al. 1955). The earthquake severely damaged 18 $\mathrm{km}$ of railroad of the Southern Pacific Company at Tehachapi Pass. Fault displacements, presumably associated with an extension of the White Wolf Fault, occurred during the earthquake and affected four tunnels along the railroad. Major damage occurred to the tunnels with portions collapsed and alignments distorted. Descriptions and interpretations of the fault damage are taken from Kupfer et al. (ibid.) and from Brown et al. (U.S. Department of Transportation 1981).

A zone of faulting and fracturing from 150 to $210 \mathrm{~m}$ wide intersected two of the tunnels approximately at right angles. Bowed up tracks and ground shortening of about $3 \mathrm{~m}$ indicated local compression across the zone and evidence for reverse fault movement. The most extensive damage to the tunnels was the buckling and cracking of sidewalls. Normal faulting, which occurred after the initial reverse fault movement, was minor although normal faults in two tunnels produced vertical offset up to about a meter. The tunnels were less than $60 \mathrm{~m}$ deep in highly weathered granitic rock. In addition, they were close to the side of a valley, which may have affected tunnel damage.

The tunnels were initially timber-lined, then later relined with 300 to $600 \mathrm{~mm}$ of reinforced concrete placed over the original wood lining. Reinforcing steel was concentrated along the intrados. According to Kupfer et al. (1955), there was a marked contrast between observed characteristics of the surface fault zone and the zone seen in the tunnels. In the tunnels the zone was about $150 \mathrm{~m}$ wide and the damage was severe. On the surface, in general, fractures were few and small, and displacements were less than $300 \mathrm{~mm}$.

Reconstruction involved replacing portions of the concrete linings in some tunnels where caveins had occurred and making extensive portal repairs. However, the solution to much of the remedial work that was required was the complete reconstruction of the damaged tunnels as open cuts.

\section{D.2.2 Balboa Inlet Tunnel, San Fernando Valley}

This example is presented essentially as reported by Brown et al. (U.S. Department of Transportation 1981). The partially completed Balboa Inlet tunnel of the Metropolitan Water District of Southern California was affected by the San Fernando earthquake (magnitude 6.6) of 1971. Displacement occurred along the Santa Susanna thrust fault, which crossed the tunnel about $300 \mathrm{~m}$ from a portal. The reinforced concrete liner was cracked and there was some spalling along a 90-m section at the fault crossing. In addition, longitudinal cracking occurred in the tunnel liner for about $300 \mathrm{~m}$ on each side of the fault. The Santa Susanna Fault had been inactive since the middle Pleistocene and was not considered related to the active faults that produced the San Fernando earthquake. Movement along the Santa Susanna Fault was thus considered a response to stress changes on the nearby active fault system.

\section{D.2.3 North Outfall Replacement Sewer Tunnel, City of Los Angeles}

This description of design features of the North Outfall Replacement Sewer is from an article by Desai et al. (1989). The tunnel, as designed, is $12.6 \mathrm{~km}$ long with inside diameters varying from 2.9 to $3.75 \mathrm{~m}$. Known faults crossing the alignment include splays of the active (displacement 
within the last 11,000 years) Newport-Inglewood fault zone, and the potentially active (displacement during the last 2 million years) Overland Avenue and Charnock faults. In consideration of tunnel design to accommodate fault movements, lateral fault displacements were considered to range from 200 to $450 \mathrm{~mm}$ and vertical displacements were estimated at half the lateral values.

The concept used in the tunnel design is to surround a conduit, placed within the tunnel, with a low modulus backpacking. The conduit is protected because the backpacking provides a much greater potential for compliance between the conduit and the natural medium than would be the case with an ordinary lining system, and allows for discrete offset to occur in the surrounding medium without imposing a discrete displacement on the pipe and limits both lateral and longitudinal forces imposed on the enclosed conduit.

An important step in the development of such a tunnel design scheme through a fault zone is the delineation of the actual zone of fault movement. Other considerations have to do with thickness and properties of the backpacking and design of pipe joints and their location relative to the fault location. The tunnel designers used segmented precast pipes with joints having specially configured neoprene seals to accommodate relatively high rotational, extensional, and compressional strains.

\section{D.2.4 Aqueduct Tunnels, Northern and Southern California}

There are a number of water transmission tunnels between the Sierra Nevada and the San Francisco Bay Area and between the Colorado River and the Los Angeles area that pass through active faults. Although there were apparently no design measures to cope with potential fault displacement, additional water storage near the pipeline terminuses and multiple water lines were believed to provide adequate contingency and redundancy in the system (Louderback 1950, p. 149). Whether these measures are adequate 45 years later is the subject of current evaluations by the affected California municipalities.

\section{D.3 EXAMPLES FROM JAPAN}

Yoshikawa and Fukuchi (1984) report on a survey by Yoshikawa of 124 cases of tunnel damage due to five earthquakes that occurred between 1923 and 1978. The "Richter magnitudes" of these earthquakes ranged from 7.0 to 7.9. Only in the two cases given below did significant damage occur due to fault movement. Fault-related damage apparently occurred within $10 \mathrm{~km}$ of the earthquake "epicentral zone," so-called because the epicenter was defined along a reach of the fault rather than at a point.

\section{D.3.1 Inatori Tunnel}

Yoshikawa and Fukuchi (1984) and Brown et al. (U.S. Department of Transportation 1981) discuss earthquake damage to the Inatori tunnel. In 1978 the "Near-Oshima" earthquake with a surface wave magnitude of $M_{s} 6.8$ produced a $1-m$, right-lateral offset on a fault intersecting the tunnel. The zone of surface rupture associated with this earthquake varied from $30 \mathrm{~m}$ to $200 \mathrm{~m}$ wide and was traced for $3 \mathrm{~km}$. Maximum displacement was $1.83-\mathrm{m}$, right-lateral and 260-mm dip slip on a steeply dipping fault.

The Inatori railroad tunnel crossed the fault at a right angle and had a cover of $90 \mathrm{~m}$. The tunnel was displaced right-laterally 500 to $700 \mathrm{~mm}$. The tunnel was constructed with a thick, nearly circular ( $4.8 \mathrm{~m}$ diameter) concrete lining and invert section designed to deal with ground 
described as fractured, volcanic, and clayey. Although severely distorted, the tunnel did not collapse. It was determined that the liner apparently was extended $200 \mathrm{~mm}$ longitudinally relative to the surrounding rock over a distance of $120 \mathrm{~m}$. Concrete buckled and fell from the crown, and sections of the sidewall were pushed into the tunnel. The tunnel was restored by removing part of the existing lining and replacing it with a concrete lining heavily reinforced with steel bars and steel fibers.

\section{D.3.2 Tanna Tunnel and New Tanna Tunnel}

Yoshikawa and Fukuchi (1984) and Brown et al. (U.S. Department of Transportation 1981) discuss earthquake damage to the Tanna tunnel. During the $1930 \mathrm{Kita}-I z u$ earthquake, with an estimated magnitude of 7.1 , left-lateral displacement of $2.7 \mathrm{~m}$ and vertical displacement of $0.6 \mathrm{~m}$ occurred along a shear zone at the working face of a drainage drift for the Tanna tunnel. Fault displacement at the ground surface, $160 \mathrm{~m}$ above the invert, was somewhat less, with a left-lateral component of $1.0 \mathrm{~m}$ and a vertical component of $0.5 \mathrm{~m}$. Displacement in the tunnel was along the Tanna Fault that happened to coincide with the face, and as a result the drainage drift was completely closed. However, the only damage to the main tunnel, which was about $0.5 \mathrm{~m}$ east of the shear zone, was cracks in the tunnel walls.

The New-Tanna tunnel, constructed "more than 20 years ago" (Yoshikawa and Fukuchi 1984) in the vicinity of the Tanna tunnel, also intersected the Tanna Fault. Design measures included a thicker lining and invert than the first Tanna tunnel. Based on an assessment that estimated a return period of 1,000 years for earthquakes on the Tanna Fault, the Japanese National Railways decided no additional design measures were needed.

\section{D.4 EXAMPLES FROM SOUTHERN AFRICA}

Deep metal mines in Africa often experience mining-induced seismicity, which results in rockbursts that jeopardize personnel safety and damage tunnels. Because of the potentially sudden and large displacements involved in these seismic events, flexible ground support systems have evolved. An example is the rock reinforcement used in a deep gold mine in Zambia (Russell et al. 1983). In this case, tunnels and other mined openings in rock have been maintained with a unique system of fully grouted steel dowels (rockbolts), wire mesh, and steel cable "lacing" stretched across the tunnel walls in a diamond pattern between the dowels. During large ground movement, this structural system provides sufficient supporting pressure to confine the rock mass, thereby maintaining its self-supporting capacity.

An example of the performance of a bolt/mesh/lacing support system is from a gold mine in South Africa (Brady and Brown 1985, p. 289) which describes the response of a 1,540-m deep haulage tunnel to a 4.0 magnitude seismic event on a fault penetrated by the tunnel. The tunnel, perhaps 4 to $5 \mathrm{~m}$ in diameter, was reinforced with $2.5-\mathrm{m}$ long grouted steel rope tendons and 7.5$\mathrm{m}$ long prestressed rock anchors. In addition, mesh and hoist rope lacing was applied to the surface of the opening. The rock was highly fractured as a result of the seismic event, several prestressed anchors failed, and closure of as much as a meter appears to have taken place. However, the damaged rock was adequately contained and the tunnel remained open.

\section{D.5 CONCLUSIONS}

In most of the tunnel design case histories there were no design provisions to accommodate fault displacement. In tunnels constructed prior to about the 1950 s, designers ignored or were unaware of the potential for fault-related damage. When damage occurred, the common approach was to 
make repairs, with the usual result being a stiffer supporting structure than was in place at the time of fault displacement. Another approach, used in the case of the shallow tunnels at Tehachapi Pass in Kern County (Section D.2.1), included partial or total reconstruction of some of the damaged tunnels as open cuts.

More recent approaches to tunnel fault displacement design have evaluated the necessity for accommodating fault displacement and if necessary have provided flexibility to allow deformation without undue disruption of the tunnel function. One example of this methodology is the North Outfall Replacement Sewer tunnel (Section D.2.3), which proposes an internal conduit or carrier pipe surrounded by a low-modulus material that is intended to sustain and distribute potential fault displacement. Another example is the flexible joint used in the Coyote Dam outlet tunnel (Section D.1.3). 


\section{APPENDIX E}

\section{REFERENCES}




\section{APPENDIX E}

\section{REFERENCES}

\section{E.1 DOCUMENTS CITED}

AEC (U.S. Atomic Energy Commission) 1973. Design Response Spectra for Seismic Design of Nuclear Power Plants, Regulatory Guide 1.60, Rev. 1. Washington, D.C.

Ahola, M.P.; Hofmann, R.B.; Hsuing, S.; and Mantenfel, R.D. 1995. "Numerical Study of the Seismic Motion Effects on Drift Stability." Proceedings of the Topical Meeting on Methods of Seismic Hazards Evaluation, Focus '95 (pp. 185-194). La Grange Park, Illinois: American Nuclear Society.

AISC (American Institute of Steel Construction) 1989. "Manual of Steel Construction: Allowable Stress Design." Ninth Edition.

APS (Arizona Public Service Company) 1978. Updated Final Safety Analysis Report for Palo Verde Nuclear Generating Stations, Units 1, 2, and 3, Rev. 6. Docket Nos. 50-528, 50-529, and 50-530.

APS 1995. Individual Plant Examination of External Events. Docket Nos. 50-528, 50-529, and 50-530. San Francisco, California.

ASCE (American Society of Civil Engineers) 1984. Guidelines for the Seismic Design of Oil and Gas Pipeline Systems. New York, New York.

ASCE 1993 Draft Seismic and Dynamic Analysis and Design Considerations for High Level Nuclear Waste Repositories. New York, New York.

ASLB (Atomic Safety and Licensing Board) 1982. Initial Decision Removing Show Cause Order and Approving Restart: General Electric Test Reactor. Majority Opinion by Dr. George Ferguson and Dr. Harry Foreman. USNRC Docket No. 50-70 SC. Washington, D.C.

ASME (American Society of Mechanical Engineers) 1991. Boiler and Pressure Vessel Code. Section III, "Rules for Construction of Nuclear Power Plant Components." New York, New York.

Barton, N.; Lien, R.; and Lunde, J. 1974. "Engineering Classification of Rock Masses for the Design of Tunnel Support." Rock Mechanics, 6:189-236. Wien, New York: Springer Verlag.

Bernreuter, D.L.; Boissonade, A.C.; and Short, C.M. 1996. Investigation of Techniques for the Development of Seismic Design Basis Using the Probabilistic Seismic Hazard Analysis. March 27, 1996, manuscript prepared for the U.S. Nuclear Regulatory Commission by Lawrence Livermore National Laboratory. Livermore, California.

Berrill, J.B. 1983. "Two-Dimensional Analysis of the Effects of Fault Rupture on Buildings with Shallow Foundations." Soil Dynamics and Earthquake Engineering. Vol. 2, No. 3.

Bieniawski, Z.T. 1984. Rock Mechanics Design in Mining and Tunneling. Boston, Massachusetts: A.A. Balkema. 
Brady, B.H.G. and Brown, E.T. 1985. Rock Mechanics for Underground Mining. London, England: George Allen \& Unwin.

Brown, I. R.; Brekke, T.L.; and Korbin, G.E. 1981. "Behavior of the Bay Area Rapid Transit Tunnels Through the Hayward Fault." Report No. UMTA-CA-06-0120-81-1. Washington D.C.: U.S. Department of Transportation, Urban Mass Transportation Administration.

BSSC (Building Seismic Safety Council) 1995. NEHRP Recommended Provisions for Seismic Regulations for New Buildings. 1994 Edition. Report No. FEMA 222A. Washington, D.C.: Federal Emergency Management Agency.

Ceylan, Z.; Bennet, S.M.; and Doering, T.W. 1995. "Seismic Structural Design for Disposal of High Level Nuclear Waste in a Geologic Repository" (pp. 195-200). Proceedings, Methods of Seismic Hazards Evaluation. La Grange Park, Illinois: American Nuclear Society.

CRWMS M\&O (Civilian Radioactive Waste Management System Management and Operating Contractor) 1994. Seismic Design Inputs for the Exploratory Studies Facility at Yucca Mountain. BAB000000-01717-5705-00001 Rev. 02. Las Vegas, Nevada.

CRWMS M\&O 1995a. Controlled Design Assumptions Document. B00000000-01717-4600-00032 Rev. 02. Las Vegas, Nevada.

CRWMS M\&O 1995b. Repository Ground Control Evaluation. BC0000000-01717-5705-00017 Rev. 00. Las Vegas, Nevada.

CRWMS M\&O 1996a. Evaluation of Geotechnical Monitoring Data from the Exploratory Studies Facility, July 1995 to June 1996. BAB000000-01717-5705-00003 Rev. 00. Las Vegas, Nevada.

CRWMS M\&O 1996b. Mined Geologic Disposal System Advanced Conceptual Design Report. B00000000-01717-5705-00027 Rev. 00. Las Vegas, Nevada.

CRWMS M\&O 1996c. Mined Geologic Disposal System Functional Analysis Document. B00000000-01717-1708-00006 Rev. 01. Las Vegas, Nevada.

CRWMS M\&O 1996d. Engineered Barrier System Performance Requirements System Study Report. BB0000000-01717-5705-00001 Rev. 00. Las Vegas, Nevada.

Desai, D.B.; Merritt, J.L.; and Chang, B. 1989. "Shake and Slip to Survive-Tunnel Design."

Proceedings of the Rapid Excavation and Tunneling Conference (pp. 13-30). Littleton, Colorado: Society for Mining Metallurgy and Exploration, Inc.

DOE (U.S. Department of Energy) 1988. Site Characterization Plan, Yucca Mountain Site, Nevada Research and Development Area, Nevada. DOE/RW-0199. Washington, D.C.: Office of Civilian Radioactive Waste Management.

DOE 1994a. Topical Report: Methodology to Assess Fault Displacement and Vibratory Ground Motion Hazards at Yucca Mountain. YMP/TR-002-NP. Las Vegas, Nevada: Office of Civilian Radioactive Waste Management. 
DOE 1994b. Natural Phenomena Hazards Design and Evaluation Criteria for Department of Energy Facilities. DOE-STD-1020-94. Washington, D.C.: Office of Scientific and Technical Evaluation.

DOE 1994c. Tectonic Effects: Evaluation of Changes in the Natural and Engineered Barrier Systems Resulting from Tectonic Processes and Events. Study Plan for 8.3.1.8.2.1, Rev. 1. Las Vegas, Nevada: Office of Civilian Radioactive Waste Management.

DOE 1994d. Q-List. YMP/90-55Q, Rev. 3. Las Vegas, Nevada: Office of Civilian Radioactive Waste Management.

DOE 1995a. Probabilistic Analyses of Vibratory Ground Motion and Fault Displacement of Yucca Mountain. Study Plan for 8.3.1.17.3.6. Las Vegas, Nevada: Office of Civilian Radioactive Waste Management.

DOE 1995b. Civilian Radioactive Waste Management System Requirements Document. DOE/RW-0406. Washington, D.C.: Office of Civilian Radioactive Waste Management.

Dowding, C.H. and Rozen, A. 1978. "Damage to Rock Tunnels from Earthquake Shaking." Journal of Geotechnical Engineering. Division of America Society of Civil Engineers, 104(GT2):175-191.

Duncan, J.M. and Lefebvre, G. 1973. "Earth Pressures on Structures Due to Fault Movement." Proceedings of the American Society of Civil Engineers, Vol. 99, No. SM12. New York, New York.

EDA (Engineering Decision Analysis, Inc.) 1980a. Additional Investigations to Determine the Effects of Combined Vibratory Motions and Surface Rupture Offset Due to an Earthquake on the Postulated Verona Fault. Report Submitted to the U.S. Nuclear Regulatory Commission. Docket No. 50-70 SC. Palo Alto, California.

EDA 1980b. Summary Report Structural Seismic Investigations of General Electric Test Reactor. Report Submitted to U.S. Nuclear Regulatory Commission. Docket No. 50-70 SC. Palo Alto, California.

ENR 1994. "Looking at Reviving Line." Engineering News Record. October 24, 1994 (p. 20). McGrawHill.

EPRI (Electric Power Research Institute) 1989. Seismic Hazard Methodology for the Central and Eastern United States. Vols. 1-10. NP-4726. Palo Alto, California.

Fishman, K.L. 1988. Constitutive Modeling of Idealized Rock Joints Under Quasi-Static and Cyclic Loading. Ph.D. Dissertation. University of Arizona.

Frame, P.A. 1995. "Evaluation of Fault Offset for the Coyote Dam Outlet Work" (pp. 26-28). AEG News, Vol. 38, No. 2. Association of Engineering Geologists.

Gauthier, H.; Wilson, M.L.; Borns, D.J.; and Arnold, B.W. 1995. "Impacts of Seismic Activity on LongTerm Repository Performance at Yucca Mountain." Proceedings of the Topical Meeting on Methods of Seismic Hazard Evaluation, Focus '95 (pp. 159-168). La Grange Park, Illinois: American Nuclear Society.

Geomatrix Consultants 1988. Final Report, Seismic Hazards Assessment for WNP-3, Satsop Washington. Contract No. C-20453. Submitted to Washington Public Power Supply System, Richland, Washington. 
Geomatrix Consultants 1994. Probabilistic Seismic Hazard Analysis, WNP-2 Nuclear Power Plant. Hanford, Washington. Prepared for Washington Public Power Supply System, Richland, Washington. Project No. 1846.

Ghosh, A.; Hsuing, S.M.; Chowdhury, A.H.; and Philip, J. 1995. "Seismic Engineering Issues for a Proposed HLW Repository at Yucca Mountain." Proceedings of the Topical Meeting on Methods of Seismic Hazards Evaluation, Focus '95 (pp.137-144). La Grange Park, Illinois: American Nuclear Society.

Hsuing, S.M.; Blake, W.; Chowdhury, A.H.; and Williams, T.J. 1992. "Effects of Mining-Induced Seismic Events on a Deep Underground Mine." PAGEOPH, 139.

Hsiung, S.M.; Ghosh, A.; Chowdhury, A.H.; and Ahola, M.P. 1993. "Evaluation of Rock Joint Models and Computer Code UDEC against Experimental Results." Center for Nuclear Waste Regulatory Analyses. NUREG/CR-6216, CNWRA 93-024.

Hsiung, S.M.; Kana, D.D.; Ahola, M.P.; Chowdhury, A.H.; and Ghosh, A. 1994. "Laboratory Characterization of Rock Joints." Center for Nuclear Waste Regulatory Analyses. NUREG/CR-6178, CNWRA 93-013.

Huang, X.; Haimson, B.C.: Plesha, M.E.; and Qiu, X. 1993. "An Investigation of the Mechanics of Rock Joints-Part I. Laboratory Investigation." International Journal of Rock Mechanics, Mining Sciences \& Geomechanics Abstracts (pp. 257-269). Vol. 30, No. 3.

ICBO (International Conference of Building Officials) 1994. Uniform Building Code. Whittier, California.

ITASCA Consulting Group, Inc. 1993. "UDEC Universal Distinct Element Code." Version 2.00, Volumes I and II: User's Manual. Minneapolis, Minnesota: ITASCA Consulting Group, Inc.

ITASCA Consulting Group, Inc. 1994a. "3DEC 3-Dimensional Distinct Element Code." Version 1.5, Volumes I and II: User's Manual. Minneapolis, Minnesota: ITASCA Consulting Group, Inc.

ITASCA Consulting Group, Inc. 1994b. "FLAC ${ }^{3 \mathrm{D}}$ Fast Lagrangian Analysis of Continua in 3 Dimensions." Version 1.0, Volumes I, II and III: User's Manual. Minneapolis, Minnesota: ITASCA Consulting Group, Inc.

ITASCA Consulting Group, Inc. 1995. "FLAC Fast Lagrangian Analysis of Continua in 3 Dimensions." Version 3.22, Volumes I, II and III: User's Manual. Minneapolis, Minnesota: ITASCA Consulting Group, Inc.

Jing, J.; Nordlund, E.; and Stephansson, O. 1992. "An Experimental Study on the Anisotrophy and Stress-Dependency of the Strength and Deformability of Rock Joints" (pp. 535-542). International Journal of Rock Mechanics, Mining Sciences \& Geometrics Abstracts, Vol. 29, No. 6.

Kana, D.D.; Fox, D.J.; Hsuing, S.M.; and Chowdhury, A.H. 1995. An Experimental Scale-Model Study of Seismic Response of an Underground Opening in Jointed Rock Mass. CNWRA 95-012. San Antonio, Texas: Center for Nuclear Waste Regulatory Analyses. 
Kennedy, R.P.; Chow, A.W.; and Williamson, R.A. 1977. "Fault Movement Effects on Buried Oil Pipelines." Transportation Engineering Journal of the American Society of Civil Engineers, Vol. 103, No. TE5.

Kennedy, R.P. and Kincaid R.H. 1985. "Fault Crossing Design for Buried Gas and Oil Pipelines." Proceedings of the Seismic Performance of Pipelines and Storage Tanks, Pressure Vessels and Piping Conference, PVP Vol. 98-4. New York, New York: American Society of Mechanical Engineers.

Kupfer, D.H.; Muessig, S.; Smith, G.I.; and White G.N. 1955. "Arvin-Tehachapi Earthquake Damage Along the Southern Pacific Railroad Near Bealville, California." In "Earthquakes in Kern County, California During 1952" (pp. 67-74). California Division of Mines Bulletin 171.

Laubscher, D.H. 1984, April. "Design Aspects and Effectiveness of Support Systems in Different Mining Conditions" (pp. 70-81) Journal of Mining and Metallurgy. Vol. 93 (Section A).

Lee, R.C.; King, J.L.; and Grant, T.A. 1991. "Multiple Effort Considerations for Postclosure Seismic Hazard Evaluations at Yucca Mountain, Nevada." Proceedings of the Second Annual International HighLevel Radioactive Waste Management Conference (pp. 76-82). New York, New York: American Society of Civil Engineers.

Louderback, G.D. 1950, November. "Faults and Engineering Geology" (pp. 125-150). Engineering Geology (Berkeley) Volume. Boulder, Colorado: Geological Society of America.

Menges, C.M.; Swan, F.H.; Oswald, J.A.; Wesling, J.R.; Coe, J.A.; Whitney, J.W.; and Thomas, A.P. 1995. "Preliminary Results of Paleoseismic Investigations of Quaternary Faults on Eastern Yucca Mountain, Nye County, Nevada" (pp. 2373-2390). Proceedings, 5th International High-Level Radioactive Waste Management Conference. New York, New York: American Society of Civil Engineers.

Niccum, M.R.; Cluff, L.S.; Chamorro, F.; and Wyllie, L. 1976. "Banco Central de Nicaragua: A Case History of a High-Rise Building that Survived Surface Fault Rupture." Proceedings of the Engineering Geology and Soils Engineering Symposium No. 14. Boise, Idaho: State of Idaho, Division of Highways.

NRC (U.S. Nuclear Regulatory Commission) 1978. Design Criteria for the Structural Analysis of Shipping Cask Containment Vessels. Regulatory Guide 7.6, Rev. 1. Washington, D.C.: U.S. Nuclear Regulatory Commission.

NRC 1983. PRA Procedures Guide. NUREG/CR-23001. Chapter 10, Vol. 2. Prepared by American Nuclear Society and Institute for Electrical and Electronic Engineers. Washington, D.C.: U.S. Nuclear Regulatory Commission.

NRC 1987. Standard Review Plan for the Review of Safety Analysis Reports for Nuclear Plants. LWR Edition. NUREG-0800. Washington, D.C.: U.S. Nuclear Regulatory Commission.

NRC 1989a. NRC Staff Site Characterization Analysis of the Department of Energy Site Characterization Plan, Yucca Mountain, Nevada. NUREG-1347. Washington, D.C.: U.S. Nuclear Regulatory Commission.

NRC 1989b. Load Combinations for the Structural Analysis of Shipping Casks for Radioactive Material. Regulatory Guide 7.8, Revision 1. Washington D.C.: U.S. Nuclear Regulatory Commission. 
NRC 1991a. Draft Safety Evaluation by the Office of Nuclear Reactor Regulation Relating to Geology and Seismology, Washington Public Power Supply System, Washington Nuclear Project No. 3 (WNP-3). Docket No. 50-508. Washington D.C.: U.S. Nuclear Regulatory Commission.

NRC 1991b. "Individual Plant Examination of External Events (IPEEE)." Generic Letter No. 88-20, Supplement 4. Washington, D.C.: U.S. Nuclear Regulatory Commission.

NRC 1991 c. Kana, D.D.; Brady, B.H.G.; Vanzant, B.W.; and Nair, P.K. Critical Assessment of Seismic and Geomechanics Literature Related to a High-Level Nuclear Waste Underground Repository.

NUREG/CR-5440. Washington, D.C.: U.S. Nuclear Regulatory Commission.

NRC 1992. McConnell, K.I.; Blackford, M.E.; and Ibrahim. A-K. Staff Technical Position on Investigations to Identify Fault Displacement Hazards and Seismic Hazards at a Geologic Repository. NUREG-1451. Washington, D.C.: U.S. Nuclear Regulatory Commission.

NRC 1994a. McConnell, K.I. and Lee, M.P. Staff Technical Position on Consideration of Fault Displacement Hazards in Geologic Repository Design. NUREG-1494. Washington D.C.: U.S. Nuclear Regulatory Commission.

NRC 1994b. Sobel, P. Revised Livermore Seismic Hazard Estimates for Sixty-Nine Nuclear Power Plant Sites East of the Rocky Mountains. NUREG-1488. Washington, D.C.: U.S. Nuclear Regulatory Commission.

NRC 1995a. Draft Regulatory Guide DG-1032, Identification and Characterization of Seismic Sources and Determination of Safe Shutdown Earthquake Ground Motion. Washington D.C.: U.S. Nuclear Regulatory Commission.

NRC 1995b. License Application Review Plan for a Geologic Repository for Spent Nuclear Fuel and High-Level Nuclear Waste. NUREG-1323, Rev. 1. Washington D.C.: U.S. Nuclear Regulatory Commission.

O'Rourke, T.D. (Editor) 1984. Guidelines for Tunnel Lining Design. New York, New York: American Society of Civil Engineers.

PG\&E (Pacific Gas and Electric Company) 1978. Seismic Evaluation for Postulated 7.5M Hosgri Earthquake, Units 1 and 2, Diablo Canyon Site, Vol. I. Docket Nos. 50-275 and 50-323. San Francisco, California.

PG\&E 1985. Final Safety Analysis Report Update, Vol. 2. San Francisco, California.

PG\&E 1988. Long Term Seismic Program Final Report. PG\&E Letter No. DCL-88-192, dated July 31. San Francisco, California.

PG\&E 1994. Individual Plant Examination of External Events Report for Diablo Canyon Power Plant Units 1 and 2 in Response to Generic Letter 88-20 Supplement 4. PG\&E Letter DCL-94-133, dated June 27. San Francisco, California.

Qiu, X.; Plesha, M.E.; Huang, X.; and Haimson, B.C. 1993. "An Investigation of the Mechanics of Rock Joints-Part II. Analytical Investigation. International Journal of Rock Mechanics, Mining Sciences \& Geomechanics Abstracts (pp. 271-287). Vol. 30, No. 3. 
Reed, J.W.; Sharpe, R.L.; and Webster, S.A. 1979. "An Analysis of a Nuclear Test Reactor for Surface Rupture Offset." Boston, Massachusetts: American Society of Civil Engineers Spring Conference.

Risk Engineering, Inc. 1993. Seismic Hazard Evaluation for the Palo Verde Nuclear Generating Station, Wintersburg, Arizona, Final Report, Rev. 2. Prepared for Arizona Public Service Co., Phoenix, Arizona.

Russell, F.M.; Armstrong, D.R.M.; and Talbot, R. 1983. "Analysis of Stoping Sequence and Support Requirements in a High Stress Environment - ZCCM - Mufulira Division" (pp. 161-173). Rockbursts: Prediction and Control. London, England: The Institution of Mining and Metallurgy.

SCE (Southern California Edison) 1995. Individual Plant Examination of External Events for San Onofre Nuclear Generating Station Units 2 \& 3, in Response to Generic Letter 88-20, Supplement 4.

Selna, L.G., and Cho, M.D. 1973. "Banco de America, Managua, A High-Rise Shear Wall Building Withstands a Strong Earthquake." Proceedings of the Earthquake Engineering Research Institute Conference. San Francisco, California.

Sharma, S. and Judd, W.R. 1991. "Underground Opening Damage from Earthquakes." Engineering Geology, 30:263-276.

SNL (Sandia National Laboratories) 1989. Subramanian, C.V.; Abrahamson, N.; Hadjian, A.H.; Jardine, L.J.; Kemp, J.B.; Kiciman, O.K.; Ma, C.W.; King, J.; Andrews, W.; and Kennedy, R.P. "Preliminary Seismic Design Cost-Benefit Assessment of the Tuff Repository Waste-Handling Facilities."

SAND88-1600 UC-70. Albuquerque, New Mexico: Sandia National Laboratories.

SNL 1990. Richardson, A.M. Preliminary Shaft Liner Design Criteria and Methodology Guide. SAND88-7060. Albuquerque, New Mexico: Sandia National Laboratories.

SNL 1991. Hardy, M.P. and Bauer, S.J. Drift Design Methodology and Preliminary Application for the Yucca Mountain Project. SAND89-0837. Albuquerque, New Mexico: Sandia National Laboratories.

SNL 1996. Barr, G.E.; Borns, D.J.; and Fridrich, C. Scenarios Constructed for the Effects of Tectonic Processes on the Potential Nuclear Waste Repository at Yucca Mountain, Nevada. SAND96-1132, preliminary draft. Albuquerque, New Mexico: Sandia National Laboratories.

Souley, M.; Homand, F.; and Amadei, B. 1995. "An Extension to the Saed and Amadei Constitutive Model for Rock Joints to Include Cyclic Loading Paths." International Journal of Rock Mechanics, Mining Sciences \& Geomechanics Abstracts (pp. 101-109). Vol. 32, No. 2.

U.S. Department of Transportation 1981. Brown, L.R.; Korbin, G.E.; and Brekke, T.L. Behavior of the Bay Area Rapid Transit Tunnels Through the Hayward Fault. UMTA-CA-06-0120-81-1.

Wang, J.-M. 1985, August. "The Distribution of Earthquake Damage to Underground Facilities During the Tang-Shan Earthquake." Earthquake Spectra, Vol. 1, No. 4.

Wells, D.L. and Coppersmith, K.J. 1994. "New Empirical Relationships among Magnitude, Rupture Length, Rupture Width, Rupture Area, and Surface Displacement" (pp. 974-1002). Bulletin of the Seismological Society of America, Vol. 84, No. 4. El Cerrito, California: Seismological Society of America. 
Wibowo, J.T.; Amadei, B.; Sture, S.; Price, R.H.; and Robertson, A.B. 1993. Effect of Boundary Conditions on the Strength and Deformability of Replicas of Natural Fractures in Welded Tuff: Data Report. SAND92-1853. Albuquerque, New Mexico: Sandia National Laboratories.

WPPSS (Washington Public Power Supply System) 1982. Final Safety Analysis Report for Washington Public Power Supply System Nuclear Project 3. Docket No. 50-508. Richland, Washington.

WPPSS 1995. Individual Plant Examination of External Events, Washington Nuclear Plant 2, Main Report, Rev. 0. Richland, Washington.

Wyllie, L.A., Jr. 1973. "Performance of Banco Central Building." Proceedings of the Earthquake Engineering Research Institute Conference. San Francisco, California.

Yoshikawa, K. and Fukuchi, G. 1984. "Earthquake Damage to Railway Tunnels in Japan." Advances in Tunnelling Technology and Subsurface Use, Proceedings of the International Tunnelling Association (pp. 75-83).Vol. 4, No. 3. Pergammon Press.

\section{E.2 PUBLIC LAWS AND REGULATIONS}

10 CFR 20. Standards for Protection Against Radiation. Washington, D.C.: U.S. Nuclear Regulatory Commission.

10 CFR 50. Safety Goals for the Operations of Nuclear Power Plants; Policy Statement. 51 Federal Register 50028. Washington, D.C.: U.S. Nuclear Regulatory Commission.

10 CFR 52. Early Site Permits; Standard Design Certifications; and Combined Licenses for Nuclear Power Plants. Washington, D.C.: U.S. Nuclear Regulatory Commission.

10 CFR 60. Disposal of High-Level Radioactive Wastes in Geologic Repositories. Washington, D.C.: U.S. Nuclear Regulatory Commission.

10 CFR 71. Licensing Requirements for the Independent Storage of Spent Nuclear Fuel and High-Level Radioactive Waste. Washington, D.C.: U.S. Nuclear Regulatory Commission

10 CFR 72. Packaging and Transportation of Radioactive Material. Washington, D.C.: U.S. Nuclear Regulatory Commission.

10 CFR 100. Reactor Site Criteria. Washington, D.C.: U.S. Nuclear Regulatory Commission.

Nuclear Waste Policy Act of 1982, as amended by the Nuclear Waste Policy Amendments Act of 1987. Public Law 97-425, 42 U.S.C. § 10101.

55 FR 28771. Notice of Receipt of Department of Energy Petition for Rulemaking to 10 CFR Part 60. Washington, D.C.: U. S. Nuclear Regulatory Commission.

59 FR 52255. Reactor Site Criteria Including Seismic and Earthquake Engineering Criteria for Nuclear Power Plants and Proposed Denial of Petition from Free Environment, Inc., et al. Washington, D.C.: U. S. Nuclear Regulatory Commission. 
60 FR 15180. Disposal of High-Level Radioactive Wastes in Geologic Repositories; Design Basis Events. Washington, D.C.: U. S. Nuclear Regulatory Commission.

60 FR 42622. Use of Probabilistic Risk Assessment Methods in Nuclear Regulatory Activities; Final Policy Statement. Washington, D.C.: U. S. Nuclear Regulatory Commission. 
APPENDIX F

ACRONYMS 


\section{APPENDIX F}

\section{ACRONYMS}

\begin{tabular}{|c|c|}
\hline $\mathrm{ACD}$ & Advanced Conceptual Design \\
\hline AEC & U.S. Atomic Energy Commission \\
\hline AISC & American Institute of Steel Construction \\
\hline APS & Arizona Public Service Company \\
\hline ASCE & American Society of Civil Engineers \\
\hline ASLB & Atomic Safety and Licensing Board \\
\hline ASME & American Society of Mechanical Engineers \\
\hline BSSC & Building Seismic Safety Council \\
\hline CDA & Controlled Design Assumptions Document \\
\hline CEUS & Central or Eastern United States \\
\hline CFR & Code of Federal Regulations \\
\hline CRD & Civilian Radioactive Waste Management System Requirements Document \\
\hline CRWMS & Civilian Radioactive Waste Management System \\
\hline CSCI & Computer Software Configuration Item \\
\hline DCPP & Diablo Canyon Power Plant \\
\hline DOE & U.S. Department of Energy \\
\hline EDA & Engineering Decision Analysis, Inc. \\
\hline ENR & Engineering News Record \\
\hline EPRI & Electric Power Research Institute \\
\hline ESR & Excavation Support Ratio \\
\hline FR & Federal Register \\
\hline GETR & General Electric Company Test Reactor \\
\hline ICBO & International Conference of Building Officials \\
\hline IPEEE & Individual Plant Examination of External Events \\
\hline LA & License Application \\
\hline MGDS & Mined Geologic Disposal System \\
\hline $\mathrm{M} \& \mathrm{O}$ & Management and Operating Contractor \\
\hline NRC & U.S. Nuclear Regulatory Commission \\
\hline PGA & Peak Ground Acceleration \\
\hline PG\&E & Pacific Gas and Electric Company \\
\hline PGV & Peak Ground Velocity \\
\hline PSAA & Pseudo Spectral Absolute Acceleration \\
\hline PSV & Pseudo Spectral (Relative) Velocity \\
\hline PVNGS & Palo Verde Nuclear Generating Station \\
\hline RMQ & Rock Mass Quality \\
\hline
\end{tabular}


SCE Southern California Edison

SL Seismic Load

SNL Sandia National Laboratories

SSC Structures, Systems, and Components

SONGS San Onofre Nuclear Generating Station

TL Thermal Load

WNP-2 Washington Nuclear Plant 2

WNP-3 Washington Nuclear Plant 3

WPPSS Washington Public Power Supply System 


\section{U. S. DEPARTMENT OF ENERGY RESPONSES TO U. S. NUCLEAR REGULATORY COMMISSION STAFF COMMENTS ON THE TOPICAL REPORT, "SEISMIC DESIGN METHODOLOGY FOR A GEOLOGIC REPOSITORY AT YUCCA MOUNTAIN," YMP/TR-003-NP, REV. 0}

$$
\text { YMPFTR- -OO3-NP-Revale }
$$

In response to the NRC staff's comments, the DOE has revised the subject topical report. Revision 1 of the topical report incorporates the changes that are indicated in the following responses.

\section{COMMENT 1}

The linkages between the proposed preclosure seismic design methodology and the postclosure performance considerations as provided in the Seismic Topical Report \#2 are inadequate.

\section{RESPONSE 1}

Following Nataraja (1995), Figure 1-1 has been corrected to show explicitly that both preclosure and postclosure performance objectives must and will be considered in the final design of structures, system, or components (SSCs). Also following Nataraja (1995), Figure A-1 has been added to illustrate the DOE's process for integrating design, performance assessment, requirements definition, and site characterization. A discussion of DOE's process for integrating all preclosure and postclosure design requirements has been added to Section 1.3 and is detailed in Appendix A of the revised report. Appendix A also examines the linkage between the preclosure seismic design of emplacement drifts, the potential for repetitive seismic loading, and the postclosure performance requirements for the emplacement drifts.

\section{COMMENT 2}

The relationship between the DOE proposed four seismic performance categories and the NRC Category 1 and Category 2 design basis events in the proposed rule change to 10 CFR Part 60 needs to be established.

\section{RESPONSE 2}

The DOE has decided to drop the performance-goal based seismic design approach in favor of the approach to identifying design-basis events that is in the NRC's proposed rule change to 10 CFR 60 (60 FR 15180). As described in the revised topical report, the DOE refers to the two categories of events as "Frequency-Category-1" and "Frequency-Category-2." The topical report presents and justifies quantitative probabilistic criteria for determining Frequency-Category-1 and -2 design basis vibratory ground motions (see Section 3.1) and Frequency-Category-1 and -2 design basis fault displacements (see Section 4.4). In addition, Appendix B of the report describes the process that the DOE will use to identify those SSCs that must be designed for Frequency-Category-1 and -2 design basis events. 


\section{COMMENT 3}

No rationale is given concerning the choice of uncertainty measures to be used for ground motion and fault offset criteria. It is stated that the mean of probabilistic seismic hazards will be used, but no rationale for this choice is provided.

\section{RESPONSE 3}

A detailed rationale for using mean annual exceedance probabilities is now provided in Section 3.1.2.1 of the revised report. At a given probability level, the mean normally exceeds the median (e.g., NRC 1994) and its use is conservative. The use of a mean annual exceedance probability of 1.0E-04 in determining the Frequency-Category-2 design basis ground motions is consistent with the risk of exceeding the NRC-accepted design bases of the more recently licensed nuclear power reactors in the United States (NRC 1994 and Section 3.1.2.1 of this report). The use of a mean annual exceedance probability of $1.0 \mathrm{E}-03$ for the Frequency-Category-1 design basis ground motion is an extremely conservative translation of the frequency implied in the phrase, "those natural and human-induced events that are reasonably likely to occur regularly, moderately frequently, or one or more times before permanent closure of the geologic repository operations area," which is the definition of Category-1 design basis events in the proposed rulemaking. The reference probabilities for design basis fault displacements are an order of magnitude lower than the corresponding values for design basis vibratory ground motions, reflecting the more limited experience in the engineering design of facilities for fault displacement.

A central tendency measure of exceedance probabilities such as the mean or the median, as is used in Draft Regulatory Guide DG-1032 (NRC 1995), is the appropriate measure to use in this probabilistic methodology, rather than some other measure such as the median plus a standard deviation or the 85th or other percentile. Use of the mean allows target exceedance probabilities and their conservatism to be benchmarked against the exceedance probabilities of the more recently licensed nuclear power plants in the United States (NRC 1995 and this report). In addition, use of the mean or median permits a useful and relatively straightforward interpretation of the physical meaning of those earthquakes that control the seismic hazard at a specified exceedance probability, which would not be the case if a different statistical measure were used.

\section{COMMENT 4}

The treatment by DOE of repetitive seismic loadings as "low-probability/low-consequence" events is inappropriate.

\section{RESPONSE 4}

Current information indicates that the likelihood of experiencing drift-damaging seismic loads more than once or twice during the preclosure period is negligible, and that many episodes of seismically induced joint slip would likely be required to lead to drift failure (see Section 3.3.2.2 of the revised report). The ground support system will be designed to withstand thermal and 
Performance Confirmation Concepts Study (CRWMS M\&O 1996), which identified performance confirmation requirements that must be addressed in the Viability Assessment design. As part of this study, the DOE also developed an annotated outline of a Performance Confirmation Plan (CRWMS M\&O 1996, Appendix A) that overviews the performance confirmation approach and objectives, responsibilities, concept of operations, and schedules. The Performance Confirmation Plan will define the test and evaluation program for confirming the waste containment and isolation performance of the repository. The scope of the tests and evaluations includes process modeling, performance predictions, and monitoring and testing of the site, waste package, and repository. The Performance Confirmation Plan is scheduled for completion in FY 1997 and will specifically address requirements for seismic monitoring and confirmation of the performance of ground support systems for underground openings.

\section{COMMENT 6}

The recommended safety factors for design of ground support components as listed in Table 6-2 for combined in situ, thermal, and seismic loads may not be conservative with regard to the design method for conventional structural steel and concrete.

\section{RESPONSE 6}

Specific ground support safety factors are no longer included in the topical report, in recognition of the fact that there is not an accepted standard for the design of underground support system components. Structural design codes that have been developed for surface facilities are of limited utility because they do not adequately account for the influence on performance of the ground support construction method or the capacity of the rock mass to be self-supporting.

To achieve ground support stability and performance goals, the DOE will develop load and safety factors considering the unique aspects of underground structures (see Section 3.3.4). For ground support components such as concrete linings and steel sets that are subjected to both axial thrust and bending moment, the DOE intends to develop acceptance criteria for combined stresses. For concrete, the combined stresses will be compared with a moment-thrust failure envelope or interaction diagram as described by the Underground Technology Research Council (O'Rourke 1984). For steel, analogous acceptance criteria will be developed based on guidelines such as those published by the American Institute of Steel Construction (AISC 1989).

\section{COMMENT 7}

Seismic Topical Report \#2 does not provide specific details regarding the nature of fault-specific investigations that would be conducted to define the values of set-back distance for faultavoidance in design.

\section{RESPONSE 7}

The DOE's fault-specific investigations will comply fully with the NRC staff guidance in NUREG-1451, Staff Technical Position on Investigations to Identify Fault Displacement 
Hazards and Seismic Hazards at a Geologic Repository, as discussed in Section 4.3 of the topical report. The technical database upon which interpretations of fault locations and characteristics will be based and the interpretations themselves will be fully documented in the DOE's planned probabilistic seismic hazard assessment. An inherent part of this assessment will be explicit estimates of the uncertainty associated with each interpretation, and estimated faultdisplacement probabilities will reflect the uncertainty estimates. The results of the probabilistic seismic hazard assessment will be documented and submitted for NRC staff review and comment.

\section{COMMENT 8}

The proposed approach for probabilistic fault-displacement design is not likely to ensure adequate consideration of uncertainties in fault-slip history for the Yucca Mountain region from which design parameters can be adequately calculated.

\section{RESPONSE 8}

As noted in the previous response, the interpretation of faulting-related data and estimation of faulting probabilities will be accomplished in the probabilistic seismic hazard analysis. These interpretations will be based on all available data and will explicitly consider alternate admissible conceptual models of subsurface fault geometry and uncertainties in the interpretation of paleoseismic data. 


\section{REFERENCES}

AISC (American Institute of Steel Construction) 1989. Manual of Steel Construction: Allowable Stress Design. Ninth Edition.

CRWMS M\&O (Civilian Radioactive Waste Management System Management and Operating Contractor) 1996. Performance Confirmation Concepts Study Report. B00000000-01717-570500035 Rev. 00. Las Vegas, Nevada.

Nataraja, M. S. 1995. "Seismic Design and Peformance Considerations: A Regulatory Perspective." Proceedings of the Topical Meeting on Methods of Seismic Hazard Evaluation, Focus '95 (pp. 25-34). La Grange Park, Illinois: American Nuclear Society.

NRC (U. S. Nuclear Regulatory Commission) 1994. Sobel, P. Revised Livermore Seismic Hazard Estimates for Sixty-Nine Nuclear Power Plant Sites East of the Rocky Mountains. NUREG-1488. Washington, D.C.: U. S. Nuclear Regulatory Commission.

NRC 1995. Draft Regulatory Guide DG-1032, Identification and Characterization of Seismic Sources and Determination of Safe Shutdown Earthquake Ground Motion. Washington, D.C.: U. S. Nuclear Regulatory Commission.

O'Rourke, T. D. (Editor) 1984. Guidelines for Tunnel Lining Design. New York, New York: American Society of Civil Engineers. 